Universitat Politècnica de ValènCia

Departament de Matemàtica APlicada

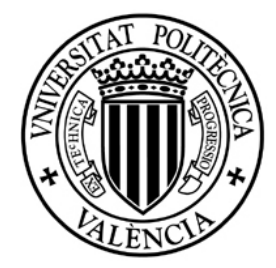

\title{
Equacions efectives de l'equació de Schrödinger no lineal en sistemes periòdics i quasiperiòdics
}

\author{
TESI DOCTORAL \\ LLÚCIA MONREAL MENGUAL
}

DIRECTORS:

PEDRO FERNÁNDEZ DE CÓRDOBA CASTELLÁ

ALBERT FERRANDO COGOLLOS

MARIO ZACARÉS GONZÁLEZ

JULIOL 2010 

A Julio

Als meus fills Eva i Julio 

I'm sorry, she said. I was about to order some coffee and Danish but now I can't seem to remember the Schroedinger equation. Isn't that silly? It's just slipped my mind.

Woody Allen

Strung out. The New Yorker. Juliol 2003 



\section{Resum}

El propòsit d'aquesta tesi s'emmarca dins del camp de l'òptica no lineal i, com que el problema és formalment idèntic, té aplicació directa en el camp de la matèria condensada, en particular en els condensats de Bose-Einstein. L'objectiu és l'obtenció d'equacions efectives de l'equació de Schrödinger no lineal, tant per a potencials periòdics com quasiperiòdics, i omplir així el buit teòric existent en el darrer cas. Aquestes equacions descriuen la dinàmica, a baixes energies o llarg abast, de l'envolupant (envelope) de la solució no lineal. Per a obtenir-lo, en el cas periòdic, es fa ús de la base de funcions de Wannier solució del problema no lineal estacionari, en lloc de l'aproximació clàssica que utilitza com a base les funcions de Wannier lineals. Es demostra que l'equació efectiva és lliure de potencial. En el cas quasiperiòdic, el marc de la geometria no commutativa resultarà ser l'eina adequada per a tractar el problema i es prova que es pot obtenir un resultat equivalent si considerem un espai no commutatiu amb el doble de dimensions.

Aquestes equacions estableixen una nova ferramenta teòrica per a l'anàlisi de l'estabilitat i l'existència de solucions no lineals en el règim de baixes energies. 



\section{Resumen}

El propósito de esta tesis se enmarca dentro del campo de la óptica no lineal y, como el problema es formalmente idéntico, tiene aplicación directa en el campo de la materia condensada, en particular en los condensados de Bose-Einstein. El objetivo es obtener las ecuaciones efectivas de la ecuación de Schrödinger no lineal, tanto para potenciales periódicos como cuasiperiódicos, e intenta llenar el vacío teórico existente en el último caso. Estas ecuaciones describen la dinámica, a bajas energías o largo alcance, de la envolvente de la solución no lineal. Para su obtención, en el caso periódico, se hace uso de la base de funciones de Wannier solución del problema no lineal estacionario, en lugar de la aproximación clásica que utiliza como base las funciones de Wannier lineales. Se demuestra que la ecuación efectiva es libre de potencial. En el caso cuasiperiódico, el marco de la geometría no conmutativa resultará ser la herramienta adecuada para tratar el problema y se prueba que se puede obtener un resultado equivalente si consideramos un espacio no conmutativo con el doble de dimensiones.

Estas ecuaciones establecen una nueva herramienta teórica para el análisis de la estabilidad y de la existencia de soluciones no lineales en el régimen de bajas energías. 



\section{Abstract}

This thesis offers new advances in the study of nonlinear Schödinger equation, therefore being of application in different scientific fields. Among them, we pay particular attention to the application in nonlinear optics, keeping an eye in possible applications to condensed matter physics, such as Bose-Einstein condesation in optical lattices. Our aim is to get the effective equations of nonlinear Schrödinger equation for both periodic and quasiperiodic potentials, and fill the theoretical gap that exists in the latter case. These equations describe the dynamics for the envelope of the nonlinear solution, at low energies or long-range. In the periodic case, we made use of Wannier functions basis from the nonlinear stationary problem, instead of the more common approach based on linear Wannier functions, to obtain the corresponding effective equation. It is shown that the equation is, effectively, potential-free. On the other hand, the framework of noncommutative geometry turn out to be the right tool to address the problem in the quasiperiodic case. By cosidering a noncommutative space in two dimensions we obtain an effective equations formally identical to the one obtained in the former periodic case.

These equations establish a new theoretical tool to addres the problem of the stability and the existence of nonlinear solutions in the regime of low energies. 



\section{Agraïments}

Aquesta tesi ha estat desenvolupada al Departament de Matemàtica Aplicada de la Universitat Politècnica de València, sota la direcció dels Drs. Pedro Fernández de Córdoba, Albert Ferrando i Mario Zacarés. Vull expressar el meu agraïment i reconeixement a tots aquells que han fet possible la realització d'aquest treball: a Pedro, Albert i Mario per la seua dedicació, interès i suport; a José Mª Isidro, ja que aquesta tesi no seria possible sense la seua ajuda i les seues contribucions; als companys del grup d'investigació; en particular, a Jeza, qui m'ha escoltat i aconsellat en moments bons i dolents així com als membres del grup de fotònica, i als meus companys de la unitat docent del Departament de Matemàtica Aplicada a l'E.T.S. Enginyeria Geodèsica, Cartogràfica i Topogràfica, que m'han alliberat d'algunes tasques en les últimes setmanes per a poder acabar la memòria. També vull agrair a la meua família el seu suport incondicional: als meus fills, Eva i Julio, que amb un bes em fan agafar forces per a continuar i qui potser no he dedicat tot el temps que cal; als meus pares, Pedro i Juanita, que són el millor exemple que he pogut tenir, i en especial a mon pare - no sé si he complit els seus somnis-, i a Julio, per ser i ésser. 

Resum

Resumen

Abstract

xi

Agraïments

xiii

1 Introducció $\quad 3$

2 Equació efectiva en potencials periòdics $\quad \mathbf{1 5}$

2.1 Introducció . . . . . . . . . . . . . . . . . 15

2.2 Equació discreta per als coeficients de Wannier . . . . . . . . . . 16

2.3 Els modes no lineals de Bloch _. . . . . . . . . . . . . 20

2.4 Equació contínua efectiva per a amplituds de llarg abast . . . . . 24

2.4.1 Cas unidimensional . . . . . . . . . . . . . 27

2.4.2 Cas bidimensional ............... . . 31

3 Equació efectiva en potencials quasiperiòdics 35

3.1 Introducció . . . . . . . . . . . . . . . . . . 35

3.2 Equació d'ones no commutativa . . . . . . . . . . . . 37

3.3 Equació efectiva per a amplituds de llarg abast . . . . . . . . . . 38 
3.4 Equació efectiva lliure . . . . . . . . . . . . . . . 43

$\begin{array}{lll}4 & \text { Conclusions } & 47\end{array}$

A Funcions de Bloch

A.1 Nocions bàsiques sobre la estructura dels cristalls . . . . . . . . . 53

A.2 Xarxa recíproca . . . . . . . . . . . . . 56

A.3 Teorema de Bloch . . . . . . . . . . . . . . . . 58

B Propietats de l'hamiltonià lineal $\quad 61$

$\begin{array}{lll}\text { C Propietats de l'hamiltonià no lineal } & 67\end{array}$

$\begin{array}{ll}\text { D Caràcter real de les funcions de Wannier } & 71\end{array}$

E Càlcul de bandes en l'aproximació d'enllaç fort

F Nocions bàsiques de geometria no commutativa $\quad 81$

F.1 Introducció . . . . . . . . . . . . . . . . . . . . . 81

F.2 Conceptes algebraics . . . . . . . . . . . . . . . 82

F.3 L'àlgebra d'Heisenberg . . . . . . . . . . . . . . . 85

$\begin{array}{ll}\text { Bibliografia } & 87\end{array}$ 


\section{Capítol 1}

\section{Introducció}

L'estudi de l'estructura de la matèria ha estat basat, tradicionalment, en la noció d'una distribució regular d'àtoms en l'espai, que pot ser generada a partir de translacions periòdiques d'una cel-la o bloc bàsic. Així, les simetries de translació i rotació, derivades de l'ordre periòdic, permeten d'explicar algunes de les propietats físiques més rellevants dels cristalls. Les substàncies cristal-lines es caracteritzen per posseir una periodicitat espacial perfecta, per tant es descriuen com materials cristal-lins aquells materials sòlids els elements constitutius dels quals es repeteixen de manera ordenada i periòdica, i la distribució en l'espai mostra certes relacions de simetria. Així, la propietat característica i definidora del medi cristal-lí és ser periòdic. Existeix un altre tipus de sòlids, anomenats amorfs, com el vidre i altres polímers, que no pertanyen a la categoria de cristalls perquè no posseeixen aquesta propietat de periodicitat de llarg abast. Per tant, la periodicitat introdueix, de forma natural, una primera classificació dels sòlids en dues categories: matèria cristal-lina i matèria amorfa. La física de l'estat sòlid ha estat relacionada, fonamentalment, amb els cristalls i els electrons en els cristalls encara que avui inclou altres camps com l'estudi dels sòlids amorfs o dels cristalls líquids.

La xarxa cristal-lina és una abstracció del medi cristal-lí, i el tractar-lo únicament en funció de les translacions presents constitueix l'essència de la teoria de les xarxes cristal-lines (en l'apèndix A s'exposen els conceptes bàsics necessaris 
d'aquesta teoria). Les xarxes cristal-lines poden traslladar-se o superposar-se sobre elles mateixes mitjançant una translació de la xarxa o d'altres operacions de simetria [Kittel96], com, per exemple, una rotació al voltant d'un eix que passe per un dels punts de la xarxa. Doncs bé, podem trobar xarxes que romanen invariants després de fer rotacions d'angle $2 \pi / n, n=2,3,4,6$, però no podem construir una xarxa periòdica amb simetria puntual de 5è ordre, ja que amb pentàgons no podem omplir el pla i no tindríem la periodicitat de translació desitjada. De fet, durant dècades, es considerà la simetria rotacional de cinquè ordre com una simetria prohibida en sòlids cristal-lins.

La primera referència de cristall aperiòdic va ser introduïda per Schrödinger en el seu treball [Schroedinger44]. Les grans molècules biològiques conegudes en aquella època posseïen periodicitat espacial, manifestada per la seua capacitat de cristal-litzar. No obstant això, anotà Schrödinger, una molècula amb periodicitat espacial no seria capaç de contenir prou informació. Aleshores, proposa un "cristall aperiòdic", al qual la informació quedaria emmagatzemada com en un tros escrit en codi Morse. Aquest "cristall aperiòdic" imaginat el 1944 és el que avui anomenem un àcid nucleic. Però el concepte de cristall aperiòdic no prosperà fins a que, quatre dècades més tard es va descobrir un nou tipus de sòlid que desafiava les lleis de la cristal-lografia, és a dir, que presentava simetries que es consideraven prohibides fins aleshores. En 1984 Shechtman, Blech, Gratias i Cahn publicaren un article [Shechtman84] en el que mostraven uns cristalls d'alumini-manganès amb simetria icosaèdrica. Aquesta aliatge presentava un patró de difracció amb punts tan nítids com els dels cristalls però que no podien ser indexats en cap xarxa de Bravais [apèndix A]. Aquests sòlids s'anomenaren, des d'aleshores, quasicristalls. En l'article [Levine84] es defineix el quasicristall com una extensió natural del concepte de cristall a estructures amb un quasiperiòdic, en lloc de periòdic, ordre translacional. Des del seu descobriment, el 1984, s'han trobat molts tipus de quasicristalls, tant estables com metastables. Podem afirmar, doncs, que els quasicristalls són materials amb un ordre perfecte de llarg abast, com es pot veure en les figures de difracció, però sense periodicitat de translació tridimensional i amb simetries de rotació no permeses 


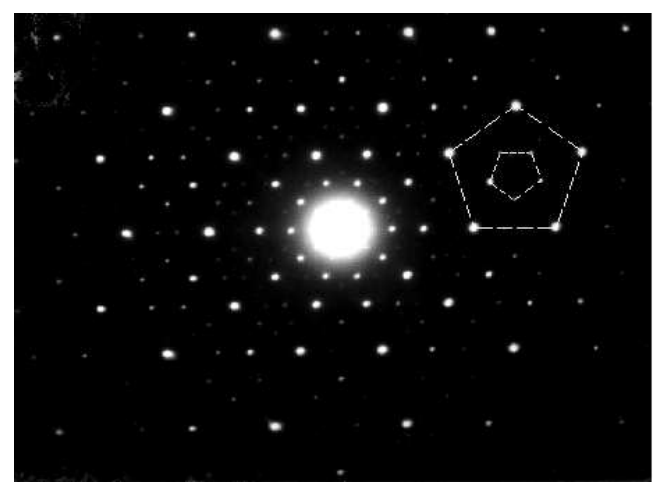

Figura 1.1: Patró de difracció corresponent a un quasicristall d'AlCuFe. (Dr. Reyes-Gasca. Dep. Matèria Condensada. UNAM)

per la cristal-lografia clàssica, com es mostra a la fig.1.1. Com diu Marjorie Senechal en el seu article [Senechal06] un quasicristall és un cristall amb simetria prohibida, prohibida en el sentit cristal-logràfic, que redueix les simetries de rotació de les xarxes de translació en dues i tres dimensions als ordres 2, 3, 4 i 6. Unes bones referències per ampliar la relació entre geometria i quasicristalls són [Senechal96, Levine84, Maciá06].

Uns anys abans del descobriment dels quasicristalls, el físic matemàtic britànic Roger Penrose va idear una manera de cobrir el pla de forma no periòdica utilitzant dos tipus diferents de rajoles. Un exemple el podem veure a la fig.1.2. Des del punt de vista dels matemàtics l'ordre que presenten els quasicristalls és l'extensió natural del concepte de cristall quan l'ordre periòdic espacial es substitueix per una classe d'ordre translacional descrit en termes de funcions quasiperiòdiques, que també s'anomenen aperiòdiques [Maciá06, Baake02].

L'exemple més simple de funció quasiperiòdica unidimensional és

$$
f(x)=\cos x+\cos \alpha x .
$$




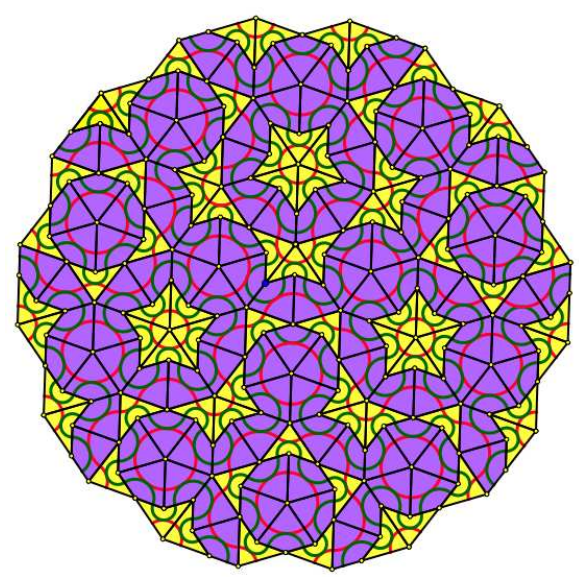

Figura 1.2: Mosaic de Penrose amb quadrilàters que només poden omplir el pla de forma aperiòdica. (http://geometriadinamica.es)

on $\alpha$ és un nombre irracional ${ }^{1}$. Una propietat molt interessant és que aquesta funció quasiperiòdica pot obtenir-se per projecció de la funció periòdica en dues dimensions $f(x, y)=\cos x+\cos y$ mitjançant la restricció $y=\alpha x$. Nombrosos treballs sobre quasicristalls unidimensionals utilitzen la sèrie de Fibonacci com a exemple de conjunt ben ordenat però aperiòdic [Maciá01, Freedman07]. En aquesta sèrie numèrica cada terme s'obté com la suma dels dos anteriors $f_{k+1}=$ $f_{k}+f_{k-1}$ i resulta que el límit $\lim _{k \rightarrow \infty} \frac{f_{k+1}}{f_{k}}=\frac{1+\sqrt{2}}{5}$ és el nombre d'or, conegut des de la Grècia clàssica i el que marca les proporcions perfectes.

El coneixement de les propietats dels materials a partir de la seua estructura cristal-lina ha propiciat gran part dels avanços tecnològics del darrer segle. Així, s'han conegut i controlat les propietats elèctriques dels materials, i s'ha revolucionat el món de l'electrònica i les comunicacions a partir del desenvolupament de dispositius electrònics, com, per exemple, el transistor.

Com ja hem referit adés, un cristall és un sòlid en el qual existeix un bloc

\footnotetext{
${ }^{1}$ Seria equivalent considerar la funció $f(x, y)=\cos \omega_{1} x+\cos \omega_{2} x$, on la raó $\frac{\omega_{1}}{\omega_{2}}$ és irracional. Igualment vàlid seria considerar una combinació de sinus.
} 
elemental que es repeteix a l'espai de manera ordenada i periòdica. Per a estudiar la interacció dels electrons amb la xarxa cristal-lina s'utilitza, en física de l'estat sòlid, l'equació de Schrödinger amb un potencial periòdic [Ashcroft76,Kittel96, Pavlov87] ja que el model d'electrons lliures, que permet explicar algunes propietats físiques com la conductivitat tèrmica i elèctrica i la susceptibilitat elèctrica, no explica, per exemple, la distinció entre metalls, semiconductors i aïllants, entre altres propietats. Bloch demostrà el 1928 que les solucions de l'equació de Schrödinger amb un potencial periòdic són de la forma $\psi_{\mathbf{p} ; \alpha}(\mathbf{x})=e^{i \mathbf{p} \cdot \mathbf{x}} u_{\mathbf{p} ; \alpha}(\mathbf{x})$, on la funció $u_{\mathbf{p} ; \alpha}(\mathbf{x})$ té la mateixa periodicitat que la xarxa cristal-lina. Aquest resultat rep el nom de teorema de Bloch [apèndix A]. El model explica, per exemple, perquè a determinades energies els electrons es propaguen i a altres energies, no. En matemàtiques el teorema de Bloch se'l coneix com teorema de Floquet i hi ha moltes referències en el camp de la física matemàtica al voltant de l'operador de Schrödinger periòdic i les seues propietats [Besicovitch54, Simon82, Hislop95].

La dificultat principal que hom troba en l'estudi dels sistemes quasiperiòdics és la manca d'un resultat equivalent al teorema de Bloch. El concepte de zona de Brioullin, tal i com s'usa en els cristalls, no existeix [apèndix A]. No obstant això, trobem treballs teòrics on consideren una pseudozona de Brioullin per a fer una predicció sobre l'estructura de bandes i definir un anàleg al teorema de Bloch en el cas dels quasicristalls. En aquests sistemes, els vectors de la xarxa recíproca d'una estructura quasiperiòdica omplin densament tot l'espai recíproc. Tanmateix, és habitual triar un subconjunt de vectors de la xarxa recíproca, que corresponen als punts relativament més intensos del patró de difracció, per a definir l'esmentada pseudozona de Brioullin [Janssen07]. Així, consideren que les solucions de l'equació de Schrödinger amb un potencial quasiperiòdic són de la forma $\psi(\mathbf{x})=e^{i \mathbf{k} \cdot \mathbf{x}} u_{\mathbf{k}}(\mathbf{x})$, on la funció $u_{\mathbf{k}}(\mathbf{x})$ és quasiperiòdica, i estaria ben definida sobre un conjunt dens de vectors de la xarxa recíproca, encara que, per les raons adduïdes, es restringeix al subconjunt de vectors que dominen l'espectre.

En el camp de la física matemàtica hi ha nombrosos estudis al voltant de 


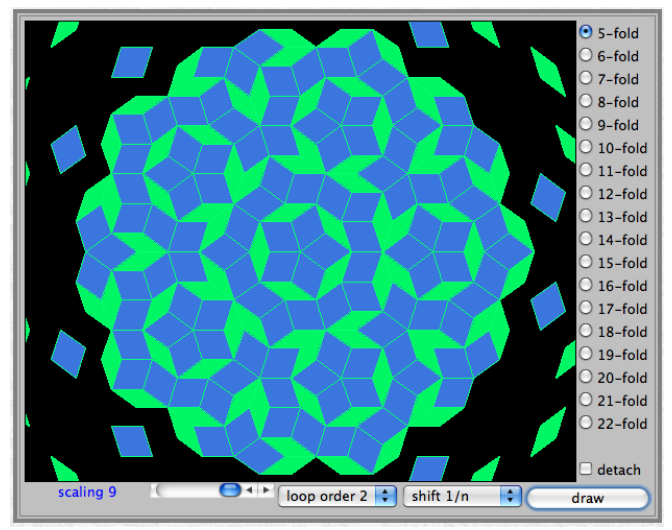

Figura 1.3: Mosaic de Penrose amb dos tipus de rombes i simetria d'ordre 5. (http://jcrystal.com)

l'operador de Schrödinger quasiperiòdic i les seues propietats [Bellissard00, Bellissard03, Chierchia87, Dinaburg75, Moser84]. La diferència principal és que l'anomenada zona de Brillouin es converteix en una varietat no commutativa, amb una topologia no trivial. En les referències [Bellissard03, Szabo04] s'expliquen amb detall els aspectes topològics i algunes de les seues conseqüències en la física.

La tecnologia electrònica, basada en les propietats elèctriques dels materials semiconductors, ha estat capaç d'arribar a un alt grau de miniaturització i d'eficiència, però, de forma paral-lela han sorgit problemes derivats d'aquest grau d'integració. Un d'ells és com dissipar la calor generada a aquesta escala. Cal, aleshores, trobar alternatives que solucionen aquests problemes. Per tant, de forma natural, ha sorgit una nova frontera al desenvolupament: el control de les propietats òptiques dels materials. Encara que, des del 1887 s'havien estudiat les propietats òptiques dels materials, aquest procés ha estat molt més lent, ja que, fins als anys 50 del passat segle, no es podia generar llum suficientment centrada al voltant d'una única freqüència (làser) o de transportar-la de manera controlada. L'estudi és anàleg al de les propietats elèctriques: ¿som capaços de trobar o dissenyar materials que impossibiliten la propagació de determinades 
ones electromagnètiques, amb una certa longitud d'ona, o que permeten la transmissió però només en unes direccions determinades de l'espai? ¿som capaços de localitzar-la en una determinada regió de l'espai? En resum, ¿podrem trobar materials que ens permeten controlar completament la llum? ¿quina classe de materials són? Per a respondre a aquestes qüestions tornem a l'analogia amb l'estudi dels materials, les propietats elèctriques dels quals han estat ja controlades, és a dir, els cristalls. L'equivalent òptic del cristall semiconductor és el cristall fotònic ${ }^{2}$, però amb una diferència molt important i interessant: els cristalls electrònics són naturals mentre que els cristalls fotònics, encara que n'hi ha de naturals, també poden fabricar-se, per tant, es pot fer un disseny a mida. En els cristalls fotònics, el potencial periòdic dels semiconductors és equivalent a una variació periòdica de la constant dielèctrica al llarg del cristall fotònic. Si la variació de la constant dielèctrica a l'interior de l'estructura és suficientment gran i l'absorció del material a la longitud d'ona a la qual es treballa és suficientment petita, aleshores apareixen, per a la propagació dels fotons, propietats equivalents a les que presenten els semiconductors per a la propagació d'electrons [Joannopoulos95]. Així, els cristalls fotònics permeten bandes prohibides i bandes de propagació, en determinades zones de l'espectre. Les equacions que s'han de resoldre són molt semblants a l'equació de Schrödinger de la física de l'estat sòlid, però en aquest cas les equacions, que es deriven de les equacions de Maxwell on la constant dielèctrica té una variació periòdica, impliquen les components del camp electromagnètic.

Una vegada establerta l'equivalència entre els cristalls electrònics i els cristalls fotònics cal preguntar-se si existeix l'equivalent fotònic del quasicristall electrònic és a dir, existeixen els quasicristalls fotònics? i, com es poden generar? La resposta a aquestes preguntes és sí. Els quasicristalls fotònics poden generar-se mitjançant sèries de Fibonacci en el cas unidimensional, i s'obtenen intercalant làmines de material amb alt índex de refracció amb d'altres amb baix índex tot

\footnotetext{
${ }^{2} \mathrm{El}$ terme cristall fotònic no apareix en la literatura fins a finals dels anys 80 del segle passat, després de les publicacions d'Ely Yablonovich i Saajev John [Yablonovitch87, John87]. Aquests articles són un referent en el camp del disseny de cristalls fotònics.
} 
seguint una sèrie de Fibonacci [Dal Negro03], i tessel-les de Penrose i d'AmmannBeenker en el bidimensional, on el quasicristall es genera amb la col-locació de varetes idèntiques de dielèctric en els vèrtexs dels rombes de les tessel-les de Penrose [Della Villa06]. També es poden generar fent incidir un cert nombre d'ones planes amb un angle adequat per a generar patrons de difracció quasicristal-lins, que, sobre un medi fotorefractiu, generaran un quasicristall fotònic, en modular el medi el seu index de refracció segons el patró quasiperiòdic [Bazán Sulzberger09].

Les bandes prohibides (gaps) en els cristalls fotònics, igual que passa en els cristalls electrònics, són una conseqüència de la seua estructura -simetries i configuració periòdica de la constant dielèctrica-. Així cal preguntar-se si existeixen bandes prohibides també per als quasicristalls fotònics. La resposta és que sí, i s'han trobat de forma experimental i per simulació numèrica. A més, una de les propietats més importants dels quasicristalls fotònics és la seua habilitat per a prohibir la propagació d'ones en un ampli marge espectral: els gaps fotònics dels quasicristalls fotònics són més nombrosos i de major ample de banda que en els cristalls fotònics per raó del seu alt nivell de simetria rotacional (simetries de llarg abast d'ordre 8, 10, 12) [Chan98, Della Villa06, Rodriguez08, Torres03,Zoorob00]. No obstant això, hi ha pocs exemples de com es pot resoldre el problema teòric de propagació de la llum dins d'un quasicristall. El problema teòric és equivalent al dels quasicristalls electrònics, perquè les equacions són formalment les mateixes, tot substituint el potencial quasiperiòdic per una variació quasiperiòdica de la constant dielèctrica, i la funció d'ona de l'electró per les components del camp electromagnètic. Per tant, anàlogament, no hi ha un equivalent al teorema de Bloch. En la referència [Rodriguez08] es proposa un mètode per a resoldre el problema teòric d'obtenció d'autovalors i autofuncions mitjançant les equacions de Maxwell però amb el doble de dimensions que la xarxa i es mostra una generalització al teorema de Bloch en el cas d'un quasicristall unidimensional simulat per una sèrie de Fibonacci.

Fins ara hem parlat de cristalls i quasicristalls fotònics, fent l'analogia amb els seus equivalents electrònics. Els models teòrics impliquen l'equació de Schrö- 
dinger amb potencials periòdics i quasiperiòdics. No obstant això, aquest model no és vàlid per a explicar el comportament de la llum dins d'un medi periòdic si la intensitat del camp és elevada. Aquest nou grau de llibertat permet també controlar les propietats de la llum i ha donat lloc al descobriment de nombrosos fenòmens amb un alt potencial tecnològic [Agrawal07, Boyd92], entre d'altres la formació de solitons. En presència d'un material no lineal, la propagació de la llum modifica l'índex de refracció del medi, la qual cosa permet, sota determinades circumstàncies, compensar efectes com la dispersió o la difracció, de forma que totes les components del paquet d'ones viatgen a la mateixa velocitat de fase. El resultat és un paquet d'ones que no canvia de forma al llarg de la propagació i que rep el nom de solitó ${ }^{3}$ [Kivshar03, Stegeman99]. El 1964 s'utilitzà l'equació de Schrödinger no lineal (NLSE) per a explicar la propagació de la llum en un medi no lineal i la formació de solitons mitjançant un mecanisme en què la llum genera la seua pròpia guia a mesura que es propaga [Chiao64]. Des d'aleshores, s'han modelitzat, mitjançant una NLSE, una gran quantitat de fenòmens de propagació no lineal, tant temporals com espacials. Aquest camp, a diferència d'allò que ocorre amb els cristalls i quasicristalls fotònics lineals, no té analogia amb el camp de l'estat sòlid clàssic, on tots els fenòmens són lineals.

Els cristalls fotònics no lineals han sigut objecte d'estudi tant teòric com experimental al llarg de les dues últimes dècades. Els primers treballs, amb xarxes de guies d'ona, que no són més que cristalls fotònics unidimensionals, són de finals de la dècada dels vuitanta [Christodoulides88]. El sistema es va modelitzar mitjançant un conjunt d'equacions discretes acoblades cadascuna de les quals descrivia la propagació en una de les guies. La interacció amb les guies veïnes es va modelitzar mitjançant un terme que només tenia en compte les guies

\footnotetext{
${ }^{3}$ Un pols és un paquet d'ones planes amb distintes freqüències, cada una de les quals, en el cas lineal, viatja a distinta velocitat de fase dins del medi. Això provoca un eixamplament del paquet d'ones. Aquest efecte reb el nom de dispersió cromàtica.

Si suposem que la llum s'emet quasi a una única freqüència (tota la dinàmica temporal està determinada per aquesta freqüència), podem generar paquets d'ones planes amb distintes freqüències espacials. En aquest cas el paquet d'ones, que s'anomena feix, està format per un conjunt d'ones planes que es propaguen formant diferents angles respecte d'un cert eix. Cadascuna de les ones del feix es propaga a una velocitat de fase diferent respecte de l'eix, donant lloc a un eixamplament del feix, fenomen que es coneix com de difracció del feix.
} 
veïnes. Aquesta aproximació es coneix com aproximació d'enllaç fort [apèndix E]. Aquest sistema pot reduir-se a un sistema continu per a l'envolupant del camp en cada guia, i presenta solucions estables tipus solitó, que s'anomenen solitons discrets. En aquest tipus d'estructura s'ha demostrat l'existència de solitons brillants i foscos [Kivshar92, Christodoulides03]. També s'han estudiat sistemes on l'índex de refracció varia de forma periòdica amb la direcció de propagació [Chen87] i l'extensió natural a sistemes periòdics bidimensionals la trobem en treballs com [Efremidis02, Fleischer03b, Fleischer03a] tots modelats mitjançant una NLSE discreta.

Les possibles aplicaciones del quasicristalls fotònics no lineals [Lifshitz05, Bahabad08] han dirigit l'interès dels investigadors en l'última dècada cap a aquests sistemes. No obstant això, hi ha poques referències teòriques sobre el particular. Això és natural, ja que hem vist que, fins i tot, en el cas lineal, hi ha poques ferramentes teòriques. La majoria dels treballs es restringeixen a simulacions numèriques i treballs experimentals. Així, s'han simulat quasicristalls unidimensionals generats per una sèrie de Fibonacci [Clausen99], i quasicristalls bidimensionals amb simetria dodecagonal [Xie03], on mostren l'existència de solitons (també els anomenen quasisolitons). Més recentment, s'han obtingut numèricament quasisolitons estables de tipus vòrtex amb càrrega topològica 3 i 4 [Law10]. Cal destacar alguns treballs experimentals d'alt impacte [Freedman06,Freedman07, Man05] que demostren l'interès que ha despertat l'estudi de les propietats òptiques associades als quasicristalls fotònics no lineals.

Gran part dels resultats obtinguts, en el camp de l'òptica no lineal, per a sistemes periòdics i quasiperiòdics són aplicables també en el camp dels condensats de Bose-Einstein (BEC). La raó és que el model teòric en ambdós casos és formalment idèntic: ve donat per una equació de Schrödinger no line$\mathrm{al}^{4}$ [Kivshar03, Pitaevskii03]. Així, els resultats obtinguts en un dels camps són d'aplicació directa en l'altre, com, per exemple, s'han fet hipòtesis sobre molts tipus d'estructures no lineals en els BEC i s'han observat experimentalment al-

\footnotetext{
${ }^{4}$ Les propietats estàtiques i dinàmiques d'un condensat de Bose-Einstein es descriuen mitjançant una equació de Schrödinger no lineal que s'anomena equació de Gross-Pitaevskii.
} 
guns resultats com solitons foscos [Burger99], solitons brillants [Khaykovich02], solitons amb gaps [Ostrovskaya03, Eiermann04, Ostrovskaya04] i xarxes de solitons [Efremidis03]. Encara que no massa nombrosos, també trobem referències sobre condensats de Bose-Einstein en sistemes quasiperiòdics [Roati08].

El propòsit d'aquesta tesi s'emmarca dins del camp de l'òptica no lineal, i, en conseqüència, té aplicació directa en el camp dels condensats de Bose-Einstein. Per tant, parlarem en general de sistemes periòdics i quasiperiòdics tenint en compte que els resultats obtinguts seran d'aplicació en ambdós casos. El nostre objectiu serà l'obtenció d'una nova ferramenta teòrica que permeta analitzar la dinàmica d'una solució no lineal estacionària sotmesa a una pertorbació menuda. Ens centrarem en solucions que òmpliguen tots els nodes de la xarxa i, per tant, tindran simetria translacional en el cas de potencials periòdics i seran aperiòdiques en el cas de potencials quasiperiòdics. Tractarem d'obtenir les equacions efectives de l'equació de Schrödinger no lineal per a l'envolupant d'aquestes solucions no lineals en el règim de baixes energies, és a dir, sota l'aproximació que les variacions siguen suaus en relació a l'espaiat de la xarxa, tant per a potencials periòdics com quasiperiòdics, omplint el buit teòric existent en el darrer cas.

En el capítol 2 considerem una xarxa bidimensional periòdica. El punt de partida és l'equació de Schrödinger no lineal (NLSE) i en presència d'un potencial periòdic. El nostre primer objectiu és l'obtenció de les equacions discretes de la NLSE, és a dir, les equacions que s'obtenen com a conseqüència de l'expansió de l'amplitud del camp en funcions localitzades sobre la xarxa. En lloc d'utilitzar l'aproximació clàssica [Alexander06, Trager06] que pren com a base les funcions solució del problema lineal periòdic, o les funcions localitzades solució del potencial individual en cada punt de la xarxa en l'aproximació d'enllaç fort [apèndix E], utilitzarem la base de Wannier no lineal, que definirem i construirem. A continuació introduïm el concepte d'envolupant discreta per tal d'analitzar el comportament del sistema en les rodalies de la solució del problema no lineal. Per últim, fem el pas al continu considerant el límit quan l'espaiat de la xarxa tendeix a 0 . Les equacions efectives per a l'envolupant contínua s'obtenen en el cas unidimensional i en el bidimensional. 
L'objectiu del capítol 3 és donar unes equacions efectives vàlides per a tot tipus de sistemes quasiperiòdics. El marc de la geometria no commutativa, proposada i desenvolupada per A. Connes [Connes94] des de finals dels setanta, resultarà ser l'eina adequada per a tractar el problema. Haurem de treballar amb un espai no commutatiu amb el doble de dimensions i provarem que l'equació per a l'envolupant a baixes energies té un terme addicional respecte del cas periòdic, conseqüència de la no commutativitat.

Per últim, en el capítol 4 s'exposen les conclusions d'aquesta tesi i les perspectives de futur. 


\section{Capítol 2}

\section{Equació efectiva en potencials periòdics}

\section{$2.1 \quad$ Introducció}

Les equacions discretes de l'equació de Schrödinger no lineal (NLSE) bidimensional en un potencial periòdic ixen de forma natural com a conseqüència de l'expansió de l'amplitud del camp en funcions localitzades sobre la xarxa. L'amplitud original $\phi(x, y)$, definida sobre un continu espacial, se substitueix per un conjunt d'infinites variables complexes $\left\{c_{i}\right\}$ definides sobre un espai discret corresponent a les diferents cel.les que formen el potencial periòdic. De forma intuïtiva, nosaltres esperem que aquest tipus d'expansió siga exacta si l'amplitud del camp està localitzada en els punts de la xarxa. La dinàmica, en termes d'aquest nou conjunt de variables, està descrita mitjançant una equació de Schrödinger no lineal discreta generalitzada. En aquestes circumstàncies, l'amplitud física té l'aspecte d'una distribució discreta d'intensitat, i la fase posseeix la mateixa simetria que el potencial periòdic. Amb aquesta imatge és interessant considerar la situació en què aquesta distribució "discreta" varia suaument amb el període de la xarxa $a$. Si caracteritzem la variació espacial d'aquesta amplitud per una escala de longitud $\xi$, aquesta propietat significa que $\xi \gg a$. És natural, 
aleshores, considerar un nou límit del continu de la NLSE definit per la condició $a \rightarrow 0$. La nova amplitud continua $\Phi(x, y)$ definida per aquest procediment representa una funció espacial que varia suaument. Com que la nova amplitud no "veurà" la xarxa espacial subjacent a causa del límit al continu $a \rightarrow 0$, la informació sobre ella serà codificada en l'acoblament efectiu de l'equació continua satisfeta per $\Phi(x, y)$. Així, la nova equació efectiva continua diferirà d'aquella que verifica l'amplitud original $\phi(x, y)$. Una diferència important i evident entre aquestes dues equacions està relacionada amb llurs simetries espacials; mentre que la NLSE original amb un potencial periòdic, que és l'equació que verifica la funció $\phi(x, y)$, gaudeix d'un conjunt de simetries discretes marcades per la presència del potencial periòdic, l'equació efectiva per a la funció que varia suaument $\Phi(x, y)$ ha de ser, per construcció, simètrica sota rotacions. La raó és que el caràcter discret del potencial ha estat inclòs en el conjunt de variables discretes $\left\{c_{i}\right\}$, el límit al continu $a \rightarrow 0$ de les quals és, precisament, $\Phi(x, y)$. Per això no roman, en l'equació efectiva per a $\Phi(x, y)$, cap traça del potencial periòdic. La dinàmica per a l'amplitud espacial que varia suaument $\Phi(x, y)$ està, aleshores, determinada per aquesta nova equació continua.

\subsection{Equació discreta per als coeficients de Wan- nier}

Considerem la NLSE que conté el terme del potencial periòdic lineal $V(\mathbf{x})$, on $\mathbf{x}=(x, y)$, i en presència d'un potencial químic $\mu^{1}$ :

$$
i \frac{\partial \phi}{\partial t}=\left(-\nabla^{2}+V(\mathbf{x})-\mu-g|\phi|^{2}\right) \phi
$$

on ja s'ha fet l'aproximació d'envolupant suau $\tilde{\phi}=\phi(\mathbf{x}, t) e^{-i \mu t}$. Així, si el camp $\tilde{\phi}$ és estacionari, el potencial químic $\mu$ està ben definit i la funció $\phi$ és independent

\footnotetext{
${ }^{1}$ En condensats de Bose-Einstein hom parla que treballa a potencial químic donat, que és una dada del sistema, i que és el potencial a què cal treballar per a tenir un nombre de partícules ben definit en el sistema.
} 
del temps $(\dot{\phi}=0)$.

Com ja s'ha comentat en la introducció, l'amplitud del camp $\phi$ pot expandirse en termes d'una base de funcions localitzades centrades en cada cel.la de la xarxa bidimensional. La base està formada per les funcions anomenades de Wannier $W_{\alpha}\left(\mathbf{x}-\mathbf{x}_{\hat{i}}\right)$. Aquestes estan caracteritzades per la coordenada de la cel.la de la xarxa $\mathbf{x}_{\hat{i}}$ i per l'índex de la banda $\alpha$. Les funcions de Wannier són les recíproques de les funcions de Bloch i, per tant,

$$
W_{\alpha}\left(\mathbf{x}-\mathbf{x}_{\hat{i}}\right)=N_{0} \sum_{\mathbf{p}} e^{-i \mathbf{p} \cdot \mathbf{x}_{\hat{i}}} f_{\mathbf{p} ; \alpha}(\mathbf{x})=N_{0} \sum_{\mathbf{p}} e^{i \mathbf{p} \cdot\left(\mathbf{x}-\mathbf{x}_{\hat{\imath}}\right)} u_{\mathbf{p} ; \alpha}(\mathbf{x})
$$

Les funcions de Bloch $f_{\mathbf{p} ; \alpha}(\mathbf{x})=e^{i \mathbf{p} \cdot \mathbf{x}} u_{\mathbf{p} ; \alpha}(\mathbf{x})$ són les funcions pròpies d'un hamiltonià periòdic, caracteritzat per un vector $\mathbf{a}=a \hat{\mathbf{e}}_{1}+a \hat{\mathbf{e}}_{2}-$ on $\hat{\mathbf{e}}_{1} \mathrm{i} \hat{\mathbf{e}}_{2}$ no són paral.lels - [apèndix A], i invariant sota l'acció del operador de translació finit $T_{\mathbf{a}}\left[\right.$ Ashcroft76]. Al temps, les funcions de Bloch són funcions pròpies de $T_{\mathbf{a}}$ :

$$
T_{\mathbf{a}} f_{\mathbf{p} ; \alpha}(\mathbf{x})=f_{\mathbf{p} ; \alpha}(\mathbf{x}+\mathbf{a})=e^{i \mathbf{p} \cdot \mathbf{a}} f_{\mathbf{p} ; \alpha}(\mathbf{x})
$$

Les funcions de Bloch estan definides per allò que anomenem el seu pseudomoment $\mathbf{p}$ i el seu index de banda $\alpha$, i poden veure's com a ones planes modulades que duen pseudo-moment $\mathbf{p}$. La funció de modulació $u_{\mathbf{p} ; \alpha}(\mathbf{x})$ és, doncs, periòdica amb la mateixa periodicitat que el potencial:

$$
u_{\mathbf{p} ; \alpha}(\mathbf{x}+\mathbf{a})=u_{\mathbf{p} ; \alpha}(\mathbf{x})
$$

Així com les funcions de Bloch formen una base per a les funcions definides sobre $\mathbb{R}^{2}$ — ja que són autofuncions de l'operador autoadjunt hamiltonià-, les funcions de Wannier també formen una base. Per a provar aquesta propietat és convenient considerar que totes les funcions, per una banda, estan definides en una regió finita $\Omega$ de grandària $L \times L$ que conté $N \times N$ cel.les elementals de grandària $a^{2}$ (de manera que $L=N a$ ) i, d'altra banda, són periòdiques en $\mathbf{L}=L \hat{\mathbf{e}}_{1}+L \hat{\mathbf{e}}_{2}$, açò és, $\phi(\mathbf{x}+\mathbf{L})=\phi(\mathbf{x})$. La regió $\Omega$ es coneix com el domini bàsic i defineix la zona 
on les propietats d'ortogonalitat estan ben establides. Quan exigim condicions de frontera periòdiques a les funcions de Bloch $f_{\mathbf{p} ; \alpha}(\mathbf{x})=e^{i \mathbf{p} \cdot \mathbf{x}} u_{\mathbf{p} ; \alpha}(\mathbf{x})$ el pseudomoment $\mathbf{p}$ es discretiza segons $e^{i \mathbf{p} \cdot \mathbf{L}}=1$, que implica que $\mathbf{p}=\frac{2 \pi}{N a}\left(m_{1}, m_{2}\right)$ on $\left(m_{1}, m_{2}\right) \in\left[-N / 2, N / 2\left[\cup\left[-N / 2, N / 2\left[\subset \mathbb{Z}^{2}\right.\right.\right.\right.$. Si la normalització de les funcions de Bloch ve donada per $P$, la condició d'ortogonalitat per a $f_{\mathbf{p} ; \alpha}$ en un domini periòdic vindrà donada per

$$
\int_{\Omega} d^{2} x f_{\mathbf{p}^{\prime} ; \alpha}^{*}(\mathbf{x}) f_{\mathbf{p} ; \alpha}(\mathbf{x})=P \delta_{\mathbf{p}^{\prime} \mathbf{p}} \delta_{\alpha \alpha^{\prime}},
$$

i la condició d'ortogonalitat per a les funcions de Wannier pot provar-se que ve donada per

$$
\begin{aligned}
\int_{\Omega} d^{2} x W_{\alpha^{\prime}}^{*}\left(\mathbf{x}-\mathbf{x}_{\hat{j}}\right) W_{\alpha}\left(\mathbf{x}-\mathbf{x}_{\hat{i}}\right) & =N_{0}^{2} \sum_{\mathbf{p}^{\prime}, \mathbf{p}} e^{i\left(\mathbf{p}^{\prime} \cdot \mathbf{x}_{\hat{j}}-\mathbf{p} \cdot \mathbf{x}_{\hat{i}}\right)} \int_{\Omega} d^{2} x f_{\mathbf{p}^{\prime} ; \alpha^{\prime}}^{*}(\mathbf{x}) f_{\mathbf{p} ; \alpha}(\mathbf{x}) \\
& =N_{0}^{2} P \delta_{\alpha^{\prime} \alpha} \sum_{\mathbf{p}} e^{i \mathbf{p} \cdot\left(\mathbf{x}_{\hat{j}}-\mathbf{x}_{\hat{i}}\right)} .
\end{aligned}
$$

Si tenim en compte que $\mathbf{x}_{\hat{i}}=i_{1} a \hat{\mathbf{e}}_{1}+i_{2} a \hat{\mathbf{e}}_{2} \mathrm{i} \mathbf{x}_{\hat{j}}=j_{1} a \hat{\mathbf{e}}_{1}+j_{2} a \hat{\mathbf{e}}_{2}$, on $\hat{i}=\left(i_{1}, i_{2}\right)$ i $\hat{j}=\left(j_{1}, j_{2}\right)$ pertanyen a $\mathbb{Z}^{2}$, s'obté

$$
\begin{aligned}
N_{0}^{2} P \delta_{\alpha^{\prime} \alpha} \sum_{\mathbf{p}} e^{i \mathbf{p} \cdot\left(\mathbf{x}_{\hat{j}}-\mathbf{x}_{\hat{i}}\right)} & =N_{0}^{2} P \delta_{\alpha^{\prime} \alpha} \sum_{m_{1}, m_{2}} e^{i \frac{2 \pi}{L} a m_{1}\left(j_{1}-i_{1}\right)} e^{i \frac{2 \pi}{L} a m_{2}\left(j_{2}-i_{2}\right)} \\
& =N_{0}^{2} P N^{2} \delta_{\alpha^{\prime} \alpha} \delta_{j_{1} i_{1}} \delta_{j_{2} i_{2}},
\end{aligned}
$$

de manera que la condició d'ortonormalitat pot obtenir-se prenent com a constant de normalització $N_{0}$ el valor $1 /(N \sqrt{P})$, és a dir,

$$
\int_{\Omega} d^{2} x W_{\alpha^{\prime}}^{*}\left(\mathbf{x}-\mathbf{x}_{\hat{j}}\right) W_{\alpha}\left(\mathbf{x}-\mathbf{x}_{\hat{i}}\right)=\delta_{\alpha^{\prime} \alpha} \delta_{\hat{i} \hat{j}} .
$$

La condició d'ortonormalització de la base de funcions de Wannier permet d'escriure la inversa de la relació (2.2), i així, expressar les funcions de Bloch com 
una expansió en termes de les funcions localitzades de Wannier centrades en cada cel.la de la xarxa:

$$
f_{\mathbf{p} ; \alpha}(\mathbf{x})=\frac{\sqrt{P}}{N} \sum_{\hat{i}} e^{i \mathbf{p} \cdot \mathbf{x}_{\hat{i}}} W_{\alpha}\left(\mathbf{x}-\mathbf{x}_{\hat{i}}\right)
$$

De la mateixa manera, podem usar la base de funcions de Wannier per a representar l'amplitud de qualsevol camp arbitrari en un temps donat $t$ :

$$
\phi(\mathbf{x}, t)=\sum_{\hat{i}, \alpha} c_{\hat{i}, \alpha}(t) W_{\alpha}\left(\mathbf{x}-\mathbf{x}_{\hat{i}}\right)
$$

Aquesta expressió pot usar-se per a integrar sobre les coordenades espacials $\mathbf{x}$ i quedar-nos amb una equació en els coeficients discrets $c_{\hat{i}, \alpha}$. Així, utilitzem l'acció associada a la NLSE amb un potencial periòdic - eq.(2.1) — per a fer dita integració:

$$
\begin{aligned}
S & =\int_{\Omega} d^{2} x d t \mathcal{L} \\
& =\int_{\Omega} d^{2} x d t\left\{\frac{i}{2}\left[\dot{\phi} \phi^{*}-\dot{\phi}^{*} \phi\right]-\phi^{*}\left[-\nabla^{2}+V(\mathbf{x})-\mu+\frac{g}{2}|\phi|^{2}\right] \phi\right\}
\end{aligned}
$$

L'hamiltonià corresponent ve donat per:

$$
H=\int_{\Omega} d^{2} x \mathcal{H}=\int_{\Omega} d^{2} x\left\{\nabla \phi^{*} \cdot \nabla \phi+\phi^{*}\left[V(\mathbf{x})-\mu+\frac{g}{2}|\phi|^{2}\right] \phi\right\} .
$$

Si ara introduïm el desenvolupament del camp en termes de les funcions de Wannier (2.5) en les expressions de $S$ i $\mathcal{H}$, i integrem sobre les coordenades transversals $\mathbf{x}$ (per a simplificar la notació inclourem l'índex de la banda $\alpha$ i l'índex espacial $\hat{i}$ en un índex comú: $(\hat{i}, \alpha) \rightarrow i)$ ), obtenim:

$$
S=\int d t\left\{\sum_{i} \frac{i}{2}\left[\dot{c}_{i} c_{i}^{*}-\dot{c}_{i}^{*} c_{i}\right]-\sum_{i, j} L_{i j} c_{i}^{*} c_{j}+\sum_{i j k l} T_{i j k l} c_{i}^{*} c_{j}^{*} c_{k} c_{l}\right\},
$$


i

$$
H=\sum_{i, j} L_{i j} c_{i}^{*} c_{j}-\sum_{i j k l} T_{i j k l} c_{i}^{*} c_{j}^{*} c_{k} c_{l} .
$$

Per tal d'arribar a aquestes expressions hem utilitzat la condició d'ortonormalització (2.3) i hem introduït els tensors de segon i quart ordre $L_{i j}$ i $T_{i j k l}$ donats per les expressions:

$$
L_{i j} \equiv \int_{\Omega} d^{2} x W_{i}^{*}\left(-\nabla^{2}+V(\mathbf{x})-\mu\right) W_{j},
$$

i

$$
T_{i j k l} \equiv \frac{1}{2} \int_{\Omega} d^{2} x g W_{i}^{*} W_{j}^{*} W_{k} W_{l} .
$$

Les equacions de moviment per als coeficients de Wannier $c_{i}$ s'obtenen mitjançant les equacions d'Euler-Lagrangre per a l'acció (2.8):

$$
i \dot{c}_{i}=\sum_{j} L_{i j} c_{j}-2 \sum_{j k l} T_{i j k l} c_{j}^{*} c_{k} c_{l} .
$$

\subsection{Els modes no lineals de Bloch}

Les equacions de moviment per als coeficients de l'expansió de Wannier eq.(2.12) — així com l'acció corresponent —eq.(2.6) — i el seu hamiltonià eq.(2.9) - preserven la seua forma, independentment de l'elecció de la base. No obstant això, els coeficients del tensors efectius $L_{i j}$ i $T_{i j k l}$ sí que depenen de dita elecció. Aparentment, aquesta qüestió sembla artificial ja que, ingènuament, hom pot pensar que l'elecció natural per a la base de Wannier associada a la nostra equació de partida - eq.(2.1) — és la que proporcionen els modes de Bloch associats a l'operador periòdic lineal $H_{0} \equiv-\nabla^{2}+V(\mathbf{x})$. Els modes de Bloch del sistema lineal semblen ser les úniques solucions relacionades amb el problema físic representat per l'eq.(2.1) que satisfan totes les propietats necessàries per a derivar les equacions discretes (2.12) obtingudes en la secció anterior. No obstant 
això, la versió no lineal de l'equació de Schrödinger ens ofereix més alternatives que els modes lineals per a complir les condicions descrites anteriorment. Aquestes solucions són els anomenats modes de Bloch no lineals. Anem a veure com es poden construir.

Siga $\phi_{\text {sol }}(\mathbf{x})$ una solució no lineal independent del temps de l'eq.(2.1). Si la seua amplitud $\left|\phi_{\text {sol }}(\mathbf{x})\right|$ és invariant sota translacions iguals al període de la xarxa $\mathbf{a}$, això és, si satisfà la condició d'invariança discreta translacional $\left|\phi_{\text {sol }}(\mathbf{x}+\mathbf{a})\right|=$ $\left|\phi_{\text {sol }}(\mathbf{x})\right|$, aleshores $\phi_{\text {sol }}(\mathbf{x})$ ha de tenir la forma d'una ona de Bloch:

$$
\phi_{\text {sol }}(\mathbf{x})=\phi_{\mathbf{Q} ; \beta}(\mathbf{x})=e^{i \mathbf{Q} \cdot \mathbf{x}} v_{\mathbf{Q} ; \beta}(\mathbf{x}) .
$$

La NLSE independent del temps pot obtenir-se a partir de l'eq.(2.1) substituint $\dot{\phi}=0$ :

$$
\left(-\nabla^{2}+V(\mathbf{x})-g|\phi|^{2}\right) \phi=\mu \phi .
$$

Si $\phi_{\text {sol }}$ satisfà l'eq.(2.14) i, simultàniament, verifica la condició $\left|\phi_{\text {sol }}(\mathbf{x}+\mathbf{a})\right|=$ $\left|\phi_{\text {sol }}(\mathbf{x})\right|$ llavors el potencial total $V_{\text {sol }}(\mathbf{x}) \equiv V(\mathbf{x})-g\left|\phi_{\text {sol }}(\mathbf{x})\right|^{2}$ de la NLSE independent del temps també serà periòdic amb un període donat per $\mathbf{a}$, a causa de la periodicitat de $V(\mathbf{x})$ i de la invariança de $\left|\phi_{\text {sol }}(\mathbf{x})\right|$ sota translacions finites:

$$
V_{\mathrm{sol}}(\mathbf{x}+\mathbf{a}) \equiv V(\mathbf{x}+\mathbf{a})-g\left|\phi_{\mathrm{sol}}(\mathbf{x}+\mathbf{a})\right|^{2}=V(\mathbf{x})-g\left|\phi_{\mathrm{sol}}(\mathbf{x})\right|^{2}=V_{\mathrm{sol}}(\mathbf{x}) .
$$

Com que $\phi_{\text {sol }}$ és una solució de l'equació d'autovalors (2.14), ha d'aparèixer, per autoconsistència, com una de les autofuncions de l'operador hamiltonià $H_{\text {sol }}=-\nabla^{2}+V_{\text {sol }}(\mathbf{x})$ generat per ella mateix. Donada la funció $\phi_{\text {sol }}$, l'hamiltonià $H_{\text {sol }}$ també és un operador que pot ser diagonalitzat per diferents procediments d'anàlisi, bé analítics o bé numèrics. Considerem ara l'espectre de l'hamiltonià $H_{\text {sol }}$. Atès que acabem de demostrar que $V_{\text {sol }}(\mathbf{x})$ és periòdic, l'espectre de $H_{\text {sol }}$ ha d'estar format per un conjunt infinit de funcions de Bloch $g_{\mathbf{q} ; \beta}(\mathbf{x})=e^{i \mathbf{q} \cdot \mathbf{x}} v_{\mathbf{q} ; \beta}(\mathbf{x})$ que satisfan:

$$
\left(-\nabla^{2}+V_{\mathrm{sol}}(\mathbf{x})\right) g_{\mathbf{q} ; \beta}(\mathbf{x})=\lambda_{\mathbf{q} ; \beta} g_{\mathbf{q} ; \beta}(\mathbf{x})
$$


on, com és habitual, $\mathbf{q}$ és el pseudo-moment, $\beta$ és l'índex de banda i $v_{\mathbf{q} ; \beta}(\mathbf{x}+\mathbf{a})=$ $v_{\mathbf{q} ; \beta}(\mathbf{x})$. L'autoconsistència implica que, al ser $\phi_{\text {sol }}$ una solució de l'equació d'autovalors (2.14), $\phi_{\text {sol }}$ ha de ser igual a una de les autofuncions de $H_{\text {sol }}$ que apareixen en l'eq.(2.15). D'altra banda, $H_{\text {sol }}$ és un operador autoadjunt ja que ambdues parts, lineal $\left(H_{0}=-\nabla^{2}+V(\mathbf{x})\right)$ i no lineal $\left(-g\left|\phi_{\text {sol }}(\mathbf{x})\right|^{2}\right)$, ho són. En conseqüència, els valors propis $\lambda_{\mathbf{q} ; \beta}$ són, necessàriament, reals. En resum, existeix un valor donat de $\mathbf{q}=\mathbf{Q}$ i un de $\beta=\beta_{0}$ per als quals

$$
\phi_{\mathrm{sol}}(\mathbf{x})=g_{\mathbf{Q} ; \beta_{0}}(\mathbf{x})=e^{i \mathbf{Q} \cdot \mathbf{x}} v_{\mathbf{Q} ; \beta_{0}}(\mathbf{x}),
$$

i

$$
\mu=\lambda_{\mathbf{Q} ; \beta_{0}} \in \mathbb{R}
$$

El que hem obtingut no és una condició suficient per a l'existència d'aquestes solucions. Només estableix que si una solució s'ha trobat verificant la condició d'invariança translacional discreta $\left|\phi_{\text {sol }}(\mathbf{x}+\mathbf{a})\right|=\left|\phi_{\text {sol }}(\mathbf{x})\right|$ llavors la seva forma ha de ser la d'un mode no lineal de Bloch. No obstant això, l'experiència numèrica ens ha mostrat que aquestes solucions existeixen de fet per a un rang ample de valors del potencial químic $\mu$. A més, el nostre argument anterior recolza que apareguin diferents tipus de modes de Bloch no lineals, caracteritzats per diferents valors del pseudo-moment i de l'índex de la banda. De fet, les simulacions numèriques indiquen que, per a un determinat valor del potencial químic, poden existir diferents modes de Bloch no lineals de diversos tipus [García March08]. Atès que, per a un valor fix de $\mu$, diferents solucions no lineals es poden distingir per diferents normalitzacions $P\left(P \equiv \int_{\Omega}|\phi|^{2}\right)$, s'espera trobar una família de corbes no lineals $P(\mu)$ per als diferents modes de Bloch. Cada família serà, naturalment, descrita pels valors de $\mathbf{q}$ i $\beta$, és a dir, $P=P_{\mathbf{q} ; \beta}(\mu)$.

La construcció de la base de Wannier associada als modes no lineals de Bloch $\phi_{\mathbf{Q} ; \beta_{0}}(\mathbf{x})$, caracteritzats per els seus valors $\mathbf{Q}, \beta_{0}$ i el potencial químic $\mu$, és senzilla d'acord amb tot allò que s'ha detallat a la secció anterior. Donat un valor de $\mu$, fem una recerca de la solució de l'eq.(2.14) de la forma $\phi_{\mathbf{Q} ; \beta_{0}}^{\mu}(\mathbf{x})=$ $e^{i \mathbf{Q} \cdot \mathbf{x}} v_{\mathbf{Q} ; \beta_{0}}^{\mu}(\mathbf{x})$. Un cop $\mu, \mathbf{Q}$ i $\beta_{0}$ estan fixades, aquesta solució ha de ser única. 
Si es troba, aquesta solució definirà l'operador no lineal periòdic, però ara fixat,

$$
H_{\mathrm{sol}}=-\nabla^{2}+V(\mathbf{x})-g\left|v_{\mathbf{Q} ; \beta_{0}}^{\mu}(\mathbf{x})\right|^{2},
$$

les funcions pròpies del qual proporcionen una base formada per les funcions de Bloch

$$
\left\{g_{\mathbf{q} ; \beta}^{\left(\mu, \mathbf{Q}, \beta_{0}\right)}(\mathbf{x})=e^{i \mathbf{q} \cdot \mathbf{x}} v_{\mathbf{q} ; \beta}^{\left(\mu, \mathbf{Q}, \beta_{0}\right)}(\mathbf{x})\right\}_{\mathbf{q} \in \mathbb{Z}^{2}, \beta \in \mathbb{N}},
$$

que determinen, al temps, la base de Wannier com en l'eq.(2.2):

$$
\begin{aligned}
W_{\beta}^{\left(\mu, \mathbf{Q}, \beta_{0}\right)}\left(\mathbf{x}-\mathbf{x}_{\hat{i}}\right) & =\frac{1}{N \sqrt{P}} \sum_{\mathbf{q}} e^{-i \mathbf{q} \cdot \mathbf{x}_{\hat{\imath}}} g_{\mathbf{q} ; \beta}^{\left(\mu, \mathbf{Q}, \beta_{0}\right)}(\mathbf{x}) \\
& =\frac{1}{N \sqrt{P}} \sum_{\mathbf{q}} e^{i \mathbf{q} \cdot\left(\mathbf{x}-\mathbf{x}_{\hat{i}}\right)} v_{\mathbf{q} ; \beta}^{\left(\mu, \mathbf{Q}, \beta_{0}\right)}(\mathbf{x}) .
\end{aligned}
$$

Com que $P$ és la normalització de la solució $\phi_{\mathbf{Q} ; \beta_{0}}^{\mu}$, és clar que també tindrà dependència en els paràmetres $\mu, \mathbf{Q}$ i $\beta_{0}$ que la defineixen, és a dir, $P=P_{\mathbf{q} ; \beta}(\mu)$, com ja hem dit adés. A causa d'aquesta dependència implícita de la base de Wannier sobre els paràmetres que defineixen els modes de Bloch no lineals, els tensors de segon i quart ordre, que hi figuren en l'acció discretitzada - eq.(2.8) , hamiltonià — (2.9) — i equacions de moviment — (2.12) — per als coeficients de l'expansió de Wannier $c_{i}$, heretaran la dependència en aqueixos paràmetres, això és, $L_{i j}=L_{i j}\left(\mu, \mathbf{Q}, \beta_{0}\right)$ i $T_{i j k l}=T_{i j k l}\left(\mu, \mathbf{Q}, \beta_{0}\right)$.

La conclusió final d'aquesta secció és que l'espectre de Bloch de l'hamiltonià lineal no és l'únic vàlid per a definir la base de Wannier necessària per realitzar la discretització de l'eq.(2.1). De fet, hi ha arguments que invoquen la "proximitat" de les solucions que afavoreixen clarament la utilització d'una base de Wannier derivada dels modes de Bloch no lineals. Com a exemple, suposem que estudiem l'evolució temporal d'una solució de l'eq.(2.1) en les proximitats d'una solució de Bloch no lineal independent del temps caracteritzada per un valor fix del potencial químic $\mu$, és a dir, pertorbarem la solució. L'evolució de l'amplitud ja no serà descrita pel mateix valor de $\mu$ però fluctuarà al voltant de la solució 
independent del temps de tal manera que mostrarà un valor promig del potencial químic que estarà prop del valor de $\mu$. Anàlogament, la "proximitat" de l'evolució de l'amplitud es manifestarà en la proximitat del valor de $P$. En aquests casos, una descripció més precisa de la dinàmica de l'evolució del sistema estarà a càrrec de la base de Wannier, associada a l'operador no lineal, generada per la solució no lineal de Bloch independent del temps donada per $\mu$. Com ja es veurà en la següent secció, les amplituds de llarg abast compliran aquesta condició de "proximitat" per a un mode no lineal de Bloch específic. En aquest escenari, l'elecció natural per a l'esquema de discretització serà el proporcionat per la base de Wannier associada als modes de Bloch no lineals.

\subsection{Equació contínua efectiva per a amplituds de llarg abast}

L'objectiu d'aquesta secció és proporcionar la descripció matemàtica del camp òptic prop d'un estat estacionari constituït per una ona de Bloch no lineal del tipus descrit en la secció anterior. Per a això, utilitzarem la teoria discretitzada per als coeficients de Wannier presentada a la secció 2.2. Per tal de proporcionar una descripció apropiada, és convenient identificar, en primer lloc, les principals característiques dels modes de Bloch no lineals en la seua forma discretitzada. Si descrivim el mode no lineal de Bloch $\phi_{\mathbf{Q} ; \beta}(\mathbf{x})$ a partir de les funcions de Wannier (2.16) associades a l'operador no lineal generat pel mateix mode, el mode de Bloch no lineal tindrà una representació donada per:

$$
\phi_{\mathbf{Q} ; \beta}(\mathbf{x})=\frac{\sqrt{P}}{N} \sum_{\hat{i}} e^{i \mathbf{Q} \cdot \mathbf{x}_{\hat{i}}} W_{\beta}\left(\mathbf{x}-\mathbf{x}_{\hat{i}}\right),
$$

que indica que, en termes dels coeficients discrets, aquest mode no lineal de Bloch es representa com:

$$
c_{\hat{i}}=\frac{\sqrt{P}}{N} e^{i \mathbf{Q} \cdot \mathbf{x}_{\hat{i}}} .
$$


La invariança espacial de l'amplitud del mode no lineal de Bloch $\left|\phi_{\mathbf{Q} ; \beta}(\mathbf{x})\right|=$ $\left|\phi_{\mathbf{Q} ; \beta}(\mathbf{x}+\mathbf{a})\right|$ està ací transferida al mòdul dels coeficients discrets $\left|c_{\hat{i}}\right|=\sqrt{P} / N$, $\forall \hat{i}$. Així, en la xarxa associada als coeficients discrets, un mode de Bloch no lineal apareix com un camp d'amplitud constant en què l'única variació espacial es deu al factor de fase característic depenent del pseudo-moment $\mathbf{Q}$.

Si el nostre interès radica en estudiar el comportament d'una configuració del camp "prop" del mode no lineal de Bloch $\phi_{\mathbf{Q} ; \beta}(\mathbf{x})$, hem d'analitzar, en realitat, el problema discretitzat equivalent sobre la xarxa associada, és a dir, aquelles configuracions $c_{\hat{i}}$, els valors de les quals no es desvien molt dels valors de referència (2.17) que defineixen $\phi_{\mathbf{Q} ; \beta}$. Sense pèrdua de generalitat, és natural llavors, considerar per a la representació de les configuracions de la següent forma funcional en la qual s'introdueix la funció envolupant $\Phi_{\hat{i}}$ :

$$
c_{\hat{i}}(t)=e^{i \mathbf{Q} \cdot \mathbf{x}_{\hat{i}}} \Phi_{\hat{i}}(t)
$$

Podem entendre els significat dels termes "prop a $\phi_{\mathbf{Q} ; \beta}$ " com que tots els coeficients $\Phi_{\hat{i}}(t)$ són similars a aquells del mode de Bloch no lineal (2.17).

També és interessant analitzar l'eq. (2.18) en l'espai de moments. El mode no lineal de Bloch està representat en l'espai de moments per una funció delta centrada en $\mathbf{k}=\mathbf{Q}$. En el cas d'una configuració discreta caracteritzada per una funció envolupant $\Phi_{\hat{i}}$, que és suau espacialment, l'espectre de moments seria el donat per una distribució picada $\Phi_{\Delta \mathbf{k}}=\Phi(\mathbf{k}-\mathbf{Q})$ al voltant de $\mathbf{k}=\mathbf{Q}$, amb una amplada típica $\delta \mathbf{k}$ que verifica que $|\delta \mathbf{k}| \ll 2 \pi / a$. En conseqüència, a l'espai de posicions aquesta configuració mostrarà un rang espacial característic $\xi=|\delta \mathbf{x}|$ molt més gran que el de la xarxa $(\xi \gg a)$. El fet que l'envolupant siga suau permet, de manera consistent, construir un límit continu per a les configuracions de la xarxa introduint la funció envolupant continua $\Phi(\mathrm{x}, t)$ com

$$
\Phi_{\hat{i}}(t)=\left.\Phi(\mathbf{x}, t)\right|_{\mathbf{x}=\mathbf{x}_{\hat{i}}},
$$

i, llavors, prenent el límit $a \rightarrow 0$. Aquest límit potser no és vàlid i no és aplicable 
quan considerem fluctuacions no suaus en el ordre del espaiat de la xarxa. D'altra banda, ja que les configuracions $c_{\hat{i}}$ es defineixen en una xarxa periòdica, els seus moments permesos presenten un punt de tall d'alta freqüència introduïts per la pròpia existència de la xarxa, $\left|k_{x}\right|,\left|k_{y}\right| \leq \pi / a$. D'aquesta manera, la ruptura del límit continu pot ser entesa també en l'espai de moments com la situació en la que les fluctuacions de moment són de l'ordre del seu valor màxim permès $|\delta \mathbf{k}| \sim 2 \pi / a$.

Com demostrarem més avant, la component espectral de l'energia $\mathcal{E}(\Delta \mathbf{k})$ que correspon a una configuració suau al voltant del mode de Bloch (2.17) és una funció que depèn de forma analítica de la diferència de moments $\Delta \mathbf{k}=\mathbf{k}-\mathbf{Q}$ de tal manera que pot ser desenvolupada en sèrie de potències al voltant de $\Delta \mathbf{k}=0$ :

$$
\mathcal{E}(\Delta \mathbf{k})=\mathcal{E}_{0}+\mathcal{E}_{1} \Delta \mathbf{k}+\mathcal{E}_{2}(\Delta \mathbf{k})^{2}+\cdots
$$

Així, des del punt de vista de l'energia, les configuracions més "properes" al mode de Bloch no lineal original (2.17) seran aquelles amb el menor $\Delta \mathbf{k}$ ja que $\Delta \mathcal{E} \stackrel{\Delta \mathbf{k} \rightarrow 0}{\rightarrow} 0$. En l'espai de posicions, aquesta afirmació és equivalent a dir que la dinàmica de les excitacions de baixa energia està dominada per amplituds que varien lentament, és a dir, per termes locals en l'envolupant del camp junt amb les seues derivades d'ordre inferior $\left|\Phi_{\hat{i}+\hat{n}}-\Phi_{\hat{i}}\right| / a \approx|\nabla \Phi| \ll 1$. L'hamiltonià i l'acció que descriuen el sistema en règim de baixa energia s'espera, per tant, que siguen representats per un desenvolupament en les seues derivades de l'envolupant del camp $\Phi(\mathbf{x}, t)$ en el que els termes dominants vindran donats per un potencial local $V\left(|\Phi|^{2}\right)$ (independent de les derivades) i pels ordres més baixos de les derivades.

A continuació procedirem a trobar sistemàticament l'hamiltonià continu i l'equació de moviment que governen la dinàmica de l'envolupant a baixes energies, o de manera equivalent, en el règim espacial de llarg abast. Analitzarem, per separat, els casos corresponents a una i dues dimensions. 


\subsubsection{Cas unidimensional}

Per tal de simplificar el càlcul, començarem considerant la versió unidimensional de l'eq.(2.1). En aquest cas, tots els resultats obtinguts en la secció anterior per a les magnituds discretes i equacions es mantindran. L'única diferència és que el vector d'índex $\hat{i}=\left(i_{1}, i_{2}\right)$ se substituirà ara pel nombre enter $i$. Els índexs de la banda continuen estant-hi inclosos.

Comencem per l'aproximació no trivial més simple, que està definida per les eq. (2.8), (2.9), i (2.12) on les interaccions no lineals impliquen només termes locals i la no localitat apareix en la part lineal exclusivament a través dels termes amb els veïns més pròxims. A més, les interaccions entre bandes es menyspreen de tal manera que els índexs de la banda se suprimeixen. L'argument físic que hi ha darrere d'aquesta aproximació altament local prové de la forma dels tensors de segon i quart ordre $L_{i j}$ i $T_{i j k l}$, tal com s'ha definit en les eq. (2.10) i (2.11). En ambdós casos, tenen la forma d'unes integrals superposades de funcions de Wannier en diferents nodes de la xarxa (en el cas de $L_{i j}$, aquesta integral de superposició està "ponderada" per l'operador lineal $H_{0}$ ). Aquesta propietat estableix una jerarquia entre els diferents elements de $L_{i j}$ i $T_{i j k l}$, de tal manera que s'espera obtenir els valors més alts quan la superposició de funcions de Wannier és màxima, i que han d'aparèixer valors més petits si aquesta superposició disminueix. Per aquesta raó, els valors més grans per als tensors $L_{i j}$ i $T_{i j k l}$ es donen per als índexs diagonals $(i=j, i=j=k=l)$ seguits pels més propers fora de la diagonal (és a dir, $|i-j|=1$ per a $L_{i j}$ i $|i-j|=1,|i-k|=1,|i-l|=1$ per a $\left.T_{i j k l}\right)$ i així successivament. Quan les funcions de Wannier estan ben localitzades, com en l'anomenada aproximació d'enllaç fort (apèndix E), aquesta jerarquia es farà més estricta, de manera que els termes diagonals i els més propers a la diagonal esdevindran dominants. El terme principal no diagonal prové de la part lineal — això és, de $L_{i j}$ - ja que per a funcions ben localitzades la superposició de quatres funcions molt picades que apareix en

$$
T_{i \pm 1, i, i, i}=\int_{\Omega} W_{i \pm 1}^{*} W_{i}^{*} W_{i} W_{i}
$$


serà sempre molt menor que la de dues funcions del mateix tipus en

$$
L_{i \pm 1, i}=\int_{\Omega} W_{i \pm 1}^{*} H_{0} W_{i}
$$

Per aquesta raó, les contribucions dominants en el règim de localització forta s'espera que sorgeixen de les interaccions locals, tant lineals com no lineals, i d'interaccions no locals lineals de veïns propers (termes pròxims a la diagonal en $L_{i j}$ ). En l'apèndix B es mostra que el coeficient per als veïns pròxims $L_{i \pm 1, i}$ depèn només de la diferència entre els índexs del lloc i, per tant, és independent del lloc. A més, per raons de simetria, té el mateix valor per als veïns de la dreta i de l'esquerra, això és

$$
L_{i \pm 1, i}=L_{1} \equiv-t
$$

Al mateix temps, els coeficients lineal i no lineal són, també, independents del lloc $\left(L_{i i}=L_{0} \equiv l\right.$ i $\left.T_{i i i i}=T_{000} \equiv U / 2\right)$ de manera que podem aproximar l'hamiltonià (2.9) com es mostra a continuació:

$$
H=-t \sum_{i} c_{i}^{*}\left(c_{i+1}+c_{i-1}\right)+l \sum_{i}\left|c_{i}\right|^{2}-\frac{U}{2} \sum_{i}\left|c_{i}\right|^{4} .
$$

L'equació de moviment (2.12) esdevé, en la mateixa aproximació:

$$
i \dot{c}_{i}=-t\left(c_{i+1}+c_{i-1}\right)+l c_{i}-U\left|c_{i}\right|^{2} c_{i}
$$

Procedim ara a introduir l'envolupant $\Phi_{i}$, tal i com s'ha definit en l'eq.(2.18), en les eq.(2.20) i (2.21) per tal d'analitzar el comportament del sistema en les "proximitats" del mode de Bloch no lineal unidimensional original $\phi_{Q}$, representat pels seus coeficients de xarxa $c_{i}^{Q}=(\sqrt{P} / N) e^{i Q x_{i}}$ (recordem que $x_{i}=i a$, $i \in \mathbb{Z}$, sent a l'espaiat de la xarxa). Introduïm ara el factor de fase $\epsilon=e^{i \Delta \phi}$, que depèn de la diferència de fase entre dos punts veïns del mode de Bloch $\phi_{Q}$ (és a dir, $\Delta \phi=Q a$ ) en la solució no lineal de Bloch, i que jugarà un paper important en la dinàmica del sistema. La diferència de fase present en el factor 
$\epsilon$ està determinada completament pel pseudo-moment $Q$ que, quan es defineix en el domini periòdic $\Omega$, pren valors discretitzats $Q_{m}=2 \pi m /(N a)$, on $N$ és el nombre de punts del domini i $m$ és un nombre enter que verifica que $|m| \leq N / 2$ (de manera que $Q$ pot satisfer la condició de Brillouin $Q \in[-\pi / a, \pi / a[$ ). Així doncs, la diferència de fase és, simplement, $\Delta \phi_{m}=2 \pi m / N$ i està completament definida pel nombre enter $m$ que marca el pseudo-moment aportat per la solució no lineal de Bloch. Utilitzant aquest nou factor de fase definit per $\epsilon_{m}=e^{i \Delta \phi_{m}}$, és senzill demostrar que l'hamiltonià, en termes de $\Phi_{i}$,pot escriure's com:

$$
H=-t \sum_{i} \Phi_{i}^{*}\left(\epsilon_{m} \Phi_{i+1}+\epsilon_{m}^{*} \Phi_{i-1}\right)+l \sum_{i}\left|\Phi_{i}\right|^{2}-\frac{U}{2} \sum_{i}\left|\Phi_{i}\right|^{4},
$$

que, després d'introduir-hi les parts real i imaginària de $\epsilon_{m}=\epsilon_{m}^{\mathrm{r}}+i \epsilon_{m}^{\mathrm{i}}=$ $\cos \left(\Delta \phi_{m}\right)+i \sin \left(\Delta \phi_{m}\right)$, és equivalent a la següent expressió:

$$
\begin{aligned}
H= & -t \epsilon_{m}^{\mathrm{r}} \sum_{i} \Phi_{i}^{*}\left(\Phi_{i+1}+\Phi_{i-1}\right)-i t \epsilon_{m}^{\mathrm{i}} \sum_{i} \Phi_{i}^{*}\left(\Phi_{i+1}-\Phi_{i-1}\right) \\
& +l \sum_{i}\left|\Phi_{i}\right|^{2}-\frac{U}{2} \sum_{i}\left|\Phi_{i}\right|^{4}
\end{aligned}
$$

Si se segueix un procediment semblant, es pot escriure, de manera immediata, l'equació de moviment corresponent per a l'envolupant discreta $\Phi_{i}$ :

$$
i \dot{\Phi}_{i}=-t \epsilon_{m}^{\mathrm{r}}\left(\Phi_{i+1}+\Phi_{i-1}\right)-i t \epsilon_{m}^{\mathrm{i}}\left(\Phi_{i+1}-\Phi_{i-1}\right)+l \Phi_{i}-U\left|\Phi_{i}\right|^{2} \Phi_{i} .
$$

Ara només cal introduir l'envolupant contínua $\Phi(x, t)$, com a l'eq.(2.19), i prendre el límit $a \rightarrow 0$ en les eq.(2.22) i (2.23) a la fi d'arribar al límit continu. Com que, per construcció, $\Phi(x, t)$ és una funció suau en la variable espacial $x$, podem fer un desenvolupament de Taylor de l'envolupant $\left(\Phi\left(x_{i \pm 1}\right)=\Phi\left(x_{i} \pm a\right)\right)$ avaluada als punts veïns del punt de referència $i$ al voltant del seu valor central 
$\Phi_{i}=\Phi\left(x_{i}\right)$ i considerar només els termes d'ordre més baix:

$$
\Phi_{i \pm 1}=\Phi_{i} \pm \frac{\partial \Phi_{i}}{\partial x} a+\frac{1}{2} \frac{\partial^{2} \Phi_{i}}{\partial x^{2}} a^{2}+O(a)^{3}
$$

D'aquesta manera és senzill arribar a

$$
\Phi_{i+1}+\Phi_{i-1}=2 \Phi_{i}+\frac{\partial^{2} \Phi_{i}}{\partial x^{2}} a^{2}+O(a)^{4}
$$

i

$$
\Phi_{i+1}-\Phi_{i-1}=2 \frac{\partial \Phi_{i}}{\partial x} a+O(a)^{3} .
$$

Si apliquem aquestes transformacions en l'equació de moviment unidimensional (2.23), obtenim:

$$
i \frac{\partial \Phi}{\partial t}=-b_{m} \frac{\partial^{2} \Phi}{\partial x^{2}}+i v_{m} \frac{\partial \Phi}{\partial x}+M \Phi-U|\Phi|^{2} \Phi
$$

on

$$
\begin{gathered}
b_{m} \equiv t \epsilon_{m}^{\mathrm{r}} a^{2}=\cos \left(\Delta \phi_{m}\right) t a^{2}, \\
v_{m} \equiv-2 t \epsilon_{m}^{\mathrm{i}} a=-2 \sin \left(\Delta \phi_{m}\right) t a
\end{gathered}
$$

i

$$
M_{m} \equiv l-2 t \epsilon_{m}^{\mathrm{r}}=l-2 t \cos \left(\Delta \phi_{m}\right) .
$$

Un procediment anàleg, en què també considerem la transformació del sumatori $a \sum_{i} \rightarrow \int d x$, permet trobar el límit al continu de l'hamiltonià ${ }^{2}(2.22)$ :

$$
H=\int_{\Omega} d x\left[b_{m}\left(\frac{\partial \Phi^{*}}{\partial x}\right)\left(\frac{\partial \Phi}{\partial x}\right)+i v_{m} \Phi^{*} \frac{\partial \Phi}{\partial x}+M_{m}|\Phi|^{2}-\frac{U}{2}|\Phi|^{4}\right],
$$

on també hem integrat el primer terme per parts per transformar la segona derivada en un producte de les derivades de primer ordre (cal notar el canvi de signe). Per a això, l'equació de moviment per a l'amplitud espacial de llarg

\footnotetext{
${ }^{2}$ Per a simplificar la notació, també redefinirem l'hamiltonià $a H \rightarrow H$.
} 
abast (2.26) pot ser obtinguda a partir de la densitat hamiltoniana $\mathcal{H}$, com es defineix en l'eq.(2.27) $H=\int_{\Omega} \mathcal{H}$, pel procés ordinari de derivar respecte de $\Phi^{*}$ : $i \partial \Phi / \partial t=\partial \mathcal{H} / \partial \Phi^{*}$. Si escrivim l'eq.(2.27) en l'espai de moments fent la transformada de Fourier de l'envolupant $\Phi(x, t)=\sum_{\Delta k} \Phi_{\Delta k}(t) e^{-i \Delta k x}$, immediatament es reconeix la forma $H=\sum_{\Delta k} \mathcal{E}(\Delta k)$, en la qual la component espectral de l'energia $\mathcal{E}(\Delta k)$ és, necessàriament i com s'havia avançat, una funció analítica de la diferència de moments $\Delta k$, ja que ambdues, $\Phi$ i $\Phi_{\Delta k}$ són analítiques i aquesta propietat es preserva per a totes les operacions en l'eq. (2.27).

\subsubsection{Cas bidimensional}

La generalització dels resultats obtinguts en el cas unidimensional al cas bidimensional és senzilla. Començarem assumint les mateixes hipòtesis: (i) només es consideren interaccions no lineals locals (és a dir, interaccions no lineals en el mateix punt de la xarxa), (ii) la no localitat espacial ve donada, exclusivament, per interaccions entre veïns pròxims en els termes lineals, i (iii) es menysprea la interacció entre bandes. Per tal de mantenir la descripció en la seua forma més simple, s'assumirà que, a més, el potencial periòdic correspon a una xarxa quadrada. Sota aquestes condicions, l'hamiltonià, quan s'escriu en termes dels coeficients de la xarxa $c_{\hat{i}}$, presenta dues contribucions diferents, de forma anàloga a la trobada en l'hamiltonià unidimensional (2.20): una que descriu les interaccions locals, que inclou un terme lineal i un no lineal, i un altra, només lineal que inclou les interaccions amb els veïns pròxims. L'estructura del terme de veïns pròxims s'analitza amb tot detall en l'apèndix B. Com que els termes locals en el punt són idèntics a aquells que apareixen en l'hamiltonià unidimensional, és senzill comprovar que l'hamiltonià, en una xarxa bidimensional, ve donat per:

$$
H=-t \sum_{\hat{i}} \sum_{\nu=1}^{2} c_{\hat{i}}^{*}\left(c_{\hat{i}+\hat{n}_{\nu}}+c_{\hat{i}-\hat{n}_{\nu}}\right)+l \sum_{\hat{i}}\left|c_{\hat{i}}\right|^{2}-\frac{U}{2} \sum_{\hat{i}}\left|c_{\hat{i}}\right|^{4},
$$

on hem introduït els vectors de xarxa "horitzontal" i "vertical", $\hat{n}_{1}$ i $\hat{n}_{2}$, i els coeficients efectius $t \equiv-L_{1}, l \equiv L_{0}$ i $U \equiv 2 T_{000}$. El següent pas és incloure 
l'envolupant $\Phi_{\hat{i}}$ en l'esmentat hamiltonià. Usarem la definició de $\Phi_{\hat{i}}$ en l'eq.(2.18) per a construir-ho

$$
H=-t \sum_{\hat{i}} \sum_{\nu=1}^{2} \Phi_{\hat{i}}^{*}\left(\epsilon_{\mathbf{m}, \nu} \Phi_{\hat{i}+\hat{n}_{\nu}}+\epsilon_{\mathbf{m}, \nu}^{*} \Phi_{\hat{i}-\hat{n}_{\nu}}\right)+l \sum_{\hat{i}}\left|\Phi_{\hat{i}}\right|^{2}-\frac{U}{2} \sum_{\hat{i}}\left|\Phi_{\hat{i}}\right|^{4},
$$

on hem introduït la contrapart bidimensional del factor de fase $\epsilon_{\mathbf{m}, \nu}=e^{i \Delta \phi_{\nu}}$ en el qual la diferència de fase $\Delta \phi_{\nu}$ entre nodes veïns és aquella solució de Bloch $\phi_{\mathbf{Q}}$ al voltant de la qual analitzem la dinàmica de les amplituds de gran escala. Aquesta diferència de fase depèn ara de la direcció i ve donada per $\Delta \phi_{\nu}=\left(\mathbf{Q} \cdot \hat{n}_{\nu}\right) a$. En un domini periòdic bidimensional la condició de discretització per al pseudo-moment implica que $\mathbf{Q}_{\mathbf{m}}=2 \pi \mathbf{m} /(N a)$ on $\mathbf{m} \in \mathbb{Z}^{2}$ i compleix $-N / 2 \leq m_{x}, m_{y} \leq N / 2$. Ací $N$ representa el nombre de nodes dins del domini periòdic $\Omega$ al llarg de qualsevol de les dues direccions perpendiculars; per tant, el domini periòdic $2 D$, $\Omega$, conté $N^{2}$ nodes. Com en el cas unidimensional, la diferència de fase $\Delta \phi_{\nu}$ està determinada completament pel vector discretitzat $\mathbf{m}$ que caracteritza el mode de Bloch no lineal: $\Delta \phi_{\mathbf{m}, \nu}=2 \pi\left(\mathbf{m} \cdot \hat{n}_{\nu}\right) / N$. Si introduïm en l'hamiltonià les parts real i imaginària de de $\epsilon_{\mathbf{m}, \nu}$ obtenim:

$$
\begin{aligned}
H= & -t \sum_{\hat{i}} \sum_{\nu=1}^{2} \epsilon_{\mathbf{m}, \nu}^{\mathrm{r}} \Phi_{\hat{i}}^{*}\left(\Phi_{\hat{i}+\hat{n}_{\nu}}+\Phi_{\hat{i}-\hat{n}_{\nu}}\right) \\
& -i t \sum_{\hat{i}} \sum_{\nu=1}^{2} \epsilon_{\mathbf{m}, \nu}^{\mathrm{i}} \Phi_{\hat{i}}^{*}\left(\Phi_{\hat{i}+\hat{n}_{\nu}}-\Phi_{\hat{i}-\hat{n}_{\nu}}\right)+l \sum_{i}\left|\Phi_{i}\right|^{2}-\frac{U}{2} \sum_{i}\left|\Phi_{i}\right|^{4} .
\end{aligned}
$$

Ara podem prendre el límit al continu d'aquest hamiltonià mitjançant les contraparts bidimensionals de les regles de transformació per a les derivades de primer i segon ordre, (2.25) i (2.24), és a dir,

$$
\Phi_{\hat{i}+\hat{n}_{\nu}}+\Phi_{\hat{i}-\hat{n}_{\nu}}=2 \Phi_{\hat{i}}+\frac{\partial^{2} \Phi_{\hat{i}}}{\partial x_{\nu}^{2}} a^{2}+O(a)^{4}, \quad(\nu=1,2)
$$


i

$$
\Phi_{\hat{i}_{+} \hat{n}_{\nu}}-\Phi_{\hat{i}-\hat{n}_{\nu}}=2 \frac{\partial \Phi_{\hat{i}}}{\partial x_{\nu}} a+O(a)^{3}, \quad(\nu=1,2),
$$

Com hem fet adés, si substituïm ara els sumatoris per integrals d'acord amb $\sum_{\hat{i}} \rightarrow\left(1 / a^{2}\right) \int$, integrem el terme cinètic per parts per a transformar les derivades segones en productes de derivades primeres i redefinim l'hamiltonià com $a^{2} H \rightarrow$ $H$, s'obté:

$$
H=\int_{\Omega} d^{2} x\left[\sum_{\nu} b_{\mathbf{m}, \nu}\left(\frac{\partial \Phi^{*}}{\partial x_{\nu}}\right)\left(\frac{\partial \Phi}{\partial x_{\nu}}\right)+i \sum_{\nu} v_{\mathbf{m}, \nu} \Phi^{*} \frac{\partial \Phi}{\partial x_{\nu}}+M_{\mathbf{m}}|\Phi|^{2}-\frac{U}{2}|\Phi|^{4}\right]
$$

on

$$
\begin{gathered}
b_{\mathbf{m}, \nu} \equiv t \epsilon_{\mathbf{m}, \nu}^{\mathrm{r}} a^{2}=\cos \left(\Delta \phi_{\mathbf{m}, \nu}\right) t a^{2} \\
v_{\mathbf{m}, \nu} \equiv-2 t \epsilon_{\mathbf{m}, \nu}^{\mathrm{i}} a=-2 \sin \left(\Delta \phi_{\mathbf{m}, \nu}\right) t a
\end{gathered}
$$

i

$$
M_{\mathbf{m}} \equiv l-2 t \sum_{\nu} \epsilon_{\mathbf{m}, \nu}^{\mathrm{r}}=l-2 t \sum_{\nu} \cos \left(\Delta \phi_{\mathbf{m}, \nu}\right),
$$

on, recordem, $t \equiv-L_{1}, l \equiv L_{0}$ i $U \equiv 2 T_{000}$.

Es interessant observar que l'hamiltonià bidimensional (2.28) és anisotròpic en la seua forma general. La simetria rotacional es trenca per la presència dels, en general, diferents coeficients $\left(b_{\mathbf{m}, 1}\right.$ i $\left.b_{\mathbf{m}, 2}\right)$ per a les components $x$ i $y$ del terme cinètic. Les condicions per a una simetria rotacional completa es compleixen quan la diferència de fase entre els corresponents modes de Bloch no lineals de nodes veïns són els mateixos en les dues direccions espacials, és a dir, $\left|\Delta \phi_{\mathbf{m}, 1}\right|=\left|\Delta \phi_{\mathbf{m}, 2}\right|$. Com que $\Delta \phi_{\mathbf{m}, 1}=2 \pi m_{1} / N$ i $\Delta \phi_{\mathbf{m}, 1}=2 \pi m_{2} / N$ la simetria rotacional de l'hamiltonià efectiu per a envolupants de llarg abast és només assolida quan realitzem fluctuacions de baixa energia al voltant de les solucions de Bloch esteses a les diagonals de la zona de Brillouin per a la qual $\left|m_{1}\right|=\left|m_{2}\right| \equiv m$. En aquest cas, l'hamiltonià pren una forma més simple i més 
simètrica ja que, aleshores, $b_{\mathbf{m}, 1}=b_{\mathbf{m}, 2} \equiv b_{m}$ :

$$
H=\int_{\Omega} d^{2} x\left[b_{m} \nabla \Phi^{*} \nabla \Phi+i\left(\mathbf{v}_{m} \cdot \nabla \Phi\right) \Phi^{*}+M_{m}|\Phi|^{2}-\frac{U}{2}|\Phi|^{4}\right]
$$

Es poden aplicar arguments similars a l'equació de moviment que, en el cas més general, presentarà una anisotropia induïda:

$$
i \frac{\partial \Phi}{\partial t}=-b_{\mathbf{m}, 1} \frac{\partial^{2} \Phi}{\partial x^{2}}-b_{\mathbf{m}, 2} \frac{\partial^{2} \Phi}{\partial y^{2}}+i \mathbf{v}_{\mathbf{m}} \cdot \nabla \Phi+M_{\mathbf{m}} \Phi-U|\Phi|^{2} \Phi .
$$

Tanmateix, per a les envolupants definides per sobre els modes de Bloch no lineals al llarg de les diagonals de la zona de Brioullin, la simetria rotacional es recupera ja que en l'hamiltonià simètric (2.29) tenim que $b_{\mathbf{m}, 1}=b_{\mathbf{m}, 2} \equiv b_{m}$ i:

$$
i \frac{\partial \Phi}{\partial t}=-b_{m} \nabla^{2} \Phi+i \mathbf{v}_{m} \cdot \nabla \Phi+M_{m} \Phi-U|\Phi|^{2} \Phi .
$$

És interessant fer notar que, entre totes les configuracions possibles de Bloch al voltant de les quals es construeix l'envolupant, dos dels casos més importants són aquells construïts al voltant del centre de la zona de Brillouin $[\mathbf{Q}=0]$ i al voltant dels seus vèrtexs $[\mathbf{Q}=( \pm \pi, \pm \pi) / \mathrm{a}]$ que condueixen a una dinàmica rotacional invariant ja que ambdós compleixen la condició diagonal, $\left|m_{1}\right|=\left|m_{2}\right|=0$ en el primer cas i $\left|m_{1}\right|=\left|m_{2}\right|=N / 2$ en el segon cas. Al mateix temps, aquestes dues configuracions presenten una altra característica important, això és, que són les úniques per a les quals el terme de flux $i\left(\mathbf{v}_{m} \cdot \nabla \Phi\right) \Phi^{*}$ està absent, ja que el terme de velocitat $\mathbf{v}_{m}$ desapareix en ambdós casos. D'acord amb la definició de $\mathbf{v}_{m}$, un valor zero d'aquesta magnitud s'aconsegueix quan la diferència de fase entre els nodes veïns de la configuració de Bloch subjacent, o és zero o $\pm \pi$. Aquests són, justament, els casos d'una configuració de Bloch $[\mathbf{Q}=0]-\operatorname{amb} \Delta \phi=0-\mathrm{i}$ dels modes de Bloch als vèrtexs de la zona de Brillouin $[\mathbf{Q}=( \pm \pi, \pm \pi) / \mathrm{a}]$-per als quals $\Delta \phi= \pm \pi-$. 


\section{Capítol 3}

\section{Equació efectiva en}

\section{potencials quasiperiòdics}

\subsection{Introducció}

Des del seu descobriment el 1984 [Shechtman84], els quasicristalls han desafiat tant als físics com als matemàtics [Senechal96, Senechal06]. Estudis recents [Connes94, Connes98, Connes04,Landi97, Ypma04, Bellissard03] han fet ús de tècniques preses de la geometria no commutativa per a tractar el problema de la propagació d'electrons en quasicristalls. S'han estudiat les propietats de l'operador de Schrödinger quasiperiòdic per a establir una teoria de Bloch equivalent al cas del cristalls, sempre en el règim lineal. En aquest capítol anem a plantejarnos el problema de la propagació de la llum dins d'un medi quasiperiòdic no lineal, com, per exemple, dins d'un quasicristall fotònic, descrit per l'equació de Schrödinger no lineal (NLSE) amb un potencial $V$ donat per una funció quasiperiòdica. El marc de la geometria no commutativa, proposada i desenvolupada per A. Connes [Connes94] des de finals dels setanta, resultarà ser l'eina adequada per a tractar el problema. En primer lloc, presentarem els elements de geometria no commutativa que necessitarem més endavant. Per a una descripció més detallada es pot consultar l'apèndix F, on es presenten les nocions bàsiques 
d'aquesta geometria, i les referències [Szabo03, Szabo04, Monreal08b] on podem trobar una ampliació i diversos exemples de les seues aplicacions al camp de la física matemàtica.

L'espai no commutatiu $\mathbb{R}^{N}$ està definit per coordenades $x^{i}, i=1, \ldots, N$, que satisfan la relació de commutació

$$
\left[x^{i}, x^{j}\right]=\mathrm{i} L^{2} \theta^{i j}, \quad i, j=1, \ldots, N
$$

on $L$ és l'escala de longitud i $\theta^{i j}$ és un tensor antisimètric, real, constant i adimensional. El producte punt a punt habitual de funcions $f(x) \cdot g(x)$ sobre l'espai commutatiu $\mathbb{R}^{N}$ s'ha de substituir, en l'espai no commutatiu $\mathbb{R}^{N}$, pel *-producte (que serà associatiu i no commutatiu),

$$
(f \star g)(\mathbf{x})=f(\mathbf{x}) \exp \left(\frac{\mathrm{i}}{2} \overleftarrow{\partial}_{i} \theta^{i j} \vec{\partial}_{j}\right) g(\mathbf{x})
$$

Donat el desenvolupament de Fourier sobre l'espai commutatiu $\mathbb{R}^{N}$

$$
f(\mathbf{x})=\frac{1}{(2 \pi)^{N / 2}} \int \mathrm{d} \mathbf{k} \tilde{f}(\mathbf{k}) \mathrm{e}^{-\mathrm{i} \mathbf{k} \cdot \mathbf{x}}, \quad \tilde{f}(\mathbf{k})=\frac{1}{(2 \pi)^{N / 2}} \int \mathrm{d} \mathbf{x} f(\mathbf{x}) \mathrm{e}^{\mathrm{i} \mathbf{k} \cdot \mathbf{x}},
$$

on $\mathbf{k} \cdot \mathbf{x}=k^{j} x^{j}$, les eqs. (3.2) i (3.3) impliquen que la llei de multiplicació punt a punt $\tilde{f}(\mathbf{k}) \cdot \tilde{g}(\mathbf{q})$ per als modes de Fourier sobre l'espai commutatiu $\mathbb{R}^{N}$ se substitueix, en el no commutatiu $\mathbb{R}^{N}$, per

$$
\tilde{f}(\mathbf{k}) \tilde{g}(\mathbf{q}) \exp \left(-\frac{\mathrm{i}}{2} \mathbf{k} \times \mathbf{q}\right), \quad \mathbf{k} \times \mathbf{q}=k_{i} \theta^{i j} q_{j}
$$

D'això es dedueix que

$$
\int \mathrm{d} \mathbf{x}(f \star g)(\mathbf{x})=\int \mathrm{d} \mathbf{x} f(\mathbf{x}) g(\mathbf{x})
$$

per a quasevol parell de funcions $f, g$ de $\mathbb{R}^{N}$ amb transformada de Fourier. 


\subsection{Equació d'ones no commutativa}

Com ja s'ha detallat en la introducció, i hem vist també al capítol 2, l'equació de Schrödinger no lineal proporciona una descripció efectiva de nombrosos fenòmens a baixa energia, tant en el camp de l'óptica com en el camp de la física de la materia condensada [Boyd92, Pitaevskii03].

Anem a considerar l'equació de Schrödinger no lineal per a una funció d'ona $\phi=\phi\left(t ; x^{1}, \ldots, x^{N}\right)$ sobre $\mathbb{R} \times \mathbb{R}^{N}$ :

$$
\mathrm{i} \frac{\partial \phi}{\partial t}+\frac{1}{2} \nabla^{2} \phi+g|\phi|^{2} \phi=0
$$

Aquesta és l'equació de moviment que s'obté a partir de l'acció

$$
S=\int \mathrm{d} t \mathrm{~d} x\left(\mathrm{i} \phi^{*} \frac{\partial \phi}{\partial t}-\frac{1}{2} \nabla \phi^{*} \nabla \phi+\frac{g}{2}|\phi|^{4}\right) .
$$

A partir d'ara considerarem que l'espai $\mathbb{R}^{N}$ passa a ser no commutatiu, mentre que el temps $t$ continuarà commutant amb les coordenades espacials $x^{j}$. Sobre l'espai no commutatiu $\mathbb{R}^{N}$ l'acció (3.7), substituint-hi el producte de funcions pel $\star$-producte, esdevé

$$
S_{\mathrm{nc}}=\int \mathrm{d} t \mathrm{~d} x\left(\mathrm{i} \phi^{*} \star \frac{\partial \phi}{\partial t}-\frac{1}{2} \nabla \phi^{*} \star \nabla \phi+\frac{g}{2} \phi^{*} \star \phi \star \phi^{*} \star \phi\right),
$$

i per l'eq.(3.5) es redueix a

$$
S_{\mathrm{nc}}=\int \mathrm{d} t \mathrm{~d} x\left(\mathrm{i} \phi^{*} \frac{\partial \phi}{\partial t}-\frac{1}{2} \nabla \phi^{*} \nabla \phi+\frac{g}{2} \phi^{*} \star \phi \star \phi^{*} \star \phi\right) .
$$

Així, el terme d'autointeracció és sensible a la no commutativitat mentre que els termes lliures en l'acció segueixen sent com en l'espai commutatiu. L'equació de 
moviment que correspon a l'eq.(3.9) és [Szabo04]

$$
i \frac{\partial \phi}{\partial t}+\frac{1}{2} \nabla^{2} \phi+g \phi^{*} \star \phi \star \phi=0 .
$$

La no commutativitat és irrellevant en l'equació de Schrödinger lineal, ja que com observem en l'eq. (3.10), el $\star$-producte només afecta el terme no lineal de la NLSE.

A primer ordre en el paràmetre no commutatiu $\theta$ tenim que

$$
\phi^{*} \star \phi \star \phi=|\phi|^{2} \phi+\mathrm{i}\left(\nabla \phi^{*} \times \nabla \phi\right) \phi+O\left(\theta^{2}\right),
$$

per tant, en el límit de no commutativitat feble, l'eq. (3.10) es redueix a

$$
\mathrm{i} \frac{\partial \phi}{\partial t}+\frac{1}{2} \nabla^{2} \phi+g|\phi|^{2} \phi+\mathrm{i} g\left(\nabla \phi^{*} \times \nabla \phi\right) \phi=0 .
$$

Ens referirem a l'eq. (3.10) com l'equació de Schrödinger no lineal sobre l'espai no commutatiu $\mathbb{R}^{N}$, i a l'eq. (3.12) com el seu límit quan la no commutativitat és feble.

\subsection{Equació efectiva per a amplituds de llarg abast}

Considerem l'equació de Schrödinger no lineal en presència d'un potencial estàtic $V(x)$ :

$$
\mathrm{i} \frac{\partial \phi}{\partial t}+\frac{1}{2} \nabla^{2} \phi-V(x) \phi+g|\phi|^{2} \phi=0 .
$$

Si $V(x)$ és periòdic, en el capítol 2 hem vist que podem obtenir una equació per a l'envolupant $\Phi$ de la funció d'ona $\phi$, que pot escriure's com

$$
\mathrm{i} \frac{\partial \Phi}{\partial t}+\frac{1}{2} \nabla^{2} \Phi+g|\Phi|^{2} \Phi=0
$$


De fet, l'equació anterior és la NLSE lliure de potencial: $V^{\mathrm{ef}}=0$ [Landau80]. No obstant això, l'argument no és vàlid quan el potencial $V$ en l'eq.(3.13) no és periòdic; aquest és el cas en què $V(x)$ és quasiperiòdic com, per exemple, dins d'un quasicristall. Aleshores ens plantegem la següent qüestió: quina és l'equació efectiva per a les amplituds de llarg abast $\Phi$, que corresponen a $\phi$, si el potencial $V(x)$, a l'eq.(3.13), és quasiperiòdic?

Un exemple de un potencial quasiperiòdic en 1 dimensió és [Maciá06]

$$
V_{1}(x)=\sin x+\sin \omega x
$$

on $\omega$ és irracional. Realment el punt clau de la quasiperiodicitat és la irracionalitat de la raó de freqüències (en el nostre cas $\omega / 1=\omega$, però sempre es pot normalitzar una d'elles a la unitat). Hom pot veure la quasiperiodicitat com el resultat de projectar el potencial periòdic en dues dimensions

$$
V_{2}(x, y)=\sin x+\sin y
$$

sobre el subespai unidimensional definit per $y=\omega x$ :

$$
V_{1}(x)=V_{2}(x, \omega x) .
$$

En general, qualsevol potencial periòdic en $2 n$ dimensions pot escriure's com una suma (segurament infinita) de termes tals com aquells presents en (3.16), mes, possiblement, funcions cosinus. Per raons de simplicitat, només considerarem potencials quasiperiòdics $V_{n}(x)$ en un espai de $n$ dimensions, del tipus

$$
V_{n}\left(x^{1}, \ldots, x^{n}\right)=\sum_{i=1}^{n}\left(\sin x^{i}+\sin \omega_{i} x^{i}\right), \quad \omega_{i} \notin \mathbb{Q} .
$$

Potencials quasiperiòdics més generals poden tractar-se d'una forma semblant a la presentada. Això és, com a resultat de projectar un potencial periòdic 
$V_{2 n}(x, y)$ en un espai de $2 n$ dimensions

$$
V_{2 n}\left(x^{1}, \ldots, x^{n} ; y^{1}, \ldots, y^{n}\right)=\sum_{i=1}^{n}\left(\sin x^{i}+\sin y^{i}\right)
$$

sobre un de $n$ dimensions, mitjançant les condicions de projecció adients, tals com

$$
y^{i}=\omega_{i} x^{i}, \quad \omega_{i} \notin \mathbb{Q}, \quad i=1, \ldots, n .
$$

Anem a provar que, en determinades circumstàncies, hom pot tractar una teoria d'interacció $(V \neq 0)$ en un espai commutatiu $n$-dimensional, com una teoria a potencial lliure $(V=0)$ en un espai no commutatiu $2 n$-dimensional. Per a un potencial arbitrari $V(x)$ aquest tractament no és possible en general. No obstant això, hi ha un límit de la teoria de la interacció (3.13) en la qual aquest tractament esdevé possible: és a dir, el cas en què $V(x)$ és quasiperiòdic i hom considera només excitacions a grans longituds d'ona. Demostrarem que aquest cas és el límit a baixes energies de la teoria efectiva que correspon a un potencial quasiperiòdic $V(x)$ en (3.13): l'equació de Schrödinger no lineal (3.10) sobre un espai-temps no commutatiu, amb el doble de dimensions. O dit d'una altra manera, la quasiperiodicitat de $V(x)$ pot tractar-se per a un espai no commutatiu de la forma (3.1), si la funció d'ona microscòpica $\phi$ se substitueix per la seua envolupant efectiva de llarg abast $\Phi$. A continuació anem a provar aquesta afirmació. La demostració es farà en dos passos. En primer lloc, i dins d'aquest apartat, determinarem el tensor no commutatiu $\theta^{i j}$. En segon lloc, en l'apartat 3.4, provarem que el potencial efectiu s'anul-la.

Per tal d'entendre la raó per la qual la teoria no projectada $2 n$-dimensional ha de ser no commutativa observem que la irracionalitat de les raons $\omega_{i} / 1=\omega_{i}$ garanteix la quasiperiodicitat del potencial $V_{n}\left(x^{i}\right)$ al llarg de cada dimensió $x^{i}$, per a $i=1, \ldots, n$. La quasiperiodicitat és el segell de la no commutativitat [Ypma04]. No obstant això, no hi ha res en la teoria quasiperiòdica $n$-dimensional que recorde a una no commutativitat: les $x^{i}$, en efecte, commuten entre elles. Només a través de la introducció d'unes noves coordenades $y^{i}$ en les eqs. (3.19) 
i (3.20) podem arribar a un espai no commutatiu [Ypma04]:

$$
\left[X^{I}, X^{J}\right]=\mathrm{i} L^{2} \theta^{I J}, \quad I, J=1, \ldots, N
$$

on $X^{I}$ denota col-lectivament $x^{i}, y^{i}$. Tot això implica que la multiplicació apropiada en la teoria no projectada $2 n$-dimensional és el $\star$-producte (3.2) - on el tensor no commutatiu $\theta^{I J}$ ha de ser determinat. Primer observem que els índexs $I, J$ han de recórrer el rang $1,2, \ldots, N=2 n$. De fet $\theta^{I J}=0$ excepte quan $I$ denota $x^{i}$ i $J$ denota el corresponent $y^{i}$ per al mateix valor de $i$, com en (3.19). Així, les úniques entrades no nul-les del tensor no commutatiu poden marcar-se $\operatorname{com} \theta^{x^{i} y^{i}}$, per a $i=1, \ldots, n$. Ara bé, $\theta^{x^{i} y^{i}}$ ha de dependre de les freqüències $\omega_{i}$ i 1 (la raó de les quals $\omega_{i} / 1=\omega_{i}$ és irracional en el cas quasiperiòdic), perquè aquestes són les úniques dades que ens ocupa, si bé no pot dependre de cap dels altres $\omega_{l}$ quan $l \neq i$. Per tant podem assumir que $\theta^{x^{i} y^{j}}=\theta^{x^{i} y^{i}}\left(\omega_{i}\right)$. L'argument de la darrera funció és però, adimensional ja que $\omega_{i}$ és, de fet, la raó de freqüències $\omega_{i} / 1$. D'altra banda, aquesta funció ha de anul-lar-se quan $\omega_{i}$ és racional. També ha de ser antisimètrica en $x^{i}, y^{i}$. Anem a veure com podem construir un tensor que verifique tots aquests requeriments.

Estem a la recerca d'una funció $\theta^{x^{i} y^{i}}\left(\omega_{i}\right)$ que s'anul-larà quan $\omega_{i}$ siga racional. Atès que els racionals són densos en els reals, tota funció contínua que s'anul-la quan $\omega_{i} \in \mathbb{Q}$ necessàriament s'anul-la sobre $\mathbb{R}$. Això implica que hem de renunciar necessàriament a la continuïtat de $\theta^{x_{i} y_{i}}$, si més no sobre tot $\mathbb{R}$, si el tensor no commutatiu no ha de ser idènticament nul. Recordem que la funció de Dirichlet $D: \mathbb{R} \rightarrow \mathbb{R}$

$$
D(x)= \begin{cases}0, & x \in \mathbb{Q} \\ 1, & x \notin \mathbb{Q},\end{cases}
$$

és discontínua per tot arreu en $\mathbb{R}$. No obstant això, pot fer-se contínua en un conjunt adequat de punts aïllats dins de la recta real, multiplicant-la per alguna funció contínua apropiada. Per exemple, la funció $x D(x)$ és contínua en $x=0$ i discontínua per a la resta de valors. Si $p(x)$ és un polinomi, llavors $p(x) D(x)$ és contínua en els zeros de $p(x)$. Altre exemple addicional: la funció $\sin (\pi x) D(x)$ 
és contínua per a tot $x \in \mathbb{Z}$ i discontínua per a la resta de valors. Tanmateix, no hi ha cap manera de fer $f(x) D(x)$ contínua i no nul-la en un conjunt obert i connectat, per a qualsevol funció $f(x)$. Aquests arguments ens porten a definir

$$
\theta^{x^{i} y^{i}}\left(\omega_{i}\right)=\omega_{i} D\left(\omega_{i}\right)
$$

mentre que l'antisimetria es pot aconseguir si fixem, per definició,

$$
\theta^{y^{i} x^{i}}\left(\omega_{i}\right)=-\theta^{x^{i} y^{i}}\left(\omega_{i}\right)
$$

L'elecció de la funció $f\left(\omega_{i}\right)=\omega_{i}$ que multiplica per l'esquerra la funció de Dirichlet en (3.23) és tal que que assegura la continuïtat a l'origen $\omega_{i}=0$. És cert que hi ha un nombre infinit de funcions que hom pot prendre per multiplicar les funcions de Dirichlet que satisfan els nostres requeriments. No obstant això, sembla natural exigir la continuïtat en l'origen ja que estem "transformant" una teoria periòdica en $\omega_{i}=0$ en una quasiperiòdica quan $\omega_{i} \notin \mathbb{Q}$. La nostra funció $f\left(\omega_{i}\right)=\omega_{i}$ és l'elecció més senzilla.

Després d'haver especificat la necessitat de treballar amb el $\star$-producte, podem reprendre ara l'eq. (3.19) i reescriure-la com s'ha de fer en un espai no commutatiu, és a dir,

$$
V_{2 n}\left(x^{1}, \ldots, x^{n} ; y^{1}, \ldots, y^{n}\right)=\sum_{i=1}^{n}\left(\sin _{\star} x^{i}+\sin _{\star} y^{i}\right)
$$

on la funció $\sin _{\star}(z)$ està definida per la seua expansió en sèrie de potències en $\star$-productes,

$$
\sin _{\star}(z)=\sum_{j=1}^{\infty} \frac{(-1)^{j-1}}{(2 j-1) !} z \star z \star{ }^{2 j-1}{ }^{2 j} \star z .
$$

En altres paraules, totes les multiplicacions en el potencial es realitzaran amb el $\star$-producte. Afortunadament, per la discussió que va conduir a l'eq.(3.23), qualsevol funció potencial, les variables del qual són separades (tal com el nostre cas (3.25)) es redueix a la seua expressió commutativa (3.19), i podem seguir 
utilitzant aquesta darrera sense haver-nos de preocupar sobre (3.25). Per descomptat, els termes cinètics que corresponen a les noves coordenades $y^{i}$, i que sorgeixen en el potencial $V_{2 n}(x, y)$, també han de ser inclosos en el Lagrangià no commutatiu. No obstant això, per l'eq. (3.5) (veure també (3.9) i (3.10)), els termes cinètics en les $y^{i}$ no estan afectats per la no commutativitat. D'altra banda, els termes cinètics no barregen les $x^{i}$ amb les $y^{i}$, i les variables separades continuaran sent separades. D'ací que els termes cinètics extra introduïts pel pas a l'espai no commutatiu poden ser integrats i eliminats en la integral de normalització de la funció d'ona efectiva $\Phi$. Cal tenir en compte, però, que aquesta separació nítida de les variables no és necessàriament certa per a potencials arbitraris.

\subsection{Equació efectiva lliure}

Com ja s'ha comentat en la secció anterior, un punt clau és la desaparició del potencial d'interacció en la teoria efectiva per a l'envolupant de la funció d'ona $\Phi: V^{\mathrm{ef}}=0$ (2) [Landau80]; en altres paraules, l'envolupant de la funció d'ones $\Phi$ satisfà una equació de Schrödinger lliure. Això es pot representar esquemàticament com el pas de la teoria microscòpica descrita per la funció d'ona $\phi$ a una teoria efectiva descrita per la seua envolupant $\Phi$ :

$$
\begin{aligned}
& \text { microscòpica } \\
& V_{k} \neq 0 \quad \longrightarrow \quad V_{k}^{\mathrm{ef}}=0 .
\end{aligned}
$$

La fletxa representa l'operació de prendre el límit efectiu de la teoria en qualsevol nombre $k$ de dimensions commutatives. Com alternativa ens podem moure verticalment al llarg del diagrama

$$
\text { no commutativa } V_{2 n} \neq 0
$$




$$
\text { commutativa } \quad V_{n} \neq 0
$$

on la fletxa representa la projecció de l'espai amb $2 n$ dimensions no commutatives en un espai amb $n$ dimensions commutatives. Finalment estem interessats en un diagrama tal com

$$
\text { microscòpica efectiva }
$$

$$
\begin{aligned}
& \text { no commutativa } \quad V_{2 n} \neq 0 \longrightarrow V_{2 n}^{\text {ef }}=0 \\
& \downarrow \quad \downarrow
\end{aligned}
$$

$$
\text { commutativa } \quad V_{n} \neq 0 \longrightarrow V_{n}^{\text {ef }}=0 \text {. }
$$

Per consistència, el diagrama ha de produir el mateix resultat independentment de l'ordre seguit, és a dir, si hom es mou primer verticalment i després horitzontalment, o viceversa. Quan un diagrama com el (3.29) existeix, la teoria efectiva resultant per a l'envolupant de la funció d'ona $\Phi$ és lliure de potencial i ben definida tant en $2 n$ dimensions no commutatives com en $n$ dimensions commutatives. Nosaltres provarem que el diagrama (3.29) existeix. De fet, les dues implicacions verticals venen donades per la projecció (3.20); el nostre objectiu és construir les implicacions horitzontals.

Considerem la implicació horitzontal superior en (3.29)

$$
V_{2 n} \neq 0 \longrightarrow V_{2 n}^{\mathrm{ef}}=0
$$

El tractament de la referència [Landau80] i el del capítol 2 per a construir la teoria efectiva no és pot aplicar en (3.30), ja que aquesta estava basada en un espai commutatiu. A més, la implicació horitzontal inferior en (3.29),

$$
V_{n} \neq 0 \longrightarrow V_{n}^{\mathrm{ef}}=0
$$

com es construeix en la referència [Landau80], es basa fonamentalment en les propietats de periodicitat del potencial; per la qual cosa també falla quan s'aplica 
a $(3.31)$.

Estem a la recerca d'una definició de la teoria eficaç per a l'envolupant de la funció d'ona $\Phi$ que és lliure de potencial i ben definida, tant en $2 n$ dimensions no commutatives, on el potencial que actua sobre $\phi$ és periòdic, com en $n$ dimensions commutatives, on el potencial que actua sobre $\phi$ és quasiperiòdic.

Tot $\omega \in \mathbb{R}$ pot aproximar-se per una successió $\left\{w_{l}\right\}$ de racionals, el límit de la qual

$$
\lim _{l \rightarrow \infty} w_{l}=\omega, \quad w_{l} \in \mathbb{Q} \quad \forall l .
$$

En particular això implica que qualsevol potencial quasiperiòdic $V_{n}(x)$ pot estar tan a prop de ser periòdic com hom desitge (aquesta és, de fet, una possible definició de quasiperiodicitat, si hom substitueix el terme funció potencial per una funció arbitrària [Besicovitch54]). Suposem que $\left\{W_{l, n}(x)\right\}$ denota una successió de potencials periòdics $n$-dimensionals que corresponen a la successió de racionals $\left\{w_{l}\right\}$, i tals que

$$
\lim _{l \rightarrow \infty} W_{l, n}(x)=V_{n}(x)
$$

Cal notar que escrivim $W_{l, n}(x)$ en lloc de $W_{l, n}(x, y)$ ja que aquests potencials, com que són periòdics, depenen només de $n$ coordenades espacials commutatives $x$. Denotem ara per $W_{l, n}^{\mathrm{ef}}(x)$ el potencial efectiu que correspon a $W_{l, n}(x)$, obtingut tal i com ho es fa en la ref. [Landau80]. Aleshores es dedueix que l'eq. (3.31) pot aproximar-se com

$$
W_{l, n}(x) \neq 0 \longrightarrow W_{l, n}^{\mathrm{ef}}(x)=0 .
$$

Per tant podem aproximar la part dreta de (3.31) com

$$
\lim _{l \rightarrow \infty} W_{l, n}^{\mathrm{ef}}(x)=V_{n}^{\mathrm{ef}}(x)
$$

però, com que la successió $\left\{W_{l, n}^{\text {ef }}(x)\right\}$ és idènticament zero, el seu límit també 
haurà d'anul-lar-se:

$$
V_{n}^{\mathrm{ef}}(x)=0
$$

Així, hem demostrat la relació (3.31). Encara ens queda provar que la relació (3.30) també és certa. Això es dedueix del fet que les condicions de projecció (3.20) només poden conduir a l'anul-lació del $V_{n}^{\text {ef }}$ de baix si el $V_{2 n}^{\text {ef }}$ de dalt és ell mateix zero. Concloem, doncs, que el diagrama (3.29) existeix i commuta.

La demostració de l'existència de la implicació horitzontal (3.31) és un exercici simple de les propietats dels nombres racionals. Hom podria preguntar-se: per què complicar les coses mitjançant l'aixecament de tota la construcció a 2n dimensions no commutatives? La resposta és simple: la no commutativitat ens és imposada per la quasiperiodicitat [Ypma04]. Així doncs, la nostra construcció pot considerar-se com una definició de la teoria efectiva sobre l'espai no commutatiu. Per el $U V / I R$ mixing ${ }^{1}$ de les teories no commutatives [Szabo04], no és evident a priori com una teoria efectiva ha de ser definida sobre un espai no commutatiu. La nostra recepta equival, doncs, a: quan la no commutativitat té el seu origen en la quasiperiodicitat del potencial, la teoria efectiva sobre espais no commutatius és l'ascens a més dimensions de la teoria efectiva corresponent sobre l'espai commutatiu. Si aquesta última té una resolució de longitud de valor $L$, llavors $L^{2}$ ha d'aparèixer a la part dreta de les relacions de commutació (3.21) sobre l'espai no commutatiu.

\footnotetext{
${ }^{1}$ En el camp de la Física Teòrica es usual classificar els fenòmens físics d'acord amb l'escala d'energies o l'escala de distàncies. Així, la física de la curta distància, és a dir, de l'ultraviolat (UV) no afecta directament a les característiques de la llarga distància, l'infraroig (IR), i a l'inrevés. Aquesta separació es manté en la teoria quàntica de camps. No obstant això, en les seues generalitzacions no commutatives com la teoria de camps no commutativa, la gravitació quàntica i la teoria de cordes, s'espera que comencen a sortir les interrelacions entre la física de l'IR i la de l'UV. En alguns casos es pot demostrar explícitament [Armoni02].
} 


\section{Capítol 4}

\section{Conclusions}

L'objectiu d'aquesta tesi ha estat l'obtenció d'equacions efectives de l'equació de Schrödinger no lineal, tant per a potencials periòdics com quasiperiòdics. Aquestes equacions descriuen la dinàmica, a baixes energies o llarg abast, de l'envolupant del camp al voltant d'una solució no lineal estacionària, és a dir, quan les variacions de l'envolupant són suaus en comparació amb l'espaiat de la xarxa. Com a resultat rellevant hem demostrat que les equacions efectives que descriuen la dinàmica de l'envolupant de la solució no lineal són lliures de potencial, és a dir, en les equacions per a l'envolupant no queda, formalment, cap traça del potencial, tant si és periòdic com si és quasiperiòdic.

El nostre desenvolupament s'ha basat en la discretització de l'equació de Schrödinger no lineal (NLSE) mitjançant l'expansió del camp en termes de les funcions de Wannier. A l'aproximació clàssica, les funcions de Wannier es construeixen a partir de l'espectre de l'hamiltonià lineal constituït per funcions de Bloch. Nosaltres hem demostrat que, si partim d'una solució no lineal estacionària amb simetria translacional (o mode de Bloch no lineal) l'espectre de l'hamiltonià no lineal definit per la pròpia solució també verifica el teorema de Bloch i, per tant, permet construir una altra base de funcions de Wannier. De fet, considerem que la base de funcions de Wannier no lineals és l'elecció natural i adequada per a analitzar les fluctuacions al voltant de la solució no lineal de Bloch. En aquesta base discreta els coeficients $\left\{c_{i}\right\}$ del desenvolupament propor- 
cionen directament l'amplitud i la fase en cada node de la xarxa. La introducció del concepte d'envolupant discreta (2.18) ens ha permet considerar fluctuacions suaus d'aquests coeficients i analitzar el comportament del sistema al voltant del mode de Bloch no lineal caracteritzat pel valor del potencial químic $\mu \mathrm{i}$ del pseudo-moment $\mathbf{Q}$. Hem demostrat que la variació suau de l'envolupant és equivalent a considerar variacions del pseudo-moment xicotetes en relació a $\mathbf{Q}$.

Hem obtingut l'hamiltonià i l'equació de moviment discreta per als coeficients $\left\{c_{i}\right\}$. L'anàlisi dels tensors lineal (2.10) i no lineal (2.11) de l'equació discreta en funció de les integrals de superposició de les funcions de Wannier no lineals ens ha permet argumentar que, en el règim de forta localització (o aproximació d'enllaç fort), els termes dominants són els d'autointeracció, tant lineal com no lineal, i la interacció lineal amb veïns propers. Sota aquesta aproximació les eqs. (2.9) i (2.12) esdevenen (2.20) i (2.21). Aquesta simplificació està garantida amb la base de Wannier no lineal, ja que aquestes funcions depenen en cada cas de l'amplitud de la solució no lineal estacionària i són més localitzades que les funcions de Wannier lineals. De fet, amb la base de Wannier lineal, les integrals de superposició poden no ser menyspreables en la resta de termes de (2.11), encara que s'utilitze l'aproximació d'enllaç fort.

El fet que l'envolupant siga suau ens ha permet, de manera consistent, construir una envolupant contínua i fer el pas al continu considerant el límit quan l'espaiat de la xarxa tendeix a 0 . Aquest límit és vàlid sempre que les fluctuacions siguen suaus en l'ordre del espaiat de la xarxa. Les equacions efectives per a l'envolupant contínua s'han obtingut en el cas unidimensional (2.23) i en el bidimensional (2.30), i constitueixen el resultat més rellevant del capítol 2. En els dos casos, l'equació efectiva per a l'envolupant contínua és una equació de Schrödinger no lineal lliure de potencial i amb un terme de flux. La informació sobre el potencial roman en els coeficients que multipliquen els diferents termes de l'equació. A més, aquests coeficients depenen del mateix mode de Bloch no lineal al voltant del qual s'estudien les fluctuacions, així com del seu pseudomoment. En el cas particular en què les components del pseudo-moment siguen iguals en les dos direccions de l'espai, l'equació efectiva esdevé invariant sota 
rotacions. A més, en el cas en què ens trobem al centre de la zona de Brioullin $[\mathbf{Q}=0]$, o als seus vèrtexs $[\mathbf{Q}=( \pm \pi, \pm \pi) / \mathrm{a}]$, hem demostrat que el terme de flux desapareix.

El gran avantatge d'aquestes equacions efectives és que l'estabilitat de l'envolupant, i, per tant, del mode de Bloch no lineal, es pot predir en funció dels coeficients. Així, donat un potencial i un mode de Bloch no lineal caracteritzat per un pseudo-moment, els coeficients de l'equació estan perfectament definits i determinen completament la dinàmica de l'envolupant.

El propòsit del capítol 3 era donar unes equacions efectives vàlides per a tot tipus de sistemes quasiperiòdics. De forma natural ha sorgit la següent pregunta: podem obtenir equacions per a les envolupants en sistemes quasiperiòdics equivalents a les del cas periòdic?, és a dir, podem obtenir unes equacions efectives lliures de potencial? L'eina adequada per a tractar el problema ha estat la geometria no commutativa i s'ha demostrat que l'equació de Schrödinger no lineal a baixes energies (3.13) per a una funció d'ona $\phi$ en presència d'un potencial quasiperiòdic dóna lloc a l'equació de Schrödinger no lineal en absència de potencial (3.10), sobre un espai-temps no commutatiu, per a l'envolupant $\Phi$ de la funció d'ona $\phi$. Així, l'efecte de un potencial quasiperiòdic sobre un espai commutatiu pot ser mimetitzat pel pas a una teoria lliure de potencial sobre un espai no commutatiu però amb el doble de dimensions.

L'exemple més simple d'espai no commutatiu és el donat per l'eq.(3.1), on les coordenades satisfan una àlgebra d'Heisenberg [apèndix F] en lloc d'una commutativa. Es pot demostrar [Connes94,Szabo04] que l'espai commutatiu $\mathbb{R}^{n}$ esdevé no commutatiu si se substitueix l'habitual i commutatiu producte de funcions punt a punt $f(x) \cdot g(x)$ pel no commutatiu $\star$-producte de l'eq.(3.2). Aquesta subs-titució fa que l'equació de Schrödinger no lineal (3.6) passe a ser la seua anàloga no commutativa (3.10). Aquesta darrera difereix tan sols de la primera en els termes cúbics, ja que els temes quadràtics en la funció d'ona no són sensibles al $\star$-producte gràcies a l'eq.(3.5).

Per tal de definir un $\star$-producte sobre $\mathbb{R}^{n}$ és necessari i suficient determinar un tensor constant i antisimètric $\theta^{i j}$ com en (3.2). D'altra banda, un potencial 
quasiperiòdic en $n$ dimensions està especificat per un conjunt de $n$ freqüències irracionals $\omega_{i} \in \mathbb{R}$. Una vegada que aquestes es coneguin, el tensor $\theta^{i j}$ està determinat, per l'eq.(3.23), com una funció de les freqüències que defineixen el potencial. Encara que hem concentrat la nostra atenció en els potencials quasiperiòdics del tipus (3.18), la nostra tècnica pot estendre's de forma senzilla a potencials quasiperiòdics més generals. Per exemple, si el potencial quasiperiòdic és de la forma

$$
V_{1}(x)=\sin x+\sin \omega x+\sin \xi x, \quad \omega, \xi \notin \mathbb{Q},
$$

llavors, considerarem

$$
V_{3}(x, y, z)=\sin x+\sin y+\sin z, \quad y=\omega x, z=\xi x
$$

Això condueix als commutadors no nuls $[x, y]$ i $[x, z]$. Si, d'altra banda, els irracionals $\omega$ i $\xi$ són incommensurables, aleshores $[y, z]$ serà també no nul. En aquest cas, el nostre potencial esdevé periòdic en un espai no commutatiu de dimensió 3. Per tant, la teoria no commutativa té, en general, més de dues vegades tantes dimensions com la teoria original.

Els resultats d'aquesta tesi suposen una nova ferramenta teòrica per a estudiar la dinàmica de solucions de l'equació de la NLSE amb potencials periòdics i quasiperiòdics, i estableixen el punt de partida de futures línies d'investigació. El següent pas per a la consolidació de la teoria és la validació mitjançant simulacions numèriques, tant de l'equació completa com de l'efectiva. Aquestes simulacions permetran comprovar i precisar els règims de validesa de les equacions efectives. Cal esmentar que en el cas de potencials periòdics ja s'han obtingut alguns resultats que confirmen la teoria efectiva [Ferrando08]. En aquesta referència, l'equació efectiva ha sigut la clau per a predir l'existència de solucions estables d'envolupants amb una distribució de fase no trivial. En el cas de potencials quasiperiòdics el repte tècnic és major perquè suposa com a mínim duplicar les dimensions del problema. També s'ha de resoldre el problema de les 
condicions de frontera numèriques, que deixen de ser periòdiques i poden alterar l'amplitud del camp en el cas de solucions esteses a tots els punts de la xarxa. 



\section{Funcions de Bloch}

En aquest apèndix donarem els conceptes bàsics de l'estat sòlid, necessaris per a la comprensió del capítol 2. Tot es troba ampliat en qualsevol llibre clàssic de física de l'estat sòlid com en les referències següents: [Ashcroft76], [Kittel96], [Pavlov87].

\section{A.1 Nocions bàsiques sobre la estructura dels cristalls}

Les substàncies cristal-lines es caracteritzen per gaudir d'una periodicitat espacial perfecta, o dit de manera equivalent, d'una simetria de translació. Aquesta propietat afecta de forma rellevant les propietats físiques. Per a descriure la simetria de translació del cristall necessitem unes nocions bàsiques de cristal-lografia.

Introduirem un conjunt infinit de punts, que anomenarem nodes, distribuïts en l'espai de manera que cada punt sempre té el mateix entorn, és a dir, la mateixa distribució en la mateixa orientació. S'anomena xarxa el conjunt d'aquests punts. Tots els punts de la xarxa són equivalents, i si prenem un punt de la xarxa qualsevol $O$ com a origen, qualsevol altre punt $M$ ve definit pel vector de posició 


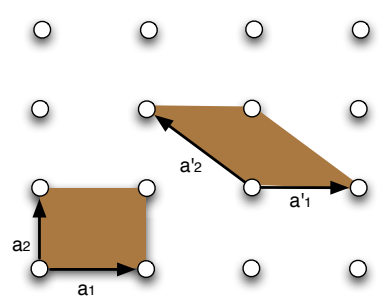

(a)

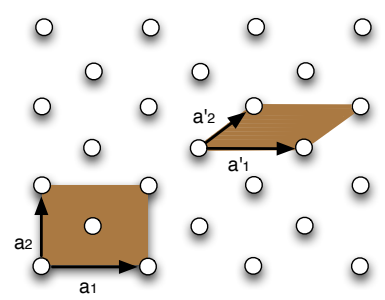

(b)

Figura A.1: Exemples de vectors primitius i llurs cel-les unitàries. En (a) els vectors $\overrightarrow{a_{1}}, \overrightarrow{a_{2}}$ i $\overrightarrow{a_{1}^{\prime}}, \overrightarrow{a_{2}}$ són primitius i, per tant, també ho són les cel-les. En (b) els vectors $\overrightarrow{a_{1}}, \overrightarrow{a_{2}}$ no són primitius $i$, per tant, tampoc ho és la cel-la que defineixen (observem que conté més d'un punt de xarxa).

$$
O M=\vec{r}=n_{1} \overrightarrow{a_{1}}+n_{2} \overrightarrow{a_{2}}+n_{3} \overrightarrow{a_{3}}
$$

on $\overrightarrow{a_{1}}, \overrightarrow{a_{2}}, \overrightarrow{a_{3}}$ són tres vectors arbitraris no coplanaris que mantenen la simetria de translació i s'anomenen vectors base primitius, i $n_{1}, n_{2}, n_{3}$ són tres enters no nuls simultàniament. Vectors base no primitius són aquells que generen la xarxa per combinacions lineals de la forma (A.1) on els $n_{i}$ poden prendre valors no enters com en la fig.A.1 [Maza08].

Un vector de xarxa és el vector que uneix dos punts de la xarxa. El denotarem per $\vec{R}$.

S'anomena base atòmica el conjunt d'àtoms que s'associa a tots i cadascun dels punts de la xarxa. S'anomena estructura cristal-lina o cristall a la combinació xarxa+base atòmica. Si la base està constituïda per un sol àtom, l'estructura cristal-lina coincideix amb la xarxa. Un exemple en 2 dimensions es mostra en la fig. A.2

Hi ha diverses maneres de triar els eixos de coordenades en una xarxa. Normalment es trien de manera que uneixen el node origen amb els nodes més pròxims, la qual cosa no sempre genera eixos ortogonals. 


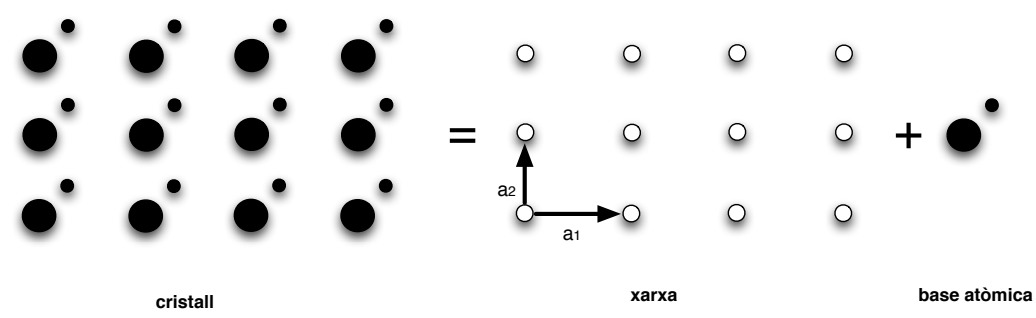

Figura A.2: Exemple d'estructura cristal-lina bidimensional i la seua representació com una xarxa més una base atòmica

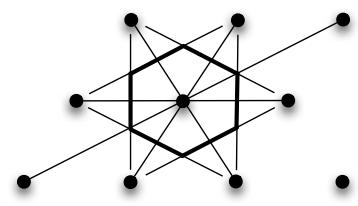

Figura A.3: Cel-la de Wigner-Steiz bidimensional

S'anomena cel-la unitària primitiva el paral-lelepíped definit pels vectors primitius $\overrightarrow{a_{1}}, \overrightarrow{a_{2}}, \overrightarrow{a_{3}}$. Com que en una xarxa pot haver més d'una elecció de vectors base primitius, hi ha més d'una cel-la primitiva, encara que totes tenen el mateix volum, ja que duen associat un i sols un punt de xarxa. Tots els punts de xarxa són indistingibles en el sentit que la xarxa es veu igual des de qualsevol dels seus punts, és a dir, és invariant sota translacions de vectors de xarxa. Aquesta definició de cel-la primitiva és la més usada en cristal-lografia. Un altra manera de definir la cel-la primitiva és considerar el node en el centre de la cel-la primitiva. Aquesta cel-la es coneix amb el nom de cel-la de WignerSteiz i es construeix de la manera següent: tracem els segments que connecten un punt de xarxa amb els veïns pròxims i tracem els plans mediatrius a aquests segments. La regió determinada, que és un poliedre (en 2D un polígon) és la cel-la de Wigner-Steiz. A la fig.A.3 es mostra un exemple en 2D de la cel-la de Wigner-Steiz. 
Un concepte fonamental en la descripció de qualsevol sòlid cristal-lí és l'anomenada xarxa de Bravais. Bravais va establir en 1845 que només existeixen 14 formes diferents, classificades pel tipus de simetria que posseeixen, de disposar un grup de punts idèntics en l'espai de manera que cada punt tinga un entorn equivalent. Aquestes formes s'anomenen xarxes de Bravais. En traslladar una xarxa de Bravais mitjançant un vector de la forma $\vec{R}=n_{1} \overrightarrow{a_{1}}+n_{2} \overrightarrow{a_{2}}+n_{3} \overrightarrow{a_{3}}$ on $\overrightarrow{a_{1}}, \overrightarrow{a_{2}}, \overrightarrow{a_{3}}$ són tres vectors primitius i $n_{1}, n_{2}, n_{3}$ són tres enters, la xarxa coincideix amb si mateixa. La invariància translacional és la característica més important d'una xarxa de Bravais. En el pla, hi ha cinc formes diferents que constitueixen les xarxes de Bravais bidimensionals.

\section{A.2 Xarxa recíproca}

Per a poder entendre i interpretar de manera més senzilla certs aspectes relacionats amb l'estructura periòdica resulta convenient introduir el concepte de xarxa periòdica. Aquesta no és més que un truc matemàtic que simplifica la descripció dels fenòmens que tenen lloc al cristall. A cada xarxa cristal-lina real li correspon una xarxa recíproca perfectament definida, la construcció de la qual s'explica a continuació:

Considerem un conjunt de punts que constitueixen una xarxa de Bravais, és a dir, invariants en conjunt sota translacions de vectors de xarxa $\vec{R}=$ $n_{1} \overrightarrow{a_{1}}+n_{2} \overrightarrow{a_{2}}+n_{3} \overrightarrow{a_{3}}$. Siga $f(\vec{x})=e^{i \vec{k} \cdot \vec{x}}$ una ona plana on $\vec{k} \in \mathbb{R}^{3}$ s'anomena moment lineal. Els vectors $\vec{k} \in \mathbb{R}^{3}$ que donen lloc a ones planes amb la mateixa periodicitat que la xarxa de Bravais, definida pels vectors $\vec{R}$, constitueixen la xarxa recíproca. Cal, doncs, veure quins vectors d'ona satisfan

$$
e^{i \vec{k} \cdot(\vec{x}+\vec{R})}=e^{i \vec{k} \cdot \vec{x}} \Longleftrightarrow e^{i \vec{k} \cdot \vec{R}}=1 \Longleftrightarrow \vec{k} \cdot \vec{R}=2 \pi n, \quad n \in \mathbb{Z} .
$$

La condició (A.2) exigeix que $\vec{k}$ siga de la forma 


$$
\vec{k}=v_{1} \overrightarrow{b_{1}}+v_{2} \overrightarrow{b_{2}}+v_{3} \overrightarrow{b_{3}}
$$

amb $v_{i} \in \mathbb{Z}$ i els vectors $\overrightarrow{b_{i}}$ verificant la condició

$$
\overrightarrow{b_{i}} \cdot \overrightarrow{a_{j}}=2 \pi \delta_{i j}, \text { on } \delta_{i j}= \begin{cases}1 & i=j \\ 0 & i \neq j\end{cases}
$$

És senzill obtenir els vectors $\overrightarrow{b_{i}}$ a partir dels vectors base primitius $\overrightarrow{a_{i}}$ de la xarxa de Bravais. La condició (A.4) la verifiquen els vectors definits per

$$
\overrightarrow{b_{1}}=2 \pi \frac{\overrightarrow{a_{2}} \times \overrightarrow{a_{3}}}{\overrightarrow{a_{1}} \cdot\left(\overrightarrow{a_{2}} \times \overrightarrow{a_{3}}\right)}, \overrightarrow{b_{2}}=2 \pi \frac{\overrightarrow{a_{3}} \times \overrightarrow{a_{1}}}{\overrightarrow{a_{1}} \cdot\left(\overrightarrow{a_{2}} \times \overrightarrow{a_{3}}\right)}, \overrightarrow{b_{1}}=2 \pi \frac{\overrightarrow{a_{1}} \times \overrightarrow{a_{2}}}{\overrightarrow{a_{1}} \cdot\left(\overrightarrow{a_{2}} \times \overrightarrow{a_{3}}\right)}
$$

Els vectors de la forma (A.3) defineixen la xarxa recíproca, i aquesta pot ser generada pels vectors primitius (A.5), és a dir, la xarxa recíproca és una xarxa de Bravais.

Com a exemple anem a obtenir el vectors que generen la xarxa recíproca d'una xarxa de Barvais bidimensional generada per dos vectors primitius $\overrightarrow{a_{1}}, \overrightarrow{a_{2}}$ que formen un angle $\alpha$. Siguen $\vec{i}$ i $\vec{j}$ els vectors que defineixen els eixos de coordenades. Si els vectors $\overrightarrow{a_{1}}, \overrightarrow{a_{2}}$ formen un angle $\alpha \neq \frac{\pi}{2}$ podem escriure $\overrightarrow{a_{1}}=$ $\left|\overrightarrow{a_{1}}\right| \vec{i}$ i $\overrightarrow{a_{2}}=\left|\overrightarrow{a_{2}}\right|(\cos \alpha \vec{i}+\sin \alpha \vec{j})$. La condició (A.4) implica que

$$
\overrightarrow{b_{1}}=\frac{2 \pi}{\left|\overrightarrow{a_{1}}\right|}\left(\vec{i}-\frac{\cos \alpha}{\sin \alpha} \vec{j}\right), \quad \overrightarrow{b_{2}}=\frac{2 \pi}{\left|\overrightarrow{a_{2}}\right|}\left(\frac{1}{\sin \alpha} \vec{j}\right), \quad \alpha \neq \frac{\pi}{2}
$$

Si $\alpha=\frac{\pi}{2}$ i $\left|\overrightarrow{a_{1}}\right|=\left|\overrightarrow{a_{2}}\right|=a$, aleshores $\overrightarrow{b_{1}}=\frac{2 \pi}{a} \vec{i}, \overrightarrow{b_{2}}=\frac{2 \pi}{a} \vec{j}$.

S'anomena primera zona de Brioullin el volum del poliedre (àrea del polígon en 2D) més petit centrat en un punt de la xarxa recíproca i limitat pels plans mediatrius (rectes mediatrius en 2D) dels vectors de la xarxa recíproca que uneixen el punt amb els seus veïns més pròxims; per tant, la primera zona de Brioullin és una cel-la primitiva de la xarxa recíproca i és l'equivalent en l'espai 
recíproc de la cel-la de Wigner-Steiz de la xarxa directa.

\section{A.3 Teorema de Bloch}

El problema dels electrons en el sòlid és, en principi, un problema de molts cossos, perquè l'hamiltonià conté, a més de la interacció dels electrons amb els nuclis, els potencials que descriuen la interacció electró-electró. Aquesta situació es resol mitjançant aproximacions, però allò que és interessant és que es pot arribar a l'existència d'un potencial periòdic amb la periodicitat de la xarxa de Bravais corresponent [Ashcroft76, Kittel96]. Considerarem una xarxa de Bravais bidimensional, ja que és la situació que s'estudia en el capítol 2.

L'existència d'un potencial periòdic amb la periodicitat de la xarxa, dins del marc de l'electró independent, permet considerar les funcions d'ona electròniques com ones planes modulades amb la periodicitat de la xarxa cristal-lina. Són les anomenades funcions de Bloch.

Una funció $f: \mathbb{R}^{2} \longrightarrow \mathbb{C}$ és una funció de Bloch si és de la forma

$$
f_{\mathbf{p}}(\mathbf{x})=e^{i \mathbf{p} \cdot \mathbf{x}} u_{\mathbf{p}}(\mathbf{x})
$$

on $\mathbf{p} \epsilon \mathbb{R}^{2}, u(\mathbf{x}+\mathbf{R})=u(\mathbf{x}), \forall \mathbf{R}$.

Anem a estudiar el comportament d'un electró en un potencial amb la propietat

$$
V(\mathbf{x}+\mathbf{R})=V(\mathbf{x})
$$

on $\mathbf{R}$ és un vector de xarxa. La periodicitat del potencial permetrà establir la forma general de la funció d'ona.

L'equació de Schrödinger per a l'electró és:

$$
H \psi=\left(-\nabla^{2}+V(\mathbf{x})\right) \psi=\varepsilon \psi
$$

on el potencial $V$ té la periodicitat (A.8). L'equació de Schrödinger per a l'electró 
lliure és un cas particular de l'eq.(A.9) quan el potencial és zero. S'anomenen electrons de Bloch els electrons independents; cadascun d'ells obeeix una equació com (A.9). Els estats estacionaris dels electrons de Bloch tenen una propietat molt important que és conseqüència de la periodicitat del potencial. Aquesta és allò que s'anomena el teorema de Bloch:

Els autoestats $\psi$ de l'operador hamiltonià $-\nabla^{2}+V(\mathbf{x})$, on $V(\mathbf{x}+\mathbf{R})=V(\mathbf{x})$, per a qualsevol $\mathbf{R}$ en una xarxa de Bravais amb vectors primitius $\overrightarrow{a_{1}}, \overrightarrow{a_{2}}$, són de la forma

$$
\psi_{\mathbf{p} ; \alpha}(\mathbf{x})=e^{i \mathbf{p} \cdot \mathbf{x}} u_{\mathbf{p} ; \alpha}(\mathbf{x})
$$

on

$$
u_{\mathbf{p} ; \alpha}(\mathbf{x}+\mathbf{R})=u_{\mathbf{p} ; \alpha}(\mathbf{x}), \forall \mathbf{R}
$$

és a dir, tenen la forma funcional de una funció de Bloch. L'índex $\alpha$ s'anomena index de banda, i apareix perquè, per a un $\mathbf{p}$ donat, hi ha diversos autoestats independents [Ashcroft76].

Les eq.(A.10) i (A.11) impliquen que

$$
\psi_{\mathbf{p} ; \alpha}(\mathbf{x}+\mathbf{R})=e^{i \mathbf{p} \cdot \mathbf{R}} \psi_{\mathbf{p} ; \alpha}(\mathbf{x})
$$

L'eq.(A.12) és una forma alternativa d'enunciar el teorema de Bloch: els autoestats de l'hamiltonià verifiquen (A.12) i, com a conseqüència, aquests autoestats són de la forma (A.10).

Demostracions del teorema de Bloch podem trobar-les en qualsevol llibre d'estat sòlid, per exemple [Ashcroft76, Kittel96].

Algunes conseqüències derivades del teorema de Bloch són:

i. El teorema de Bloch introdueix un vector $\mathbf{p}$ que, en el problema amb un potencial periòdic, juga el mateix paper que el moment en el problema de l'electró lliure. No obstant això, p no és el moment, ja que les funcions pròpies del Hamiltonià periòdic no són alhora funcions pròpies de l'operador moment. Per això, a $\mathbf{p}$ se l'anomena quasi-moment o moment del cristall. 
ii. El vector $\mathbf{p}$ que apareix en (A.10) pot estar sempre confinat en la primera zona de Brioullin (o en qualsevulla cel-la primitiva de la xarxa recíproca que es trie). Això és perquè qualsevol p' que no pertanya a la primera zona de Brioullin sempre podem escriure'l com $\mathbf{p}^{\prime}=\mathbf{p}+\mathbf{K}$, on $\mathbf{K}$ es un vector de la xarxa recíproca i $\mathbf{p}$ sí que es troba en la primera zona. És a dir, si $\mathbf{p}$ verifica (A.12), també ho fa $\mathbf{p}+\mathbf{K}$.

iii. L'índex de banda $\alpha$ apareix en el teorema de Bloch perquè per a un valor de $\mathbf{p}$ donat hi ha diverses solucions de l'equació de Schrödinger. Trobarem totes les solucions de l'eq.(A.9) que tenen la forma d'una funció de Bloch (A.7), on $\mathbf{p}$ és fix i $u$ té la periodicitat de la xarxa de Bravais. En substituir en l'eq.(A.9) observem que $u$ està determinada per l'equació d'autovalors

$$
H_{\mathbf{p}} u_{\mathbf{p}}(\mathbf{x})=\varepsilon_{\mathbf{p}} u_{\mathbf{p}}(\mathbf{x})
$$

amb la condició de contorn $u_{\mathbf{p}}(\mathbf{x}+\mathbf{R})=u_{\mathbf{p}}(\mathbf{x})$. A causa de la condició de contorn periòdica podem veure l'eq.(A.13) com un problema hermític d'autovalors restringit a una cel-la primitiva del cristall. Atès que el problema es troba en un volum finit fix, esperem trobar, en termes generals, una família infinita de solucions amb valors propis discretament espaiats, que etiquetarem amb l'índex de banda $\alpha$ [Ashcroft76]. 


\section{Apèndix B}

\section{Propietats de l'hamiltonià}

\section{lineal}

L'hamiltonià lineal està format per dos termes diferents: un que involucra les interaccions locals entre coeficients definits en el mateix punt del reticle mentre que l'altre està induït per les interaccions no locals entre coeficients que corresponen a punts diferents de la xarxa:

$$
H_{\mathrm{L}}=\sum_{i} L_{i i}\left|c_{i}\right|^{2}+\sum_{i \neq j} L_{i j} c_{i}^{*} c_{j}
$$

La part no local de l'hamiltonià ve donada (2.9) pels termes següents:

$$
H_{\mathrm{L}}^{\mathrm{nloc}}=\sum_{i \neq j} L_{i j} c_{i}^{*} c_{j}
$$

Abans de continuar, és important demostrar algunes propietats del tensor de segon ordre $L_{i j}$. En primer lloc, anem a reprendre la definició de $L_{i j}$ - recordem que $i$ representa el parell posició en la xarxa/índex de banda $(\hat{i}, \alpha)$ :

$$
L_{i j} \equiv \int_{\Omega} d^{2} x W_{\alpha}^{*}\left(\mathbf{x}-\mathbf{x}_{\hat{i}}\right)\left(-\nabla^{2}+V(\mathbf{x})-\mu\right) W_{\beta}\left(\mathbf{x}-\mathbf{x}_{\hat{j}}\right)
$$


La definició anterior involucra els índexs de banda $\alpha$ i $\beta$. La propietat més general del tensor $L_{i j}$ té a veure amb l'intercanvi simultani dels índexs espacials i de banda. Es pot veure a partir de la definició B.2 que si l'operador $H_{0} \equiv$ $\left(-\nabla^{2}+V(\mathbf{x})-\mu\right)$ és autoadjunt (condició que es verifica de forma immediata si $V$ i $\mu$ són reals) aleshores, $L_{i j}$ és un operador autoadjunt en termes dels índexs $i$ i $j$ :

$$
L_{i j}=\left(L_{j i}\right)^{*}
$$

Les propietats que es mostraran a continuació implicaràn, però, només els índexs espacials. En aquest cas, suposarem que l'índex de la banda és el mateix per a totes dues funcions de Wannier en l'eq.(B.2) $(\alpha=\beta) \mathrm{i}$, per tant, per raons de simplicitat, eliminarem els subíndexs de la banda de la nostra notació posterior. Farem el canvi de variable $\mathbf{x} \rightarrow \mathbf{x}+\mathbf{x}_{\hat{i}}=\mathbf{x}+\hat{i} a$, que correspon a una translació en la xarxa, en la integral (B.2). Com que tant l'operador $H_{o}=\left(-\nabla^{2}+V(\mathbf{x})-\mu\right)$ com el domini d'integració $\Omega$ són invariants sota translacions en la xarxa, el resultat següent s'obté després de realitzar aquesta operació

$$
\begin{aligned}
L_{i j} & =\int_{\Omega} d^{2} x W^{*}(\mathbf{x}) H_{0} W(\mathbf{x}-(\hat{j}-\hat{i}) a) \\
& =\int_{\Omega} d^{2} x W^{*}(\mathbf{x}) H_{0} W\left(\mathbf{x}-\mathbf{x}_{\hat{j}-\hat{i}}\right)=L_{\hat{j}-\hat{i}}=L_{\hat{n}},
\end{aligned}
$$

on s'ha introduït el vector "veí" $\hat{n} \equiv \hat{j}-\hat{i}=\left(j_{1}-i_{1}, j_{2}-i_{2}\right)-$ el parell $\left(i_{1}, i_{2}\right)$ correspon a les coordenades del punt $\hat{i}$ en la xarxa periòdica, és a dir, $\mathbf{x}_{\hat{i}}=$ $i_{1} a \mathbf{e}_{1}+i_{2} a \mathbf{e}_{2}-$. Com que $L_{i j}$ és autoadjunt, $L_{i j}=\left(L_{j i}\right)^{*}$, ha de ser cert que

$$
L_{\hat{n}}=L_{-\hat{n}}^{*} \text {. }
$$

D'aquesta manera s'ha demostrat que el tensor de segon ordre $L_{i j}$ és independent de les coordenades de un punt concret de la xarxa. Depèn de la diferència entre les coordenades de dos punts de la xarxa, és a dir, depèn del vector "veí" $\hat{n}$ exclusivament. 
Per exemple, per a interaccions entre veïns pròxims en una xarxa periòdica quadrada bidimensional, $L_{\hat{n}}$ pren quatre valors diferents que es corresponen a les quatre translacions elementals en la xarxa: $L_{(+1,0)}$ (dreta), $L_{(-1,0)}$ (esquerra), $L_{(0,+1)}$ (dalt) i $L_{(0,-1)}$ (baix). En una xarxa unidimensional, simplement tenim dos valors: $L_{+1}$ i $L_{-1}$.

Aplicarem aquests resultats a l'hamiltonià no local de l'eq.(B.1) mitjançant la introducció del vector $\hat{n}$ en el sumatori $\left(\sum_{i \neq j}=\sum_{i} \sum_{\hat{n}}\right)$ :

$$
H_{\mathrm{L}}^{\mathrm{nloc}}=\sum_{\hat{i}} \sum_{\hat{n}} L_{\hat{n}} c_{\hat{i}}^{*} c_{\hat{i}+\hat{n}} .
$$

Per tal de fer el càlcul més clar començarem amb el cas unidimensional:

$$
\begin{aligned}
H_{\mathrm{L}}^{\mathrm{nloc}} & =\sum_{i} \sum_{n \in \mathbb{N}^{*}}\left(L_{n} c_{i}^{*} c_{i+n}+L_{-n} c_{i}^{*} c_{i-n}\right) \\
& =\sum_{i} \sum_{n \in \mathbb{N}^{*}}\left(L_{n} c_{i}^{*} c_{i+n}+L_{n}^{*} c_{i}^{*} c_{i-n}\right) .
\end{aligned}
$$

Tenint en compte que $L_{n}$ és, en el cas més general, un nombre complex, és possible reescriure l'equació anterior $\operatorname{com}\left(L_{n}=L_{n}^{\mathrm{r}}+i L_{n}^{\mathrm{i}}\right)$ :

$$
\begin{aligned}
H_{\mathrm{L}}^{\mathrm{nloc}}= & L_{n}^{\mathrm{r}} \sum_{i} \sum_{n \in \mathbb{N}^{*}} c_{i}^{*}\left(c_{i+n}+c_{i-n}\right) \\
& +i L_{n}^{\mathrm{i}} \sum_{i} \sum_{n \in \mathbb{N}^{*}} c_{i}^{*}\left(c_{i+n}-c_{i-n}\right) .
\end{aligned}
$$

No obstant això, com es mostra en l'apèndix D, les funciones de Wannier associades a $H_{\text {sol }}$ són reals si l'operador hamiltonià complet $H_{\text {sol }}=-\nabla^{2}+V(\mathbf{x})-$ $g\left|\phi_{\text {sol }}(\mathbf{x})\right|^{2}$ és autoadjunt i real. Aquesta condició es satisfà quan el potencial $V$ és real. Així, per a un potencial real $V$ el tensor de segon ordre $L_{i j}$ no és només 
autoadjunt sinó també real ja que $V=V^{*}$ i $W_{i}^{*}=W_{i}$ :

$$
\begin{aligned}
L_{i j}^{*} & =\int_{\Omega} W_{i}\left(-\nabla^{2}+V^{*}(\mathbf{x})-\mu\right) W_{j}^{*} \\
& =\int_{\Omega} W_{i}^{*}\left(-\nabla^{2}+V(\mathbf{x})-\mu\right) W_{j}=L_{i j} \in \mathbb{R} .
\end{aligned}
$$

Com a conseqüència, les parts imaginàries en les eq.(B.6) s'anul-laran, i en el cas unidimensional, s'obté:

$$
H_{\mathrm{L}}^{\mathrm{nloc}}=\sum_{i} \sum_{n \in \mathbb{N}^{*}} L_{n} c_{i}^{*}\left(c_{i+n}+c_{i-n}\right) \text {. }
$$

Per al cas bidimensional, ens limitarem al cas d'una xarxa quadrada $\left(\mathbf{e}_{1} \cdot \mathbf{e}_{2}=0\right)$. La simetria rotacional de quart ordre d'aquesta xarxa introdueix altres relacions addicionals entre els coeficients de $L_{i j}$. Les funcions de Wannier de les bandes fonamentals, que poden associar-se a estats no degenerats d'un potencial únic en l'aproximació d'enllaç fort [Ashcroft76], són invariants sota rotacions de quart ordre — veure apèndix E- Com que tant les funcions de Wannier com l'hamiltonià $H_{0}(\mathbf{x})=-\nabla^{2}+V(\mathbf{x})-\mu$ són invariants sota rotacions discretes de quart ordre $R$, és a dir, $H_{0}(R \mathbf{x})=H_{0}(\mathbf{x})$ i $W_{i}(R \mathbf{x})=W_{i}(\mathbf{x}), \forall i$, resulta que

$$
\begin{aligned}
L_{R \hat{n}} & =\int_{\Omega} W(\mathbf{x}) H_{0}(\mathbf{x}) W(\mathbf{x}-R \hat{n} a) \stackrel{\mathbf{x} \rightarrow R \mathbf{x}}{=} \int_{R \Omega} W(R \mathbf{x}) H_{0}(R \mathbf{x}) W(R(\mathbf{x}-\hat{n} a)) \\
& =\int_{\Omega} W(\mathbf{x}) H_{0}(\mathbf{x}) W(\mathbf{x}-\hat{n} a)=L_{\hat{n}},
\end{aligned}
$$

on hem tingut en compte la invariança del domini periòdic de integració $\Omega$ sota la rotació discreta $R$. Aquesta propietat permet generalitzar l'hamiltonià (B.7) al cas bidimensional organitzant el sumatori en l'eq.(B.5) en anells pròxims al voltant del node $i$. En primer lloc, s'adonem que cada anell inclou tots els punts de la xarxa equidistants al punt de referència $i$, així, cada anell està definit pel mòdul del vector "veí" $\hat{n}$ i serà classificat únicament per un nombre natural 
distint de zero $n \in \mathbb{N}^{*}$. El valor de $n$ indica l'ordre de proximitat dels diferents anells al lloc de referència $i$, això és, $n=1$ correspon a l'anell veí més pròxim, $n=2$ al més pròxim del primer més pròxim i així successivament.

A causa de la invariança rotacional, la propietat (B.8) indica que els coeficients $L_{\hat{n}}$ depenen exclusivament del mòdul del vector $|\hat{n}|$. Per tant, el coeficient $L_{n} \equiv L_{|\hat{n}|}$ és el mateix per a tots els punts en un anell donat. Siguen ara $\left\{\hat{n}_{1}, \ldots, \hat{n}_{\nu}, \ldots, \hat{n}_{d_{n}}\right\}$ el conjunt dels no col-lineals vectors que defineixen el anell $n$. Aleshores es pot escriure l'hamiltonià en dues dimensions com:

$$
H_{\mathrm{L}}^{\text {nloc }}=\sum_{\hat{i}} \sum_{n \in \mathbb{N}^{*}} L_{n} \sum_{\nu=1}^{d_{n}} c_{\hat{i}}^{*}\left(c_{\hat{i}+\hat{n}_{\nu}}+c_{\hat{i}-\hat{n}_{\nu}}\right) \text {. }
$$

D'altra banda, la estructura de la part lineal local de l'hamiltonià (2.9) presenta una forma molt més simple:

$$
H_{\mathrm{L}}^{\mathrm{loc}}=\sum_{i} L_{i i}\left|c_{i}\right|^{2}
$$

De fet, a causa de la propietat de la invariància translacional de $L_{i j}$ que apareix en l'eq.(B.8), el coeficient $L_{i i}$ és independent del punt. Matemàticament, això significa que $L_{i i}=L_{0} \equiv l$, i, per tant:

$$
H_{\mathrm{L}}^{\mathrm{loc}}=l \sum_{i}\left|c_{i}\right|^{2}
$$

Fins ara, no s'ha considerat la possibilitat d'una barreja de banda ja que s'ha assumit que totes les funcions de Wannier que apareixen en la definició del tensor $L_{i j}$ (eq.(B.2)) pertanyen a la mateixa banda. Una barreja de banda ocorre de forma natural, ja que, de fet, el tensor $L_{i j}$ mescla components diferents de banda quan es consideren funcions de Wannier corresponents a bandes diferents en la seua definició. Recordem que $L_{i j}$ és una notació simplificada de $L_{\hat{i} \hat{j}}^{\alpha \beta}$. En general, hom espera que els termes no diagonals en els índexs de les bandes $\alpha$ i $\beta$ 
siguen més petits que els de la diagonal ja que la forma funcional de les funcions de Wannier és qualitativament diferent per a les diferents bandes. Aquest fet té com a conseqüència que el valor de la integral de superposició (B.2) que defineix $L_{\hat{i} \hat{j}}^{\alpha \beta}-\alpha \neq \beta-$ siga xicotet respecte d'aquell associat als termes diagonals $\alpha=\beta$-, que impliquen la superposició de funcions de Wannier a la mateixa banda.

En qualsevol cas, és interessant explorar la possibilitat d'acoblament entre bandes en l'hamiltonià lineal. Es senzill generalitzar aquesta situació a partir del cas diagonal (B.9). Mitjançant una xarxa de punts organitzada en anells al voltant del punt de referència $i=(\hat{i}, \alpha)$ i caracteritzada pel mòdul $|\hat{n}|$ i classificada per $n \in \mathbb{N}^{*}$ Corresponent als llocs definits per $j=\left(\hat{i} \pm \hat{n}_{\nu}, \beta\right)$ amb $\left|\hat{n}_{\nu}\right|=|\hat{n}|$ - es pot escriure un hamiltonià més general de la següent manera:

$$
H_{L}^{\text {nloc }}=\sum_{\alpha, \beta} \sum_{\hat{i}} \sum_{n \in \mathbb{N}^{*}} \sum_{\nu=1}^{d_{n}}\left(L_{\hat{n}_{\nu}}^{\alpha \beta} c_{\hat{i}}^{\alpha *} c_{\hat{i}+\hat{n}_{\nu}}^{\beta}+L_{-\hat{n}_{\nu}}^{\alpha \beta} c_{\hat{i}}^{\alpha *} c_{\hat{i}-\hat{n}_{\nu}}^{\beta}\right) .
$$

Aquesta equació es pot simplificar més. Mitjançant una deducció semblant a la que hem fet servir per provar l'eq.(B.8) per al cas diagonal, també es pot provar que

$$
L_{R \hat{n}_{\nu}}^{\alpha \beta}=L_{\hat{n}_{\nu}}^{\alpha \beta}=L_{n}^{\alpha \beta},
$$

que significa que la matriu $L_{n}^{\alpha \beta}$ és la mateixa per a tots els punts del mateix anell. Per tant si s'usa que $L_{\hat{n} \nu}^{\alpha \beta}=L_{-\hat{n} \nu}^{\alpha \beta}=L_{n}^{\alpha \beta}$ per a simplificar l'eq.(B.12), s'obté

$$
H_{L}^{\text {nloc }}=\sum_{\alpha, \beta} \sum_{\hat{i}} \sum_{n \in \mathbb{N}^{*}} L_{n}^{\alpha \beta} \sum_{\nu=1}^{d_{n}}\left(c_{\hat{i}}^{\alpha *} c_{\hat{i}+\hat{n}_{\nu}}^{\beta}+c_{\hat{i}}^{\alpha *} c_{\hat{i}-\hat{n}_{\nu}}^{\beta}\right) \text {. }
$$




\section{Apèndix $\mathrm{C}$}

\section{Propietats de l'hamiltonià}

\section{no lineal}

De la mateixa manera que en la part lineal, l'hamiltonià no lineal està constituït per un terme local i d'un no local:

$$
H_{\mathrm{NL}}=-\sum_{i} T_{i i i i}\left|c_{l}\right|^{2}-\sum_{i \neq j \neq k \neq l} T_{i j k l} c_{i}^{*} c_{j}^{*} c_{k} c_{l} .
$$

Les propietats principals de $T_{i j k l}$ deriven de la seua definició:

$$
T_{i j k l} \equiv \frac{1}{2} \int_{\Omega} d^{2} x g W_{i}^{*} W_{j}^{*} W_{k} W_{l}
$$

Si assumim que $g$ és real, és immediat demostrar que $T_{i j k l}$ compleix una mena de condició d'autoadjunt en els parells d'índexs $(i j)$ i $(k l)$, i és simètric sota permutacions en els índexs $(i j)$ i $(j k)$ :

$$
T_{k l i j}^{*}=T_{i j k l}=T_{j i k l}=T_{i j l k} .
$$

Si el potencial és real i les funcions de Bloch són no degenerades, totes les funcions de Wannier són reals (veure apèndix $\mathrm{C}$ ), i així $T_{i j k l}$ esdevé un tensor real 
completament simètric. Com s'ha fet per al terme local $L_{i j}$ en l'apèndix B, comencem considerant que no hi ha barreja de bandes per tal d'eliminar l'índex de banda de la notació i mostrar només l'índex del node, és a dir,

$$
T_{\hat{i} \hat{j} \hat{k} \hat{l}}=\frac{1}{2} \int_{\Omega} d^{2} x g(\mathbf{x}) W^{*}(\mathbf{x}-\hat{i} a) W^{*}(\mathbf{x}-\hat{j} a) W(\mathbf{x}-\hat{k} a) W(\mathbf{x}-\hat{l} a) .
$$

Si fem la transformació periòdica $\mathbf{x} \rightarrow \mathbf{x}+\hat{i} a$ en la integral anterior i considerem que la funció no lineal $g(\mathbf{x})$ és periòdica $g(\mathbf{x}+\hat{i} a)=g(\mathbf{x})$, podem escriure l'eq.(C.2) com

$$
\begin{aligned}
& T_{\hat{i} \hat{j} \hat{k} \hat{l}}= \\
& \begin{array}{r}
=\frac{1}{2} \int_{\Omega} d^{2} x g(\mathbf{x}) W^{*}(\mathbf{x}) W^{*}(\mathbf{x}-(\hat{j}-\hat{i}) a) W(\mathbf{x}-(\hat{k}-\hat{i}) a) W(\mathbf{x}-(\hat{l}-\hat{i}) a) \\
=T_{\hat{n} \hat{p} \hat{q}}
\end{array}
\end{aligned}
$$

on hem introduït els vectors "veïns" $\hat{n} \equiv \hat{j}-\hat{i}, \hat{p} \equiv \hat{k}-\hat{i}$ i $\hat{q} \equiv \hat{l}-\hat{i}$.

Les propietats de transformació d'aquests coeficients es troben fàcilment si es consideren funcions de Wannier de les bandes fonamentals ja que, en aquest cas, les funcions de Wannier són invariants sota rotacions. Així,

$$
\begin{aligned}
& T_{\hat{R n \hat{R} p R \hat{q}}}= \\
& =\frac{1}{2} \int_{\Omega} d^{2} x g(\mathbf{x}) W^{*}(\mathbf{x}) W^{*}(\mathbf{x}-R \hat{n} a) W(\mathbf{x}-R \hat{p} a) W(\mathbf{x}-R \hat{q} a) \\
& \stackrel{\mathbf{x} \rightarrow R \mathbf{x}}{=} \frac{1}{2} \int_{R \Omega} d^{2} x g(R \mathbf{x}) W^{*}(R \mathbf{x}) W^{*}(R(\mathbf{x}-\hat{n} a)) W(R(\mathbf{x}-\hat{p} a)) W(R(\mathbf{x}-\hat{q} a)) \\
& =\frac{1}{2} \int_{\Omega} d^{2} x g(\mathbf{x}) W^{*}(\mathbf{x}) W^{*}(\mathbf{x}-\hat{n} a) W(\mathbf{x}-\hat{p} a) W(\mathbf{x}-\hat{q} a) \\
& =T_{\hat{n} \hat{p} \hat{q} .} \quad \text { (C.4) }
\end{aligned}
$$

Noteu que si la funció de Wannier és real, aleshores el tensor no lineal esdevé 
real i completament simètric en els índexs veïns $\hat{n}, \hat{p}$ i $\hat{q}: T_{\hat{n} \hat{p} \hat{q}}=T_{\hat{n} \hat{q} \hat{p}}=T_{\hat{p} \hat{n} \hat{q}}$.

Per raó de la simetria completa en els índexs de lloc de $T_{\hat{i} \hat{j} \hat{j} \hat{k}}$ és immediat inferir que:

$$
T_{\hat{n} \hat{p} \hat{q}}=T_{-\hat{n},-\hat{p},-\hat{q}}
$$

Si s'assumeix que no hi ha interacció entre bandes, això és, tots els índexs de banda són els mateixos, la part local de l'hamiltonià adopta una forma molt simple ja que els elements diagonals del tensor resulten ser independents del punt d'acord amb l'eq.(C.3), és a dir, $T_{i i i i}=T_{000} \equiv U$ :

$$
H_{\mathrm{NL}}^{\mathrm{loc}}=-U \sum_{i}\left|c_{l}\right|^{4}
$$

La part no local de l'hamiltonià pot escriure's en termes dels vectors "veïns":

$$
H_{\mathrm{NL}}^{\mathrm{nloc}}=-\sum_{\hat{i}} \sum_{\hat{n} \hat{p} \hat{q}} T_{\hat{n} \hat{p} \hat{q}} c_{\hat{i}}^{*} c_{\hat{i}+\hat{n}}^{*} c_{\hat{i}+\hat{p}} c_{\hat{i}+\hat{q}}
$$

Ací ens centrarem només en les interaccions entre els veïns més pròxims. En aquest cas, per a una xarxa quadrada $\left(\mathbf{e}_{1} \cdot \mathbf{e}_{2}=0\right)$, els vectors veïns són, precisament, $\mathbf{e}_{1}$ i $\mathbf{e}_{2}$ i per tant podem escriure (definim $T_{\nu 00} \equiv T_{\hat{e}_{\nu} \hat{0} \hat{o}}$ ):

$$
H_{\mathrm{NL}}^{\mathrm{nloc}}=-\sum_{\hat{i}} \sum_{\nu=1}^{2} T_{\nu 00}\left[c_{\hat{i}}^{*}\left(c_{\hat{i}+\hat{e}_{\nu}}^{*}+c_{\hat{i}-\hat{e}_{\nu}}^{*}\right) c_{\hat{i}}^{2}+2 c_{\hat{i}}^{* 2} c_{\hat{i}}\left(c_{\hat{i}+\hat{e}_{\nu}}+c_{\hat{i}-\hat{e}_{\nu}}\right)\right],
$$

on hem tingut en compte que, d'acord amb l'eq.(C.5), $T_{-\hat{e}_{\nu} \hat{0} \hat{0}}=T_{\hat{e}_{\nu} \hat{0} \hat{0}}=T_{\nu 00}$ i hem usat la simetria del tensor $T$ sota permutacions dels índexs veïns per a traure $T_{\nu 00}$ com un factor comú $\left(T_{\nu 00}=T_{0 \nu 0}=T_{00 \nu}\right)$. A més, a causa de la propietat de rotació del tensor $T$ (C.4), també es compleix que $T_{200}=T_{\hat{e}_{2} \hat{0} \hat{o}}=$ $T_{R \hat{e}_{1} R \hat{0} R \hat{0}}=T_{\hat{e}_{1} \hat{0} \hat{0}}=T_{100}$ de manera que l'equació anterior es pot simplificar més

$$
H_{\mathrm{NL}}^{\text {nloc }}=-U^{\prime} \sum_{\hat{i}} \sum_{\nu=1}^{2}\left[c_{\hat{i}}^{*}\left(c_{\hat{i}+\hat{e}_{\nu}}^{*}+c_{\hat{i}-\hat{e}_{\nu}}^{*}\right) c_{\hat{i}}^{2}+2 c_{\hat{i}}^{* 2} c_{\hat{i}}\left(c_{\hat{i}+\hat{e}_{\nu}}+c_{\hat{i}-\hat{e}_{\nu}}\right)\right],
$$


on hem introduït el coeficient no lineal $U^{\prime} \equiv T_{\nu 00}, \quad(\nu=1,2)$.

L'hamiltonià unidimensional és només una versió simplificada del corresponent bidimensional i (C.6) es llig

$$
H_{\mathrm{NL}}^{\text {nloc }}=-U_{1} \sum_{i}\left[c_{i}^{*}\left(c_{i+1}^{*}+c_{i-1}^{*}\right) c_{i}^{2}+2 c_{i}^{* 2} c_{i}\left(c_{i+1}+c_{i-1}\right)\right] .
$$




\section{Apèndix D}

\section{Caràcter real de les}

\section{funcions de Wannier}

Mostrarem a continuació les condicions sota les quals les funcions de Wannier són reals. Anem a començar per la construcció de les funciones de Wannier a partir dels modes de Bloch com es dóna en l'eq.(2.16) — per a simplificar la notació, eliminarem la dependència en els paràmetres $\left(\mu, \mathbf{Q}, \beta_{0}\right)$ del mode de Bloch no lineal definint el operador no lineal periòdic $H_{\text {sol }}$ (veure la secció 2.3) i la normalització:

$$
W_{\beta}\left(\mathbf{x}-\mathbf{x}_{\hat{i}}\right)=\sum_{\mathbf{q}} e^{-i \mathbf{q} \cdot \mathbf{x}_{\hat{i}}} g_{\mathbf{q} ; \beta}(\mathbf{x})
$$

Ací $g_{\mathbf{q} ; \beta}(\mathbf{x})$ són els modes de Bloch associats a l'operador periòdic $H_{\text {sol }}$, és a dir, són les funcions pròpies de l'esmentat operador:

$$
H_{\mathrm{sol}} g_{\mathbf{q} ; \beta}(\mathbf{x})=\lambda_{\mathbf{q} ; \beta} g_{\mathbf{q} ; \beta}(\mathbf{x})
$$

on els valors propis $\lambda_{\mathbf{q} ; \beta}$ han de ser reals ja que $H_{\text {sol }}$ és autoadjunt. A més, $H_{\text {sol }}=$ $-\nabla^{2}+V_{\text {sol }}(\mathbf{x})$ és també un operador real ja que el potencial complet implicat en el problema $\left(V_{\text {sol }}(\mathbf{x}) \equiv V(\mathbf{x})-g\left|\phi_{\text {sol }}(\mathbf{x})\right|^{2}\right)$ inclou un potencial real lineal $\left(V=V^{*}\right)$ i un terme real generat per una solució autoconsistent $\left(-g\left|\phi_{\text {sol }}(\mathbf{x})\right|^{2} \in \mathbb{R}\right)$. Com que els modes de Bloch tenen la forma $g_{\mathbf{q} ; \beta}(\mathbf{x})=e^{i \mathbf{q} \cdot \mathbf{x}} v_{\mathbf{q} ; \beta}(\mathbf{x})$, hom pot trobar 
fàcilment l'equació corresponent a les funcions periòdiques $v_{\mathbf{q} ; \beta}$ :

$$
\left(H_{\mathrm{sol}}-2 i \mathbf{q} \cdot \nabla+\mathbf{q}^{2}\right) v_{\mathbf{q} ; \beta}(\mathbf{x})=\lambda_{\mathbf{q} ; \beta} v_{\mathbf{q} ; \beta}(\mathbf{x})
$$

Ara estem en condicions d'analitzar les propietats de $W_{\beta}$ mitjançant les eq.(D.1) i (D.2). Conjuguem l'eq.(D.2) per a trobar:

$$
\left(H_{\mathrm{sol}}+2 i \mathbf{q} \cdot \nabla+\mathbf{q}^{2}\right) v_{\mathbf{q} ; \beta}^{*}(\mathbf{x})=\lambda_{\mathbf{q} ; \beta} v_{\mathbf{q} ; \beta}^{*}(\mathbf{x})
$$

on hem utilitzat que $H_{\text {sol }}^{*}=H_{\text {sol }}$ i $\lambda_{\mathbf{q} ; \beta}^{*}=\lambda_{\mathbf{q} ; \beta}$. Si fem una transformació de paritat en el pseudo-moment $\mathbf{q} \rightarrow-\mathbf{q}$ en l'eq.(D.2), obtenim

$$
\left(H_{\mathrm{sol}}+2 i \mathbf{q} \cdot \nabla+\mathbf{q}^{2}\right) v_{-\mathbf{q} ; \beta}(\mathbf{x})=\lambda_{-\mathbf{q} ; \beta} v_{-\mathbf{q} ; \beta}(\mathbf{x})
$$

Una vegada que es fixa el pseudo-moment $\mathbf{q}$, la funció del mode de Bloch $v_{\mathbf{q} ; \beta}$ està perfectament definida pel valor de l'índex de la banda. La diagonalització de l'operador $\left(H_{\text {sol }}+2 i \mathbf{q} \cdot \nabla+\mathbf{q}^{2}\right)$ proporciona totes dels funcions dels modes de Bloch que duen pseudo-moment-q. L'única diferència entre les seues funcions pròpies està proporcionada per l'índex de banda $\beta$. Fins ara, no s'ha fet cap hipòtesi sobre la possible degeneració de l'índex de la banda $\beta$. Com es prova en física de l'estat sòlid (veure la referència [Ashcroft76]), algunes bandes poden mostrar cert grau de degeneració. Tanmateix, si assumim la no degeneració de la banda, no ha d'haver cap degeneració en l'espectre d'aquest operador per a tots els valors de q. En aquest cas, la comparació de les equacions de valors propis (D.3) i (D.4) per a aquest operador implica les següents identitats (recordem que les mateixes condicions de contorn periòdiques són complertes per les dues equacions):

$$
v_{-\mathbf{q} ; \beta}(\mathbf{x})=v_{\mathbf{q} ; \beta}^{*}(\mathbf{x}),
$$

i

$$
\lambda_{\mathbf{q} ; \beta}=\lambda_{-\mathbf{q} ; \beta} .
$$


Els modes de Bloch no degenerats han de complir aleshores

$$
g_{-\mathbf{q} ; \beta}(\mathbf{x})=g_{\mathbf{q} ; \beta}^{*}(\mathbf{x}) \text {. }
$$

El caràcter real de les funcions de Wannier associades a una banda no degenerada està garantida a causa de la condició (D.6):

$$
\begin{aligned}
W_{\beta}^{*}\left(\mathbf{x}-\mathbf{x}_{\hat{i}}\right)=\sum_{\mathbf{q}} e^{i \mathbf{q} \cdot \mathbf{x}_{\hat{i}}} g_{\mathbf{q} ; \beta}^{*}(\mathbf{x}) \stackrel{\mathbf{q} \rightarrow-\mathbf{q}}{=} \sum_{-\mathbf{q}} e^{-i \mathbf{q} \cdot \mathbf{x}_{\hat{\imath}}} g_{-\mathbf{q} ; \beta}^{*}(\mathbf{x}) \\
=\sum_{\mathbf{q}} e^{-i \mathbf{q} \cdot \mathbf{x}_{\hat{i}}} g_{\mathbf{q} ; \beta}(\mathbf{x})=W_{\beta}\left(\mathbf{x}-\mathbf{x}_{\hat{i}}\right)
\end{aligned}
$$

on hem usat el fet que $\sum_{\mathbf{q}}=\sum_{-\mathbf{q}}$.

En resum, les condicions per a que les funcions de Wannier siguen reals, per a una banda donada, són tres: (i) l'operador complet $H_{\text {sol }}$ ha de ser autoadjunt $\left(H_{\text {sol }}=H_{\text {sol }}^{\dagger}\right)$, (ii) $H_{\text {sol }}$ ha de ser real $\left(H_{\text {sol }}=H_{\text {sol }}^{*}\right)$, i (iii) tots els modes de Bloch amb el mateix índex de banda ha de ser no degenerats. Aquestes condicions són, precisament, les que reuneixen totes les situacions considerades en el capítol 2. 



\section{Apèndix E}

\section{Càlcul de bandes en}

\section{l'aproximació d'enllaç fort}

Per tal de comprendre algunes de les propietats de bandes, és interessant estudiar una manera relativament simple de calcular-les utilitzant l'aproximació d'enllaç fort. Aquesta aproximació consisteix en considerar el potencial d'un sol àtom (potencial individual) i, com una pertorbació d'aquest potencial, l'efecte dels àtoms veïns. Seguirem un argument donat en el capítol 10 del llibre [Ashcroft76].

La idea és poder construir funcions de Bloch, que són solucions de l'equació periòdica

$$
\left(-\nabla^{2}+V_{\mathbf{p}}(\mathbf{x})\right) g_{\mathbf{q} ; \beta}(\mathbf{x})=\lambda_{\mathbf{q} ; \beta} g_{\mathbf{q} ; \beta}(\mathbf{x}),
$$

a partir de solucions d'un únic potencial (potencial individual),

$$
\left(-\nabla^{2}+V_{0}(\mathbf{x})\right) \psi_{n}(\mathbf{x})=E_{n} \psi_{n}(\mathbf{x})
$$

S'assumeix que els potencials periòdics i els individuals son molt similars dins d'una cel-la unitat, és a dir, $V_{p}\left(\mathbf{x}-\mathbf{x}_{\hat{i}}\right) \approx V_{0}\left(\mathbf{x}-\mathbf{x}_{\hat{i}}\right)$, si $\mathbf{x}$ pertany a la cel-la unitat centrada en $\mathbf{x}_{\hat{i}}$. Fora d'aquesta cel-la el potencial individual decau a mesura que augmenta la distància, fins que s'anul-la a l'infinit. Pel contrari, el potencial periòdic no pot anul-lar-se per la condició de periodicitat. Si definim 
$\Delta V \equiv V_{p}-V_{0}$, llavors el potencial periòdic pot escriure's com una "pertorbació" del potencial individual $V_{p}(\mathbf{x})=V_{0}(\mathbf{x})+\Delta V(\mathbf{x})$ i l'eq.(E.1) pot escriure's com:

$$
\left(-\nabla^{2}+V_{0}(\mathbf{x})+\Delta V(\mathbf{x})\right) g_{\mathbf{q} ; \beta}(\mathbf{x})=\lambda_{\mathbf{q} ; \beta} g_{\mathbf{q} ; \beta}(\mathbf{x}) .
$$

Com es veurà a continuació, la contribució de la part pertorbada en els valors propis i els autoestats de l'equació periòdica (E.1) serà petita sempre que els estats $\psi_{n}$ del potencial individual "no pertorbat" tinguen valors petits fora de la cel-la unitat on es compleix la condició de proximitat entre el potencial individual i el periòdic $\left(V_{p}\left(\mathbf{x}-\mathbf{x}_{\hat{i}}\right) \approx V_{0}\left(\mathbf{x}-\mathbf{x}_{\hat{i}}\right)\right)$. A causa d'aquesta condició de proximitat, s'espera que els modes de Bloch i els estats del potencial individual estiguen també molt a prop l'uns dels altres dins de cada cel-la unitat. En el cas extrem en què $\Delta V(\mathbf{x})$ s'anul-la, sempre que $\psi_{n}(\mathbf{x})$ no s'anul-le i viceversa, $\psi_{n}(\mathbf{x})$ complirà simultàniament l'equació per al potencial individual i l'equació per al potencial periòdic. És a dir, considerem la cel-la centrada a l'origen — la denotem per $C_{\hat{0}}$ i assumim que els potencials individual i periòdic no són només semblants, sinó idèntics. Aleshores, $\Delta V(\mathbf{x})=0$ dins de $C_{\hat{0}}$ i l'equació periòdica (E.3) i l'equació per al potencial individual (E.2) esdevenen idèntiques en $C_{\hat{0}}$. Si , a més, $\psi_{n}(\mathbf{x})$ s'anul-la a la resta del domini $\Omega-C_{\hat{0}}$, llavors $\psi_{n}(\mathbf{x})$ esdevé una funció pròpia de l'equació periòdica amb autovalor $\lambda_{q ; \beta}=E_{n}$. D'altra banda, si $\psi_{n}(\mathbf{x})$ s'anul-la en $\Omega-C_{\hat{0}}$, llavors un argument similar podria utilitzar-se per a provar que, en qualsevol cel-la veïna $C_{\hat{i}}(\hat{i} \neq 0)$, ambdues equacions són idèntiques i $\psi_{n}\left(\mathbf{x}-\mathbf{x}_{\hat{i}}\right)$ és també una solució de l'equació periòdica i se satisfà que $\lambda_{q ; \beta}=E_{n}$. Ens podem trobar amb una situació d'alta degeneració per a la qual trobem $N$-on $N$ és el nombre de cel-les en $\Omega$ - solucions diferents de la forma $\psi_{n}\left(\mathbf{x}-\mathbf{x}_{\hat{i}}\right)$ que comparteixen el mateix autovalor de l'energia $\lambda_{q ; \beta}=E_{n}$. Si volem obtenir un mode de Bloch, hem de construir una solució que inclogui tot el domini $\Omega$ i que, al mateix temps, verifique la condició de Bloch $g_{\mathbf{q} ; \beta}(\mathbf{x}+\mathbf{a})=e^{i \mathbf{q} \cdot \mathbf{a}} g_{\mathbf{q} ; \beta}(\mathbf{x})$. Això es pot fer mitjançant una combinació lineal de funcions del potencial individual 
d'una manera adequada, és a dir,

$$
g_{\mathbf{q} ; \beta}(\mathbf{x})=\sum_{\hat{i}} e^{i \mathbf{q} \cdot \mathbf{x}_{\hat{i}}} \psi_{n}\left(\mathbf{x}-\mathbf{x}_{\hat{i}}\right)
$$

Cal notar que la combinació lineal en l'eq.(E.4) verifica l'equació periòdica en totes les cel-les del domini i, a més, satisfà les condicions de contorn periòdiques tant en el contorns de cada cel-la com en el domini complet $\Omega$. Per tant és una representació vàlida d'un mode de Bloch. Si no se satisfà una qualsevulla de les dues condicions $\Delta V(\mathbf{x})=0$ si $\mathbf{x} \in C_{\hat{i}}$, o $\psi_{n}(\mathbf{x})=0$ si $\mathbf{x} \notin C_{\hat{i}}(\Leftrightarrow$ $\psi_{n}\left(\mathbf{x}-\mathbf{x}_{\hat{i}}\right)=0$ per a $\left.\hat{i} \neq 0\right)$, llavors la representació adequada és la proporcionada per les funcions de Wannier que, a diferència de les funcions pròpies del potencial individual, han de ser calculades a partir de l'equació per al potencial periòdic:

$$
g_{\mathbf{q} ; \beta}(\mathbf{x})=\sum_{\hat{i}} e^{i \mathbf{q} \cdot \mathbf{x}_{\hat{i}}} W_{\beta}\left(\mathbf{x}-\mathbf{x}_{\hat{i}}\right) .
$$

Tanmateix, si aquestes condicions no se satisfan totalment però $\psi_{n}(\mathbf{x})$ roman petit quan $\Delta V(\mathbf{x})$ és diferent de zero i viceversa, és a dir, si el producte $\Delta V(\mathbf{x}) \psi_{n}(\mathbf{x})$ $\approx 0$, aleshores les funcions de Wannier han de ser pròximes a una funció localitzada del potencial individual o a combinacions lineals d'un estat degenerat multiplet. Hom no hauria d'oblidar que, en el cas més general, la funció de Wannier pot ser descrita per una infinita superposició d'autofuncions del potencial individual ja que aquestes funcions formen una base completa de $\mathbb{R}^{2}$. No obstant això, esperem que si $\Delta V(\mathbf{x}) \psi_{n}(\mathbf{x}) \approx 0, W_{\beta}(\mathbf{x})$ puga expressar-se com la superposició de només algunes funcions localitzades del potencial individual:

$$
W_{\beta}(\mathbf{x})=\sum_{n=1}^{d} b_{n} \psi_{n}(\mathbf{x}) .
$$

Ara les incògnites són els coeficients del desenvolupament $b_{n}$ que es determinaran resolent l'equació per al potencial periòdic (E.3). Per tal d'obtenir l'equació per als coeficicents $b_{n}$, substituirem l'expansió (E.6) en l'eq.(E.3), multiplicant- 
la per $\psi_{m}^{*}$ i integrant-la per a tot $\mathbf{x}$ en el domini periòdic $\Omega$. Substituint-hi $g_{\mathbf{q} ; \beta}=\sum_{\hat{i}, n} b_{n} \psi_{n}\left(\mathbf{x}-\mathbf{x}_{\hat{i}}\right) e^{i \mathbf{q} \cdot \mathbf{x}_{\hat{i}}}$ i tenint en compte que $H_{0} \equiv-\nabla^{2}+V_{0}(\mathbf{x})$

$$
\int_{\Omega} \psi_{m}^{*}(\mathbf{x}) H_{0} g_{\mathbf{q} ; \beta}(\mathbf{x})=\int_{\Omega}\left(H_{0} \psi_{m}(\mathbf{x})\right)^{*} g_{\mathbf{q} ; \beta}(\mathbf{x})=E_{m} \int_{\Omega} \psi_{m}^{*}(\mathbf{x}) g_{\mathbf{q} ; \beta}(\mathbf{x}),
$$

obtenim un sistema lineal homogeni d'equacions $\left(\delta E_{m}^{\mathbf{q}} \equiv \lambda_{\mathbf{q} ; \beta}-E_{m}\right)$

$$
\sum_{n}\left[\left(B+B^{\mathbf{q}}\right)_{m n}-\delta E_{m}^{\mathbf{q}}\left(1+A^{\mathbf{q}}\right)_{m n}\right] b_{n}=0
$$

en el qual els diferents elements de matriu es calculen a partir de les funcions pròpies del potencial individual de la manera següent

$$
\begin{gathered}
A_{m n}^{\mathbf{q}} \equiv \sum_{\hat{i} \neq 0} \int_{\Omega} \psi_{m}^{*}(\mathbf{x}) \psi_{n}\left(\mathbf{x}-\mathbf{x}_{\hat{i}}\right) e^{i \mathbf{q} \cdot \mathbf{x}_{\hat{i}}}=\sum_{\hat{i} \neq 0} \alpha_{n m}\left(\mathbf{x}_{\hat{i}}\right) e^{i \mathbf{q} \cdot \mathbf{x}_{\hat{i}}}, \\
B_{m n}^{\mathbf{q}} \equiv \sum_{\hat{i} \neq 0} \int_{\Omega} \psi_{m}^{*}(\mathbf{x}) \Delta V(\mathbf{x}) \psi_{n}\left(\mathbf{x}-\mathbf{x}_{\hat{i}}\right) e^{i \mathbf{q} \cdot \mathbf{x}_{\hat{i}}}=\sum_{\hat{i} \neq 0} \beta_{n m}\left(\mathbf{x}_{\hat{i}}\right) e^{i \mathbf{q} \cdot \mathbf{x}_{\hat{i}}},
\end{gathered}
$$

i

$$
B_{m n} \equiv \int_{\Omega} \psi_{m}^{*}(\mathbf{x}) \Delta V(\mathbf{x}) \psi_{n}(\mathbf{x})
$$

El sistema lineal d'equacions (E.7) pot reescriure's com una equació d'autovalors generalitzada si s'hi introdueix el nou vector $\mathbf{b}^{\prime}=\left(1+A^{\mathbf{q}}\right) \mathbf{b}$,

$$
\left(B+B^{\mathbf{q}}\right)\left(1+A^{\mathbf{q}}\right)^{-1} \mathbf{b}^{\prime}=\delta \mathcal{E}^{\mathbf{q}} \mathbf{b}^{\prime} .
$$

La resolució d'aquesta equació proporciona el vector de coeficients $\mathbf{b}_{(\sigma)}^{\mathbf{q}}-\sigma$ varia des de 1 fins a $d$ (el nombre de coeficients en l'expansió (E.6)) - per a cada autovector i, al mateix temps, la seua corresponent energia de Bloch $\lambda_{\mathbf{q} ; \beta}=$ $E_{m}+\delta \mathcal{E}_{m(\sigma)}^{\mathbf{q}}$. La banda es defineix així pel seu potencial individual antecesor, l'índex $m$ i l'índex $\sigma$ que defineixen la combinació lineal codificada en el vector de coeficients $\mathbf{b}_{(\sigma)}^{\mathbf{q}}: \beta=(m, \sigma)$. 
Si el potencial individual $V_{0}$ té també la simetria discreta rotacional del potencial periòdic, els seus estat propis podran classificar-se d'acord amb les representacions del grup de rotacions dicretes. Segons arguments de cristal-lografia, la simetria rotacional compatible amb periodicitat 2D inclou rotacions d'ordre $\mathrm{N}=2,3,4$ i 6 . Les representacions són unidimensionals per a $\mathrm{N}=2$ i tant unidimensionals com bidimensionals en els casos on $\mathrm{N}=3,4$ i 6 . Això significa que les funcions pròpies $\psi_{n}$ poden ser degenerades o no degenerades (amb degeneració d'ordre 2). Tenint en compte aquesta propietat, anem a considerar tres casos diferents en funció del nombre d'estats del potencial individual que contribueixen a la funció de Wannier en l'eq.(E.6):

i. Banda fonamental:

Generada a partir d'un estat no degenerat $(n=0)$ :

$$
W_{\beta}(\mathbf{x})=b_{0} \psi_{0}(\mathbf{x}),
$$

que indueix una banda de la forma

$$
g_{\mathbf{q} ; \beta}(\mathbf{x})=\sum_{\hat{i}} e^{i \mathbf{q} \cdot \mathbf{x}_{\hat{i}}} \psi_{0}(\mathbf{x}) .
$$

En aquest cas, l'eq.(E.7) esdevé una única equació per a $\delta \mathcal{E}_{0}^{\mathbf{q}}$ que permet escriure directament per a l'energia de la banda:

$$
\lambda_{\mathbf{q} ; \beta}=E_{0}+\delta \mathcal{E}_{0}^{\mathbf{q}}=E_{0}+\frac{B_{0}+\sum_{\hat{i} \neq 0} \beta_{0}\left(\mathbf{x}_{\hat{i}}\right) e^{i \mathbf{q} \cdot \mathbf{x}_{\hat{i}}}}{1+\sum_{\hat{i} \neq 0} \alpha_{0}\left(\mathbf{x}_{\hat{i}}\right) e^{i \mathbf{q} \cdot \mathbf{x}_{\hat{i}}}} .
$$

Aquest resultat permet identificar l'índex de la banda $\beta$ amb el nivell no degenerat del potencial individual $\beta=0$. Cal notar que quan la condició de proximitat es compleix plenament $\left(\Delta V(\mathbf{x}) \psi_{n}(\mathbf{x}) \rightarrow 0\right.$ i $\psi_{n}\left(\mathbf{x}-\mathbf{x}_{\hat{i}}\right) \rightarrow 0$ si $\hat{i} \neq 0$ ) per a $n=0$ tots els elements de matriu s'anul-len $B_{0} \rightarrow 0, \beta_{0} \rightarrow 0$ i $\alpha_{0} \rightarrow 0$ de manera que es recupera la situació de degeneració completa $\lambda_{\mathbf{q} ; \beta}=E_{0}$. 
ii. Banda-l:

Generada a partir d'un estat degenerat $(n=+l,-l)$. Els estats degenerats són doblets caracteritzats per un nombre $l$, que defineix les propietats rotacionals del doblet i que s'anomena pseudomoment angular, i tal que $l \neq 0$. Triem la base completa de la representació $2 \mathrm{D}\left(\psi_{l}, \psi_{-l}\right)=\left(\psi_{l}, \psi_{l}^{*}\right)$ en la superposició lineal de les funcions de Wannier (E.6) ja que rotacions discretes de la xarxa actúen multiplicativament sobre elles, és a dir, $\left(\psi_{l}, \psi_{l}^{*}\right) \rightarrow\left(\epsilon^{l} \psi_{l}, \epsilon^{* l} \psi_{l}^{*}\right)$ on $\epsilon=e^{i 2 \pi / N}$ [Ferrando05]. Quan es resol l'equació (E.7) per a dos estats es troben dues solucions possibles per al vector $\mathbf{b}_{l}^{\mathbf{q}}=\left(b_{+l}^{\mathbf{q}}, b_{-l}^{\mathbf{q}}\right): \mathbf{b}_{l(\sigma)}^{\mathbf{q}}(\sigma=1,2)$. Llavors, podem trobar dues funcions diferents de Wannier que poden escriure's com:

$$
W_{l(\sigma)}^{\mathbf{q}}(\mathbf{x})=b_{+l(\sigma)}^{\mathbf{q}} \psi_{l}(\mathbf{x})+b_{-l(\sigma)}^{\mathbf{q}} \psi_{l}^{*}(\mathbf{x}) \sigma=1,2
$$

que es corresponen amb dos modes diferents de Bloch definits per $\beta=(l, \sigma)$

$$
g_{\mathbf{q} ; \beta}(\mathbf{x})=\sum_{\hat{i}} e^{i \mathbf{q} \cdot \mathbf{x}_{\hat{i}}}\left(b_{+l(\sigma)}^{\mathbf{q}} \psi_{l}(\mathbf{x})+b_{-l(\sigma)}^{\mathbf{q}} \psi_{l}^{*}(\mathbf{x})\right) \quad \sigma=1,2 .
$$

iii. Bandes híbrides:

Les seues funcions de Wannier són combinacions de diferents tipus d'estats de potencials individuals, que poden incloure la banda fonamental i bandes $l:$

$$
W_{\beta}^{\mathbf{q}}(\mathbf{x})=\underbrace{b_{0}^{\mathbf{q}} \psi_{0(\sigma)}(\mathbf{x})+b_{+1(\sigma)}^{\mathbf{q}} \psi_{1}(\mathbf{x})+b_{-1(\sigma)}^{\mathbf{q}} \psi_{1}^{*}(\mathbf{x})+\cdots}_{d}, \sigma=1,2, \cdots d,
$$

on l'índex de la banda està definit $\operatorname{per} \beta=(\{0,1, \cdots l\}, \sigma)$

$$
g_{\mathbf{q} ; \beta}(\mathbf{x})=\sum_{\hat{i}} \sum_{l} e^{i \mathbf{q} \cdot \mathbf{x}_{\hat{i}}}\left(b_{0}^{\mathbf{q}} \psi_{0(\sigma)}(\mathbf{x})+b_{+l(\sigma)}^{\mathbf{q}} \psi_{l}(\mathbf{x})+b_{-l(\sigma)}^{\mathbf{q}} \psi_{l}^{*}(\mathbf{x})\right) .
$$




\section{Apèndix F}

\section{Nocions bàsiques de}

\section{geometria no commutativa}

\section{F.1 Introducció}

La commutativita no és una propietat inherent al món real. Així, algunes operacions amb nombres ho són, però d'altres, no. De fet, podem trobar alguns exemples pràctics i quotidians en els quals l'ordre de les accions no és commutatiu. Per exemple, suposem que dos vaixells parteixen alhora del mateix punt de l'Equador, un viatja cap a l'Est i recorre una distància de $5000 \mathrm{~km}$ i després $1000 \mathrm{~km}$ cap al Nord. L'altre recorre primer $1000 \mathrm{~km}$ cap al Nord i després $5000 \mathrm{~km}$ cap a l'Est sobre el paral.lel. El punt d'arribada és diferent en els dos casos a causa de la curvatura de la Terra. Per tant, no podem aplicar ací la commutativitat. La física proporciona un gran nombre de situacions en què els espais utilitzats són no commutatius: en mecànica quàntica, en física de l'estat sòlid amb els treballs de J. Bellissard [Bellissard00], l'espai d'universos de R. Penrose [Penrose99], etc. De fet es possible reformular les ferramentes clàssiques de l'anàlisi, com la topologia, la teoria de la mesura, el càlcul diferencial,..., en termes algebraics i hilbertians de forma que els seu marc natural es transforme en no commutatiu [Stadler01]. 
El pare de la geometria no commutativa és Alain Connes [Connes94] i es tracta d'una branca d'estudi prou recent. Prenent com a punt de partida la geometria proposada per Connes [Connes94, Connes98, Connes04] i altres treballs innovadors en el mateix sentit [Banks97, Douglas01], nombrosos treballs en el camp de la Física Matemàtica han anat dirigits a desenvolupar la teoria quàntica de camps i la teoria de cordes sobre l'espai-temps no commutatiu [Seiberg99, Bellissard03, Szabo03, Szabo04]. Això té sentit ja que aquestes teories, quan es posin en espai-temps continu, expliquen amb èxit gran part de la física observada. En aquest apèndix ens centrarem només en presentar les idees bàsiques sobre geometries no commutatives que són necessàries per a la física a l'escala de Planck $^{1}$ [Monreal08b]. En les referències [Bellissard00, Ypma04] es poden trobar més exemples de tot l'exposat fins ara.

\section{F.2 Conceptes algebraics}

Considerem una àlgebra associativa $A$ sobre el conjunt dels nombres complexos C. Això és, $A$ té l'estructura d'un espai vectorial complex, i a més, qualsevol parell d'elements $x, y \in A$ poden multiplicar-se i donar un element $x y \in A$, de tal manera que aquesta multiplicació és associativa i distributiva respecte de l'operació suma de l'espai vectorial. També suposarem que l'àlgebra $A$ està dotada d'una norma || || i d'una involució antilineal «. Tanmateix, per a qualsevol

\footnotetext{
${ }^{1}$ Poc després del naixement de la mecànica quàntica, s'adonaren de que les tres constants fonamentals, la velocitat de la llum $c$, la constant de Planck $\hbar$, i la constant de Newton $G$, poden combinar-se en una expressió $\sqrt{G \hbar / c^{3}}$, amb dimensions de longitud, que sol anomenarse longitud de Planck i que denotarem per $L_{P}$. Aquesta constant és a la Geometria allò que $\hbar$ és a la dinàmica, és a dir, un quant fonamental de longitud. Així, totes les longituds poden ser quantitzades en termes de $L_{P}$, i el concepte mateix de longitud haurà d'analitzar-se en escales comparables, o menors, que $L_{P}$. El seu valor és extraordinàriament menut en escala macroscòpica, $1.61 \times 10^{-33} \mathrm{~cm}$. Així doncs, les longituds (i també, àrees, volums, angles, etc.) i, en última instància, l'espai temps, ens semblen a nosaltres, observadors macroscòpics, com a quantitats contínues a les quals ens podem apropar tant com vulguem. La tecnologia actual està encara lluny d'acostar-se, sempre en escala logarítmica, a les energies necessàries per a arribar a eixes petites distàncies. A tots els efectes, l'espai-temps és un continu, al menys per a les energies que podem aconseguir avui.
} 
parell d'elements $x, y \in A$ assumim que

$$
(x y)^{\star}=y^{\star} x^{\star}, \quad\left\|x^{\star} x\right\|=\|x\|^{2} .
$$

Una àlgebra $A$ que satisfà totes aquestes condicions s'anomena una $C^{\star}$-àlgebra. (De manera estricta, tot això només defineix una pre- $C^{\star}-$ àlgebra, la pròpia $C^{\star}$ àlgebra es defineix per la completitud de la norma. Ignorarem aquest detall de forma sistemàtica). Treballarem amb $C^{\star}$-àlgebres que posseeixen element unitat 1 , és a dir, tal que per a qualsevol $x \in A$ es té que

$$
x \cdot 1=x=1 \cdot x .
$$

Una traça és una aplicació tr: $A \rightarrow \mathbf{C}$ tal que

$$
\operatorname{tr}(a+b)=\operatorname{tr}(a)+\operatorname{tr}(b), \quad \operatorname{tr}(\lambda a)=\lambda \operatorname{tr}(a), \quad \operatorname{tr}(a b)=\operatorname{tr}(b a)
$$

per a tot $a, b \in A$ i tot $\lambda \in \mathbf{C}$. La traça es diu normalitzada si a l'element unitat $1 \in A$ se li associa l'element unitat en el conjunt dels nombres complexos:

$$
\operatorname{tr}(1)=1
$$

Per definició, els elements positius de $A$ són tots aquells de la forma $a^{\star} a$ per a algun $a \in A$.

Sobre la $C^{\star}$-àlgebra $A$ considerem un mòdul per la dreta $E$. Els elements $\xi, \eta \in E$ poden sumar-se per a donar $\xi+\eta \in E$ i multiplicar-se per la dreta per elements $a \in A$ per a donar $\xi a \in E$. Aquestes operacions gaudeixen de les mateixes propietats formals que l'espai vectorial $V$ sobre el cos dels nombres complexos $\mathbf{C}$, on $V$ i $\mathbf{C}$ són reemplaçats per $E$ i $A$, respectivament. A més, assumirem que $E$ posseeix un $A$-valuat producte intern $\langle\xi, \eta\rangle$ que verifica

$$
\langle\xi, \eta a\rangle=\langle\xi, \eta\rangle a, \quad\langle\xi+\zeta, \eta\rangle=\langle\xi, \eta\rangle+\langle\zeta, \eta\rangle, \quad\langle\eta, \xi\rangle^{\star}=\langle\xi, \eta\rangle,
$$


per a qualsevol $\xi, \eta \in E$ i $a \in A$. Tanmateix, s'assumeix que $\langle\xi, \xi\rangle$ és positiu per a qualsevol $\xi \in E$, i zero si, i sols si, $\xi=0$. Tot això defineix un $C^{\star}$-mòdul.

Una $A$-aplicació lineal $T: E \rightarrow E$ d'un $C^{\star}$-mòdul $E$ satisfà

$$
T(\xi+\eta)=T(\xi)+T(\eta), \quad T(\xi a)=T(\xi) a,
$$

per a tot $\xi, \eta \in E$ i tot $a \in A$. Un endomorfisme de $E$ és una $A$-aplicació lineal $T: E \rightarrow E$ que posseeix un adjunt $T^{\dagger}: E \rightarrow E$ respecte del seu producte intern. Hom pot demostrar que l'àlgebra $\operatorname{End}_{A} E$ dels endomorfismes de $E$ és una $C^{\star}$-àlgebra, amb una involució $\star$ donada per $T \rightarrow T^{\dagger}$. La suma directa $A^{n}$ de $n$ còpies de $A$ és clarament un $A$-mòdul. Un mòdul $E$ s'anomena lliure si és isomòrfica a $A^{n}$ per a algun $n$ :

$$
E \simeq A^{n}
$$

Un mòdul $E$ s'anomena projectiu si és un sumand directe en un mòdul lliure, això és, si existeix un altre $A$-module $F$ tal que

$$
E \oplus F \simeq A^{n}
$$

Una traça sobre l'àlgebra $A$ indueix una traça sobre l'àlgebra $\operatorname{End}_{A} E$. No obstant això, la condició de normalització sobre $A, \operatorname{tr}(1)=1$, no es transfereix necessàriament sobre End $_{A} E$, així, en general, la traça de l'endomorfisme identitat $\mathbf{I}$ no estarà normalitzat a 1 . Prendrem el valor de $\operatorname{tr}(\mathbf{I})$ per a definir la dimensió de l' $A$-mòdul $E$

$$
\operatorname{dim}_{A} E=\operatorname{tr}(\mathbf{I}) .
$$

Si considerem la $C^{\star}$-àlgebra $A$ com un mòdul sobre ella mateix, un automorfisme de $A$ és un endomorfisme bijectiu. Els automorfismes de $A$ defineixen un grup, denotat $\operatorname{Aut}(A)$.

Considerem un homomorfisme $H$ d'un grup de Lie $G$ en els automorfismes de $A$ :

$$
H: G \rightarrow \operatorname{Aut}(A)
$$


Denotem per $\mathcal{G}$ l'àlgebra de Lie de $G$, i denotem per aut $(A)$ el conjunt de tots els automorfismes infinitesimals de $A$. Llavors, l'anterior $H$ determina un homomorfisme $h$ de $\mathcal{G}$ en aut $(A)$

$$
h: \mathcal{G} \rightarrow \operatorname{aut}(A) .
$$

Els elements de aut $(A)$ s'anomenen derivades de $A$. Si $\mathcal{G}$ és $n$-dimensional, les derivades corresponents als elements d'una base $\left\{b_{\alpha} \in \mathcal{G}, \alpha=1, \ldots, n\right\}$ es denotaran per $\delta_{\alpha}$. Una connexió sobre un $A$-mòdul $E$ es defineix com un operador $\nabla_{\alpha}$ que depèn linealment de $b_{\alpha} \in \mathcal{G}$ i que verifica

$$
\nabla_{\alpha}(\xi a)=\left(\nabla_{\alpha} \xi\right) a+\xi \delta_{\alpha} a, \quad \nabla_{\alpha}(\xi+\zeta)=\nabla_{\alpha}(\xi)+\nabla_{\alpha}(\zeta)
$$

per a tot $\xi, \zeta \in E$ i tot $a \in A$. Una connexió hermítica és, per definició, compatible amb el producte intern de $E$, és a dir,

$$
\left\langle\nabla_{\alpha} \xi, \eta\right\rangle+\left\langle\xi, \nabla_{\alpha} \eta\right\rangle=\delta_{\alpha}\langle\xi, \eta\rangle
$$

La curvatura $F$ de la connexió $\nabla_{\alpha}$ és la 2-forma

$$
F_{\alpha \beta}=\left[\nabla_{\alpha}, \nabla_{\beta}\right]-\nabla_{\left[b_{\alpha}, b_{\beta}\right]}
$$

que està definida sobre l'àlgebra de Lie $\mathcal{G}$ i pren valors en $\operatorname{End}_{A} E$.

\section{F.3 L'àlgebra d'Heisenberg}

Un exemple àlgebra no commutativa és l'associada als operadors posició i moment de la mecànica quàntica. Un problema bàsic és trobar operadors autoadjunts $Q$ i $P$ que satisfan les relacions de commutació

$$
[Q, P]=\mathrm{i} \hbar
$$


sobre l'espai de Hilbert $\mathcal{H}$ dels estats quàntics. El problema anterior, però, no està massa ben plantejat ja que ambdós $Q$ i $P$ són operadors no fitats i no poden ser definits en qualsevol lloc sobre $\mathcal{H}$. D'altra banda, el terme de la dreta de (F.15) és proporcional a la identitat, i per tant està definit a tot arreu sobre $\mathcal{H}$. Weyl va assenyalar que és més precís considerar, en lloc de $Q$ i $P$, els grups d'operadors unitaris

$$
\exp \left(\frac{\mathrm{i}}{\hbar} q P\right), \quad \exp \left(\frac{\mathrm{i}}{\hbar} p Q\right), \quad q, p \in \mathbf{R}
$$

que generen. Les darreres exponencials estan definides per tot arreu de $\mathcal{H}$. Si utilitzem la fórmula de Baker-Campbell-Hausdorff ${ }^{2}$ trobem que

$$
\exp \left(\frac{\mathrm{i}}{\hbar} q P\right) \exp \left(\frac{\mathrm{i}}{\hbar} p Q\right)=\mathrm{e}^{-\mathrm{i} \frac{p q}{\hbar}} \exp \left(\frac{\mathrm{i}}{\hbar} p Q\right) \exp \left(\frac{\mathrm{i}}{\hbar} q P\right) \text {. }
$$

La identificació d'aquests grups d'operadors unitaris com els generadors del torus no commutatiu en dues dimensions $\mathbf{T}_{\theta}^{2}$ és immediata ${ }^{3}$. D'altra banda, els operadors posició i moment de la mecànica quàntica, $Q$ i $P$, en el seu paper de generadors infinitesimals d'aquests grups, poden ser identificats com les funcions coordenades no commutatives sobre el pla no commutatiu, també anomenat pla quàntic, que pot ser entès com el pla tangent al torus no commutatiu en dues dimensions.

\footnotetext{
${ }^{2}$ La fórmula de Baker-Campbell-Hausdorff és $e^{A} e^{B}=e^{[A, B]} e^{B} e^{A}$

${ }^{3}$ Un exemple important d'una $C^{\star}$-àlgebra és el torus $n$-dimensional no commutatiu $\mathbf{T}_{\theta}^{n}$. Aquest torus té uns generadors $\mathcal{U}_{1}, \ldots, \mathcal{U}_{n}$ que satisfan

$$
\mathcal{U}_{k} \mathcal{U}_{j}=\mathrm{e}^{2 \pi \mathrm{i} \theta_{k j}} \mathcal{U}_{j} \mathcal{U}_{k},
$$

on $\theta_{k j}$ és una matriu $n \times n$ antisimétrica real [Monreal08b].
} 


\section{Bibliografia}

[Agrawal07]

[Alexander06]

[Armoni02]

[Ashcroft76]

[Baake02]

[Bahabad08]
G. Agrawal. Nonlinear fiber optics. Academic Press INC. San Diego (2007).

T.J. Alexander, E.A. Ostrovskaya i Y.S. Kivshar. "Selftrapped nonlinear matter waves in periodic potentials". Physical review letters 96, 40401 (2006).

A. Armoni i E. Lopez. "UV/IR mixing via closed strings and tachyonic instabilities". Nuclear Physics B 632, 240 (2002).

N.W. Ashcroft i N.D. Mermin. Solid Stale Physics. Saunders College, Philadelphia (1976).

M. Baake. Quasicrystals. An Introduction to Structure, Physical Properties and Applications, edited by J.-B. Suck, M. Schreiber and P. Haussler. Berlin: Springer (2002).

A. Bahabad, R. Lifshitz, N. Voloch i A. Arie. "Nonlinear photonic quasicrystals for novel optical devices". Philosophical Magazine 88, 2285 (2008). 
[Banks97]

T. Banks, W. Fischler, SH Shenker i L. Susskind. "M theory as a matrix model: A Conjecture". Physical Review D 55, 5112 (1997).

[Bazán Sulzberger09] A. Bazán Sulzberger. "Propagación de ondas en sistemas con geometrías complejas". Tesi Doctoral, Universidad Politénica de Madrid (2009).

[Bellissard00]

J. Bellissard, D.J.L. Herrmann i M. Zarrouati. "Hulls of aperiodic solids and gap labeling theorems". Directions in mathematical quasicrystals página 207 (2000).

[Bellissard03] J. Bellissard. "The noncommutative geometry of aperiodic solids". Proceedings of the Summer School Geometric and Topological Methods for Quantum Field Theory: Villa de Leyva, Colombia, 9-27 July 2001 página 86 (2003).

[Besicovitch54]

A.S. Besicovitch. Almost periodic functions. Dover (1954).

[Boyd92]

R.W. Boyd. Nonlinear optics. Academic Press INC. San Diego (1992).

[Burger99]

S. Burger, K. Bongs, S. Dettmer, W. Ertmer, K. Sengstock, A. Sanpera, GV Shlyapnikov i M. Lewenstein. "Dark solitons in Bose-Einstein condensates". Physical Review Letters 83, 5198 (1999).

[Chan98] Y.S. Chan, C.T. Chan i Z.Y. Liu. "Photonic band gaps in two dimensional photonic quasicrystals". Physical Review Letters 80, 956 (1998).

[Chen87] W. Chen i D.L. Mills. "Gap solitons and the nonlinear optical response of superlattices". Physical review letters 58, 160 (1987). 
[Chiao64]

[Chierchia87]

[Christodoulides88]

[Christodoulides03]

[Clausen99]

[Connes94]

[Connes98]

[Connes04]

[Dal Negro03]
R.Y. Chiao, E. Garmire i C.H. Townes. "Self-trapping of optical beams". Physical Review Letters 13, 479 (1964).

L. Chierchia. "Absolutely continuous spectra of quasiperiodic Schroedinger operators". Journal of Mathematical Physics 28, 2891 (1987).

D.N. Christodoulides i R.I. Joseph. "Discrete self-focusing in nonlinear arrays of coupled waveguides". Optics letters 13, 794 (1988).

D.N. Christodoulides, F. Lederer i Y. Silberberg. "Discretizing light behaviour in linear and nonlinear waveguide lattices". Nature 424, 817 (2003).

C.B. Clausen, Y.S. Kivshar, O. Bang i P.L. Christiansen. "Quasiperiodic envelope solitons". Physical Review Letters 83, 4740 (1999).

A. Connes. "Non Commutative Geometry". Academic Press, London (1994).

A. Connes, M.R. Douglas i A. Schwarz. "Noncommutative geometry and Matrix theory". Journal of High Energy Physics 1998, 003 (1998).

A. Connes. "Noncommutative geometry". Mathematical Research Today and Tomorrow (2004).

L. Dal Negro, C.J. Oton, Z. Gaburro, L. Pavesi, P. Johnson, A. Lagendijk, R. Righini, M. Colocci i D.S. Wiersma. "Light transport through the band-edge states of Fibonacci quasicrystals". Physical review letters 90, 55501 (2003). 
[Della Villa06]

[Dinaburg75]

[Douglas01]

[Efremidis02]

[Efremidis03]

[Eiermann04]

[Ferrando05]

[Ferrando08]

[Fleischer03a]
A. Della Villa, S. Enoch, G. Tayeb, F. Capolino, V. Pierro i V. Galdi. "Localized modes in photonic quasicrystals with Penrose-type lattice". Optic Express 14, 21 (2006).

E.I. Dinaburg i Y.G. Sinai. "The one-dimensional Schroedinger equation with a quasiperiodic potential". Functional Analysis and Its Applications 9, 279 (1975).

M.R. Douglas i N.A. Nekrasov. "Noncommutative field theory". Reviews of Modern Physics 73, 977 (2001).

N.K. Efremidis, S. Sears, D.N. Christodoulides, J.W. Fleischer i M. Segev. "Discrete solitons in photorefractive optically induced photonic lattices". Physical Review E 66, 46602 (2002).

N.K. Efremidis i D.N. Christodoulides. "Lattice solitons in Bose-Einstein condensates". Physical Review A 67, 63608 (2003).

B. Eiermann, T. Anker, M. Albiez, M. Taglieber, P. Treutlein, K.P. Marzlin i MK Oberthaler. "Bright Bose-Einstein gap solitons of atoms with repulsive interaction". Physical review letters 92, 230401 (2004).

A. Ferrando, M. Zacarés i M.A. García-March. "Vorticity cutoff in nonlinear photonic crystals". Physical review letters 95, 43901 (2005).

A. Ferrando, M.Á. García-March i M. Zacarés. "Supersolid behavior of nonlinear light". Arxiv preprint arXiv:0808.0998 (2008).

J.W. Fleischer, T. Carmon, M. Segev, N.K. Efremidis i D.N. Christodoulides. "Observation of discrete solitons in 
optically induced real time waveguide arrays". Physical review letters 90, 23902 (2003).

[Fleischer03b]

J.W. Fleischer, M. Segev, N.K. Efremidis i D.N. Christodoulides. "Observation of two-dimensional discrete solitons in optically induced nonlinear photonic lattices". Nature 422, 147 (2003).

[Freedman06] B. Freedman, G. Bartal, M. Segev, R. Lifshitz, D.N. Christodoulides i J.W. Fleischer. "Wave and defect dynamics in nonlinear photonic quasicrystals". Nature 440, 1166 (2006).

[Freedman07] B. Freedman, R. Lifshitz, J.W. Fleischer i M. Segev. "Phason dynamics in nonlinear photonic quasicrystals". Nature Materials 6, 776 (2007).

[García March08] M.A. García March. "Modelización y simulación de dsipositivosmicrométricos basados en estructuras espaciales de solitones ópticos". Tesi Doctoral, Universidad Politécnica de Valencia (2008).

[Hislop95]

P.D. Hislop i I.M. Sigal. Introduction to spectral theory: With applications to Schroedinger operators. Springer (1995).

[Janssen07] T. Janssen. "Quasicrystals: Comparative dynamics". Nature Materials 6, 925 (2007).

[Joannopoulos95] Meade R.D. Joannopoulos, J.D. i J.N. Winn. "Photonic crystals. Molding the flow of light". Pricenton University Press (1995).

[John87]

S. John. "Strong localization of photons in certain disordered dielectric superlattices". Physical Review Letters 58, 2486 (1987). 
[Kaliteevski00] M.A. Kaliteevski, S. Brand, R.A. Abram, T.F. Krauss, R.M. De La Rue i P. Millar. "Two-dimensional Penrosetiled photonic quasicrystals: diffraction of light and fractal density of modes". Journal of Modern Optics 47, 1771 (2000).

[Khaykovich02] L. Khaykovich, F. Schreck, G. Ferrari, T. Bourdel, J. Cubizolles, LD Carr, Y. Castin i C. Salomon. "Formation of a matter-wave bright soliton". Science 296, 1290 (2002).

[Kittel96] C. Kittel i P. McEuen. Introduction to solid state physics. Wiley New York (1996).

[Kivshar92]

Y.S. Kivshar. "Dark Optical Solitons". Complexity in physics and technology página 125 (1992).

[Kivshar03] Y.S. Kivshar i G.P. Agrawal. Optical solitons: from fibers to photonic crystals. Academic Press San Diego (2003).

[Landau80] L.D. Landau, E.M. Lifshits i L.P. Pitaevskii. Statistical physics, part 2. Butterworth-Heinemann (1980).

[Landi97] G. Landi. "An introduction to noncommutative spaces and their geometry". Arxiv preprint hep-th/9701078 (1997).

[Law10] K.J.H. Law, A. Saxena, P.G. Kevrekidis i A.R. Bishop. "Stable structures with high topological charge in nonlinear photonic quasicrystals". Arxiv preprint arXiv:1003.2779 (2010).

[Levine84] D. Levine i P.J. Steinhardt. "Quasicrystals: a new class of ordered structures". Physical Review Letters 53, 2477 (1984). 
[Lifshitz05]

[Maciá01]

[Maciá06]

[Man05]

[Maza08]

[Mingaleev01]

[Monreal08a]

[Monreal08b]

[Moser84]
R. Lifshitz, A. Arie i A. Bahabad. "Photonic quasicrystals for nonlinear optical frequency conversion". Physical review letters 95, 133901 (2005).

E. Maciá. "Exploiting quasiperiodic order in the design of optical devices". Physical Review B 63, 205421 (2001).

E. Maciá. "The role of aperiodic order in science and technology". Reports on Progress in Physics 69, 397 (2006).

W. Man, M. Megens, P.J. Steinhardt i P.M. Chaikin. "Experimental measurement of the photonic properties of icosahedral quasicrystals". Nature 436, 993 (2005).

J. Maza, J. Mosquera i J.A. Veira. Física del estado sólido. Univ Santiago de Compostela (2008).

S.F. Mingaleev i Y.S. Kivshar. "Self-trapping and stable localized modes in nonlinear photonic crystals". Physical review letters 86, 5474 (2001).

L. Monreal, P. Fernández de Córdoba, A. Ferrando i J.M. Isidro. "Noncommutative space and the low-energy physics of quasicrystals". International Journal of Modern Physics A 23, 2037 (2008).

L. Monreal i J.M. Isidro. Basics in Noncommutative Geometry. Mathematical Physics Rechears Developments. Nova Science Publishers (2008).

J. Moser i J. Poschel. "An extension of a result by Dinaburg and Sinai on quasi-periodic potentials". Commentarii Mathematici Helvetici 59, 39 (1984). 
[Ostrovskaya03] E.A. Ostrovskaya i Y.S. Kivshar. "Matter-wave gap solitons in atomic band-gap structures". Physical review letters 90, 160407 (2003).

[Ostrovskaya04] E.A. Ostrovskaya i Y.S. Kivshar. "Matter-wave gap vortices in optical lattices". Physical review letters 93, 160405 (2004).

[Pavlov87] P.V. Pavlov i A.F. Jojlov. "Física del estado sólido". Bibfismat, Moscú (1987).

[Penrose99] R. Penrose. La nueva mente del emperador (1999).

[Pitaevskii03] L.P. Pitaevskii i S. Stringari. Bose-Einstein Condensation. Oxford University Press, USA (2003).

[Roati08]

G. Roati, C. Errico, L. Fallani, M. Fattori, C. Fort, M. Zaccanti, G. Modugno, M. Modugno i M. Inguscio. "Anderson localization of a non-interacting Bose-Einstein condensate". Nature 453, 895 (2008).

[Rodriguez08] A.W. Rodriguez, A.P. McCauley, Y. Avniel i S.G. Johnson. "Computation and visualization of photonic quasicrystal spectra via Bloch theorem". Physical Review B 77, 104201 (2008).

[Rostami09]

A. Rostami i S. Matloub. "Band structure and dispersion properties of photonic quasicrystals". Progress In Electromagnetics Research M 9, 65 (2009).

[Schroedinger44] E. Schroedinger. What is life?: the physical aspect of the living cell; with, Mind and matter and Autobiographical sketches. Cambridge University Press (1944). 
[Seiberg99]

[Senechal96]

[Senechal06]

[Shechtman84]

[Simon82]

[Stadler01]

[Stegeman99]

[Szabo03]

[Szabo04]

[Torres03]
N. Seiberg i E. Witten. "String theory and noncommutative geometry". Journal of High Energy Physics 1999, 032 (1999).

M. Senechal. Quasicrystals and geometry. Cambridge University $\operatorname{Pr}(1996)$.

M. Senechal. "WHAT IS... a Quasicrystal?" NoticesAmerican Mathematical Society 53, 886 (2006).

D. Shechtman, I. Blech, D. Gratias i J.W. Cahn. "Metallic phase with long-range orientational order and no translational symmetry". Physical Review Letters 53, 1951 (1984).

B. Simon. "Almost periodic Schroedinger operators: A Review". Advances in Applied Mathematics 3, 463 (1982).

M.M. Stadler. "Algunas ideas sobre Geometria no conmutativa". Publicaciones de la RSME 2, 169 (2001).

G.I. Stegeman i M. Segev. "Optical spatial solitons and their interactions: universality and diversity". Science 286, 1518 (1999).

R.J. Szabo. "Quantum field theory on noncommutative spaces". Phys. Rept. 378, 207 (2003).

R.J. Szabo. "Magnetic backgrounds and noncommutative field theory". International Journal of Modern Physics A 19, 1837 (2004).

M. Torres, J.P. Adrados, J.L. Aragón, P. Cobo i S. Tehuacanero. "Quasiperiodic bloch-like states in a surface-wave experiment". Physical review letters 90, 114501 (2003). 
[Trager06] D. Trager, R. Fischer, D.N. Neshev, A.A. Sukhorukov, C. Denz, W. Krolikowski i Y.S. Kivshar. "Nonlinear Bloch modes in two-dimensional photonic lattices" (2006).

[Xie03]

P. Xie, Z.Q. Zhang i X. Zhang. "Gap solitons and soliton trains in finite-sized two-dimensional periodic and quasiperiodic photonic crystals". Physical Review E 67, 26607 (2003).

[Yablonovitch87] E. Yablonovitch. "Inhibited spontaneous emission in solidstate physics and electronics". Physical review letters 58, 2059 (1987).

[Ypma04]

F. Ypma. "Quasicrystals, C-algebras and K-theory". Master Thesis, University of Amsterdam (2004).

[Zoorob00]

M.E. Zoorob, M.D.B. Charlton, G.J. Parker, J.J. Baumberg i M.C. Netti. "Complete photonic bandgaps in 12-fold symmetric quasicrystals". Nature 404, 740 (2000). 